\title{
Subcellular localization of Kv10.1 (Eag1): functional ion channels on the inner nuclear membrane
}

\author{
PhD Thesis \\ in partial fulfilment of the requirements \\ for the degree "Doctor of Philosophy $(\mathrm{PhD}) /$ Dr. rer. nat." \\ in the Neuroscience Program \\ at the Georg August University Göttingen,
}

Faculty of Biology

submitted by

Ye Chen

born in

Ningde, China

March 2010 


\section{Declaration}

I hereby declare that this thesis has been written independently and with no other sources and aids than quoted.

Ye Chen

Göttingen, March 2010 


\section{Acknowledgement}

There is no word I could express my gratitude to my supervisor Dr. Luis. A. Pardo, who not only taught me all the aspects of science but also has been extremely nice ALL the time. I am also deeply thankful to Prof. Dr. Walter Stühmer for supporting me in his department and all his suggestions on my research.

Prof. Dr. Jakob B. Sørensen and Dr. Dirk Fasshauer have always been critical and helpful as my committee members. Their advices on my first project led to the current project I have been doing. They are keen in analysis of my data and supportive to my project.

I would like to give special thanks to Neuroscience programme, its coordinator Prof. Dr. Michael Hörner and Sandra Drube and all its members, for their constant support since I first came to Göttingen and creating such an atmosphere felt like a family. I would specially thank those in my batch (also the 'Molbios') for all the wonderful memories.

I wish to express deep sense of gratitude to the whole MBNS department. Everyone is nice and it is a splendid environment for science and life. Dr. Mišo Mitkovski introduced me to the world of imaging and is a perfect desk neighbor. Dr. Bryan Downie taught me western blot and the amazing technique of patch-clamping. Dr. Milena Ninkovic gave me invaluable advices in molecular biology. Dr. Fernanda Mello de Queiroz helped me on FACS and immunostaining. I enjoyed a lot from the spontaneous, thought-provoking discussions with Dr. Tobias Kohl. I would like to thank Barbara Boczek for the excellent technical assistance on rat brain extraction, Victor Díaz for cell culture, Ute Rust for all the paper work, Jörg Schischkoff and Schliephacke Ralph for repairing the equipments and excellent IT support.

I would like to thank the financial support from Neuroscience Early Stage Research Training (NEUREST). The great organization and immense support from the programme coordinators PD Dr. Joachim Bormann, Dr. Thomas Fritzsche and Eva Strehler.

I am thankful to Dr. Anjana Nityanandam, Andrew Woehler, Sünke Mortensen and Dr. Adema Ribic for their careful revision of my thesis draft and really helpful inputs.

Last but not least, I would like to express my gratitude and apologies to my parents and my wife. They have been always supportive to my dream of pursuing science. My wife even spent

substantial amount of time trying to understand my work, including attending my talks. All of them want me to be nearby but instead accept the fact that I am far way most of the time. 


\section{Contents}

\begin{tabular}{lll}
\hline & Declaration & 2
\end{tabular}

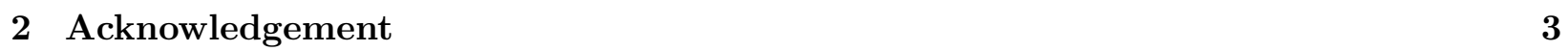

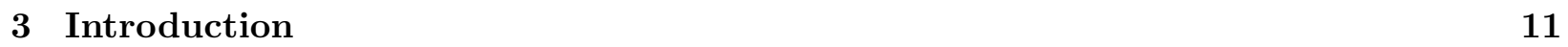

3.1 Overview of Eag1 $\ldots \ldots \ldots \ldots \ldots \ldots \ldots \ldots \ldots$

3.1 .1 hEag1 protein . . . . . . . . . . . . . . . . 11

3.1 .2 Properties of Eag1 current . . . . . . . . . . . . . . . . . . 11

3.2 Physiological role of $\mathrm{Eag} \ldots \ldots \ldots \ldots \ldots \ldots \ldots \ldots$

$3.2 .1 \quad$ D. melanogaster and C. elegans Eag . . . . . . . . . . . . . . . . . . . . 14

$3.2 .2 \quad$ Mammalian Eag1 . . . . . . . . . . . . . . . . . . . . . . . . 15

3.3 hEag1 in pathological conditions . . . . . . . . . . . . . . . . . 15

3.3.1 Ion channels in normal cell proliferation and cell cycle . . . . . . . . . . . . 15

3.3 .2 Cancer-related ion channels $\ldots \ldots \ldots \ldots \ldots$

$3.3 .3 \quad$ Distribution of Eag1 in tumors $\ldots \ldots \ldots \ldots$. . . . . . . . . . 16

3.3 .4 Transforming ability of hEag1 . . . . . . . . . . . . . . . . 17

$3.3 .5 \quad$ Roles of hEag1 in neoplasia $\ldots \ldots \ldots \ldots \ldots$

3.3.6 Discrepancy on the role of Eag1 conductance in tumorigenesis . . . . . . . . . 18 
$3.4 \quad$ Nuclear envelope and inner nuclear membrane proteins $\ldots \ldots \ldots$. . . . . . . . . . 19

$3.4 .1 \quad$ Structure of nuclear envelope $\ldots \ldots \ldots \ldots$

$3.4 .2 \quad$ Inner nuclear membrane proteins and their physiological roles . . . . . . . . . 20

$3.4 .3 \quad$ Transport of transmembrane proteins into nucleus $\ldots \ldots$. . . . . . . . . 22

3.5 Ion channels in the nuclear envelope $\ldots \ldots \ldots \ldots$. . . . . . . . . . . . 24

3.5.1 Permeability of nuclear envelope to ions and electrophysiological studies of

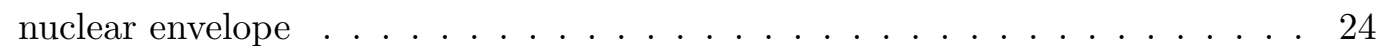

3.5.2 Channels in nuclear envelope . . . . . . . . . . . . . . . . 25

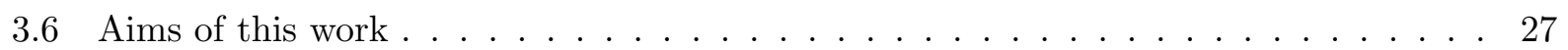

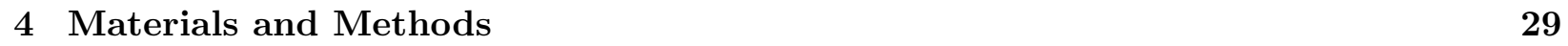

4.1 Chemicals and Solutions $\ldots \ldots \ldots \ldots \ldots$

4.2 Antibodies . . . . . . . . . . . . . . . . . . . . . . . . . . . . . . 34

4.3 DNA constructs . . . . . . . . . . . . . . . . . . . . . . . . . . 35

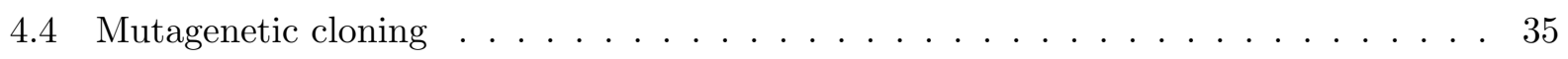

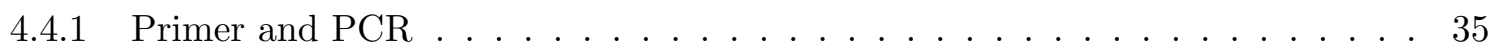

$4.4 .2 \quad$ Enzymatic digestion and transformation . . . . . . . . . . . . . . 37

$4.4 .3 \quad$ Mini- and Midipreparation of DNA $\ldots \ldots \ldots \ldots \ldots \ldots$

$4.5 \quad$ Cell culture $\ldots \ldots \ldots \ldots \ldots \ldots$ 
4.6 Transfection $\ldots \ldots \ldots \ldots \ldots$

4.7 Immunofluorescence Microscopy $\ldots \ldots \ldots$. . . . . . . . . . . . . . . . . . . . 40

$4.7 .1 \quad$ Double staining of NPC and Eag1 . . . . . . . . . . . . . . . . . 40

4.7 .2 Triton $\mathrm{X}-100$ extraction $\ldots \ldots \ldots \ldots \ldots \ldots$

$4.7 .3 \quad$ Digitonin permeabilization $\ldots \ldots \ldots \ldots \ldots \ldots$

4.7 .4 Microscopy $\ldots \ldots \ldots \ldots \ldots \ldots$. . . . . . . . . . . . . . . . . . . 41

4.8 Nuclear Isolation and western blot $\ldots \ldots \ldots$. . . . . . . . . . . . . . . . . 42

4.8 .1 Triton $\mathrm{X}-100$ extraction experiments $\ldots \ldots \ldots \ldots$. . . . . . . . 42

4.8 .2 Cytochrome c activity assay . . . . . . . . . . . . . . . 43

4.8 .3 Nuclear protein isolation $\ldots \ldots \ldots \ldots \ldots \ldots$. . . . . . . . . . . 44

4.8 .4 Protein gel electrophoresis and western blot . . . . . . . . . . . . 45

4.9 Electrophysiological recordings $\ldots \ldots \ldots \ldots \ldots$

4.10 Photobleaching experiments . . . . . . . . . . . . . . . . 48

4.10 .1 Experiment condition $\ldots \ldots \ldots \ldots \ldots \ldots$

4.10 .2 Data analysis . . . . . . . . . . . . . . . . . . 49

$\begin{array}{lll}5 & \text { Results } & 51\end{array}$

$5.1 \quad$ Eag1 colocalizes with known inner nuclear membrane proteins . . . . . . . . . . . 51 
5.2 Neither side of the peri-nuclear Eag1 is accessible from the cytoplasm $\ldots$. . . . . . 53

$5.3 \quad$ Peri-nuclear Eag1 distribution does not correlate with expression levels . . . . . . . . 56

5.4 Peri-nuclear Eag1 is resistant to Triton X-100 extraction . . . . . . . . . . . . . . . 58

5.5 Lateral diffusion is compromised in perinuclear Eag1 . . . . . . . . . . . . . . 60

5.6 Peri-nuclear Eag1 is not co-localized with NPC $\ldots \ldots \ldots$

5.7 Single channel current compatible with Eag1 at the inner nuclear membrane . . . . . 65

$5.7 .1 \quad$ Large conductance NPC currents . . . . . . . . . . . . . . . . . . 65

$5.7 .2 \quad$ No Eag1-like Current observed in non-transfected cells . . . . . . . . . . . . . 68

5.7.3 Single channel currents compatible with Eag1 at the inner nuclear membrane of HEK-Eag1 cells - conductance and pharmacology . . . . . . . . . . . . . 69

$\begin{array}{lll}6 & \text { Discussion } & 72\end{array}$

6.1 Inner nuclear membrane localization of Eag1 is not caused by overexpression $\ldots . .73$

6.2 Diffusion coefficient (D) in FRAP analysis $\ldots \ldots \ldots \ldots \ldots$

$6.3 \quad$ Reagents to separate inner nuclear membrane from outer nuclear membrane . . . . . 75

6.4 Single channel activities recorded at the inner nuclear membrane is very likely from

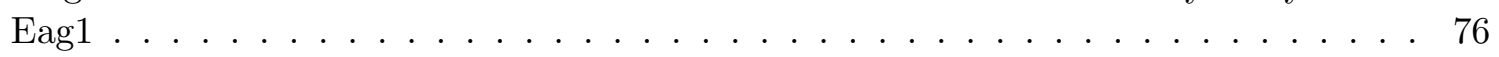

6.5 NE electrophysiology $\ldots \ldots \ldots \ldots \ldots \ldots \ldots \ldots \ldots$

6.6 Possible role of Eag1 in the inner nuclear membrane as an ion channel . . . . . . . . 80

6.7 Transport of Eag1 into nucleus and the relevance to mitosis . . . . . . . . . . . 81 
6.8 Non-canonical role of Eag1 in the 'NPC-free islands $\ldots \ldots$. . . . . . . . . . . . 82

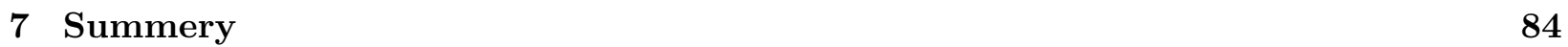

\begin{tabular}{lll}
\hline & Appendix & 102
\end{tabular}

8.1 Abbreviations . . . . . . . . . . . . . . . . . . . . 102

8.2 Publications . . . . . . . . . . . . . . . . . . . . 106

8.3 Curriculum Vitad $\ldots \ldots \ldots \ldots$. . . . . . . . . . . . . . . . . . . . 107 


\section{List of Figures}

$1 \quad$ Schematic representation of Eag1 subunit on the plasma membrane . . . . . . . . . . 12

$2 \quad$ Structure of nuclear envelope and its associated proteins . . . . . . . . . . . . 20

$3 \quad$ Model of 'nucleus-attached' single channel recording $\ldots \ldots \ldots$. . . . . . . . 26

$4 \quad$ Eag1 is found at the INM by IEM and colocalized with Lamin A/C . . . . . . . . 28

$5 \quad$ Eag1 protein was co-purified with other inner nuclear membrane proteins . . . . . 52

$6 \quad$ Peri-nuclear Eag1 is not accessible from cytoplasm $\ldots \ldots \ldots$. . . . . . . . . . 55

$7 \quad$ No correlation between peri-nuclear and cytoplasmic Eag1 fluorescence intensity . . 57

$8 \quad$ Peri-nuclear Eag1 is resistant to Triton X-100 extraction . . . . . . . . . . . . . . 59

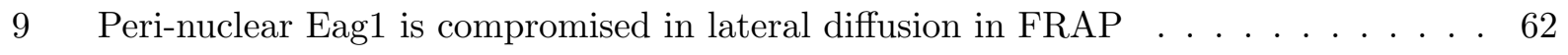

$10 \quad$ Peri-nuclear Eag1 is localized to NPC-free island $\ldots \ldots \ldots$. . . . . . . . . 64

11 Nuclei for patch-clamp measurement . . . . . . . . . . . . . . . . 67

12 Single channel recording compatible with Eag1 from the inner nuclear membrane . . 70

13 Single channel current blocked by anti-Eag1 antibodies at the inner nuclear mem-

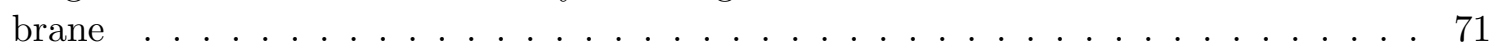




\section{List of Tables}

$1 \quad$ List of solutions $\ldots \ldots \ldots \ldots \ldots \ldots \ldots \ldots$

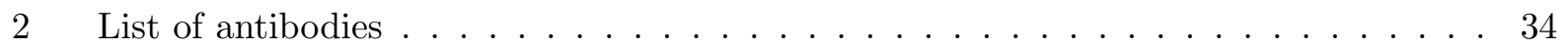

3 Primers for mutagenesis $\ldots \ldots \ldots \ldots \ldots \ldots$

$4 \quad \mathrm{PCR}$ reaction solution $\ldots \ldots \ldots \ldots \ldots \ldots$

$5 \quad$ PCR reaction for QuikChange mutagenesis $\ldots \ldots \ldots$. . . . . . . . 36

$6 \quad$ List of fluorophores and respective spectral settings . . . . . . . . . . . . . . . 42

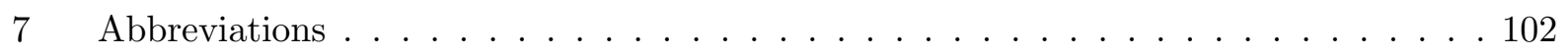




\section{Introduction}

\subsection{Overview of Eag1}

\subsection{1 hEag1 protein}

hEag1 (human ether-à-go-go-1, Kv10.1) is a voltage-gated potassium channel. Its gene belongs to the eag subfamily of the EAG family, together with hEag2. The EAG family has a shared homology with both voltage-gated Kv1-6,8-9 and cyclic nucleotide-gated cation channels Bauer and Schwarz, 2001. Based on the structural homology, the functional channel is assumed to be a tetramer Jenke et al. 2003]. Each subunit has six putative transmembrane domains with both the $\mathrm{N}$ and C-termini facing the cytoplasm (Fig. 11). There are numerous regulatory domains on both termini, including three calmodulin (CaM) binding domains [Ziechner et al., 2006], a biparticle nuclear localization signal (NLS, RKisdvKReeermKRKN) [Hegle et al., 2006 and a predicted nuclear export signal (NES, LseiLriL) for soluble proteins la Cour et al., 2004].

\subsubsection{Properties of Eag1 current}

In heterologous systems, under physiological ion distribution, the single channel conductance of Drosophila Eag in oocytes is 4.9pS derived from noise analysis Brüggemann et al., 1993. In HEK cells that value for rat Eag is 7.4pS Stansfeld et al., 1996 and in myoblast for hEag1 it was measured to be $8.4 \mathrm{pS}$ [Bijlenga et al., 1998]. Inside-out patch clamp recordings have often shown that the currents run down quickly (both in the HEK cell line [Stansfeld et al., 1996] and oocytes Ludwig et al. 1994). This is probably due to the wash-out of large cytosolic factors, because there 


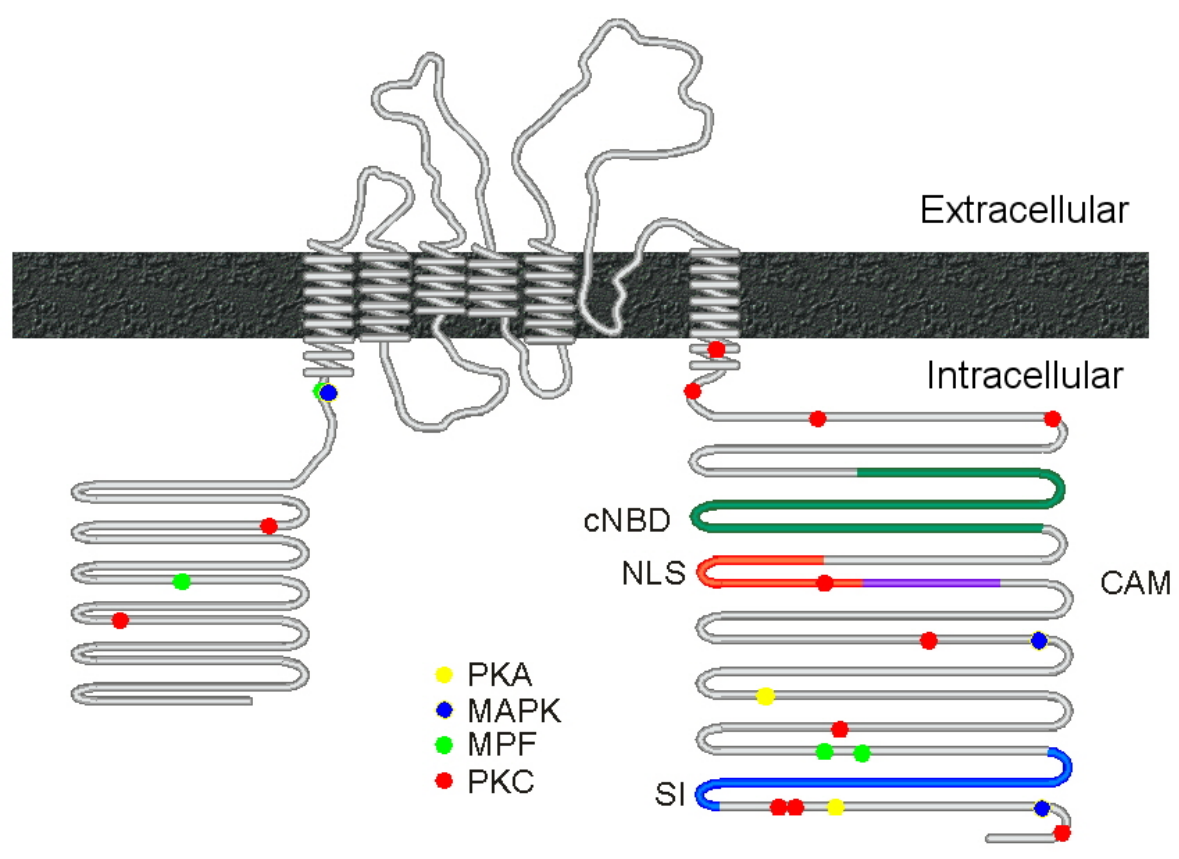

Figure 1: Schematic representation of Eag1 subunit on the plasma membrane. Some of its motifs and enzymatic modification sites are also shown.

is much less run-down in whole-cell patch clamp mode. And the current in inside-out patch can be rescued by putting the patch back to the cell, termed 'cramming' Robertson et al., 1996.

The macroscopic Eag1 current is slow-activating, non-inactivating. Its rate of activation is positively correlated with the holding potential before depolarization Bauer and Schwarz, 2001. This phenomenon is reminiscent of the Cole-Moore effect initially described for potassium currents in the squid axon COLE and MOORE, 1960]. This slow-down of activation by negative holding potential is more pronounced in the presence of extracellular $\mathrm{Mg}^{2+}$ at physiological concentrations Brelidze et al., 2009, Terlau et al., 1996.

Drosophila Eag has certain traits that are lost in hEag, such as partial inactivation and permeability to $\mathrm{Ca}^{2+}$. Cyclic nucleotides are not able to enhance the current of hEag, as they do to 
Drosophila Eag, despite the presence of a cyclic nucleotide binding domain in its structure Ludwig et al. 1994.

The macroscopic current rectifies at positive membrane potential due to a blockage from intracellular $\mathrm{Na}^{+}$Pardo et al. 1998. Interactions with other proteins also modulate Eag1 current. The current amplitude is reduced by binding to Ca-CaM [Schönherr et al., 2000, Ziechner et al., 2006 or actin filaments Camacho et al. 2000]. Interaction with microtubulin reduces the selectivity and thereby the rectification Camacho et al. 2000.

Eag1 current varies in a cell-cycle dependent manner. During the M phase in oocytes and CHO cells, rearrangement of the cytoskeleton alters the current as explained [Camacho et al., 2000]. In neuroblastoma cells, Eag1-like current is reduced when cells are arrested in G0/G1 transition by retinoic acid, which is a secondary, metabolic effect since the acute application of retinoid acid increases Eag1 current Meyer and Heinemann, 1998]. Eag1 is also expressed transiently before myoblast fusion (G1/G0) Bijlenga et al. 1998.

The only available small molecular blocker with relative specificity is astemizole. It was originally used as a histamine H1-receptor antagonist but later shown to be a blocker for channels in the EAG family García-Ferreiro et al. 2004. It is able to permeate the lipid bilayer and bind to the open channel from the intracellular side with an $\mathrm{IC}_{50}$ around $200 \mathrm{nM}$ García-Ferreiro et al. 2004. No other potassium channels have been shown to be blocked by astemizole.

A very specific blocker for Eag1 is a monoclonal antibody (mAb56) against the extracellular pore region of Eag1, with an $\mathrm{IC}_{50}$ around $300 \mathrm{nM}$. Unlike astemizole, mAb56 does not affect current from HERG or hEag2 Gómez-Varela et al., 2007. 


\subsection{Physiological role of Eag}

\subsubsection{D. melanogaster and C. elegans Eag}

The Drosophila genome contains only one eag gene Ganetzky et al., 1999. Drosophila Eag has been most widely studied at the neuromuscular junction (NMJ) where it has been implicated in the repolarization after action potential Drysdale et al. 1991. Loss of function mutant flies show reduction in four potassium currents: the transient, delayed, fast Ca-activated and slow Caactivated Zhong and Wu, 1991. Consequently, these flies have longer and larger depolarizations as well as more frequent spontaneous excitatory junction potentials, both of which result in an increase in neurotransmitter release Ganetzky and $\mathrm{Wu}, 1983$. All these effects together explain the rhythmic leg-shaking phenotype of mutant flies upon etherization from which the gene was named Kaplan and Trout, 1969]. Loss of function of eag also enhances the habituation of postsynaptic response Engel and Wu, 1998 and produces defects in the olfactory system Dubin et al. 1998 as well as associated learning Griffith et al., 1994.

Drosophila eag acts synergistically with another potassium channel, shaker. Hence the flies with double mutations have a plateau-shaped action potential at the NMJ and an even longer duration of neurotransmitter release Warmke et al. 1991. Because of this it is not surprising that the gain-of-function point mutation of eag in the voltage-sensor can rescue the shaker mutation in a $\mathrm{Mg}^{2+}$-dependent manner Cardnell et al. 2006.

The C. elegans orthologue of eag gene is egl-2. It acts in parallel with erg to inhibit the sex muscle contraction LeBoeuf et al. 2007. In gain of function mutants, neurons and muscles are less excitable and those mutants have defects in odorant sensing [Weinshenker et al., 1999]. 


\subsubsection{Mammalian Eag1}

Though Eag1 is expressed almost exclusively in the central nervous system of rats and humans Martin et al. 2008, no endogenous Eag1 current has been reported from the soma of neurons and little is known about its role. Intriguingly, Eag1 is distributed predominantly intracellularly in neurons JJeng et al., 2005, Martin et al., 2008, Saganich et al., 2001. It is not present at the NMJ but it is transiently expressed before myoblast fusion Bijlenga et al. 1998. In addition, an Eaglike current has been reported in rod inner segment of bovine retina [Frings et al., 1998 and Eag immunoreactivity has been detected in the rat retina [Jow and Jeng, 2008, both of which suggest a contribution of Eag1 to the dark current. In cultured rat hippocampal neurons, surface Eag1 is localized mostly at presynaptic termini, where it diffuses into and out of laterally. Its diffusion behavior also differs inside or outside of presynaptic membrane because the cytoskeleton restricts its mobility inside the presynaptic region in a fast manner, which may indicate its physiological role as well as a regulation mechanism Gómez-Varela et al., 2010].

\section{3 hEag1 in pathological conditions}

\subsubsection{Ion channels in normal cell proliferation and cell cycle}

Since many ion channels are responsible for regulating various fundamental physiological processes such as maintenance of resting membrane potential, it is of no much surprise that inhibition of different ion channels leads to impairments of cell proliferation. This has been described in numerous cell types, most thoroughly in T-lymphocytes. Besides, it has also been noted that the membrane potentials of terminally differentiated cells are more hyperpolarized than those of quiescent cells, 
which require a hyperpolarization by potassium channels to initiate the G0/G1 transition. It was also noticed that potassium channels associated with hyperpolarization were required during the G1/S transition of cycling cells Wonderlin and Strobl, 1996].

\subsubsection{Cancer-related ion channels}

Parallel to these findings in normal cells, membrane potentials of cancer cells under continuous mitotic cycles are the least polarized [Wonderlin and Strobl, 1996]. Hence, it is easy to postulate a relationship between the proliferation of a cell and its ion channels content, particularly for cancer cells. On one hand, expression of many $\mathrm{K}, \mathrm{Na}$ and $\mathrm{Ca}$ channels has been found to be deregulated in tumors Kunzelmann, 2005, Pardo et al., 2005, Wang, 2004. And a number of channel blockers, either specific or broad spectrum, have the ability to inhibit tumor growth. On the other hand, only a few channels provide growth advantages for tumors. Among these few channels, only hEag1 has been shown to have transforming capability Pardo et al. 2005.

As mentioned previously, hundreds of channels are able to conduct ion flow across the membrane and affect the membrane potential and/or cell volume to some extent. The question that imposes itself is why are only a few are expressed during the micro-evolution of tumor progression, or to put it in the context of this study, why hEag1 Pardo, 2004]?

\subsubsection{Distribution of Eag1 in tumors}

A striking feature of Eag1 is its prevalent mRNA and protein distribution in various tumor tissues, that do not express hEag1 under normal physiological conditions [Hemmerlein et al., 2006]. Eag1 
has been detected in $>75 \%$ of primary solid tumor samples from various origins de Queiroz et al. 2006. Hemmerlein et al., 2006 and around 50\% of hemopoietic neoplasms Agarwal et al., 2010.

And its expression level correlates with the survival rate in both sarcoma and leukemia.

As a well established plasma membrane channel, its current can be measured in neuroblastoma cell lines [Meyer and Heinemann, 1998, melanoma cell line Meyer et al., 1999 and primary tumors Farias et al. 2004]. For example, before the proliferation of MCF-7 cells, there is a significant increase of Eag1 current and mRNA Ouadid-Ahidouch et al. 2001. However, similar to the situation in neurons, the majority of Eag1 stays in the intracellular pool in tumor and tumor cells.

\subsubsection{Transforming ability of hEag1}

When ectopically expressed, hEag1 shows oncogenic potential. The host cells proliferate faster and lose the contact inhibition as well as the requirement of serum for growth. They form tumors in immunocompromised mice after transplantation [Pardo et al. 1999]. For tumorigenesis in vivo, hEag1 expression is more likely to take place secondary to other initiating factors Pardo and Stühmer, 2008a such as papillomavirus oncogenes Díaz et al., 2009.

Nevertheless, these transformed cells become dependent on hEag1 expression possibly due to the selective advantages conferred by hEag1 Pardo et al., 1999]. Both the knock-down of hEag1 expression level by antisense oligonucleotides Pardo et al., 1999 or siRNA [Weber et al., 2006], and the blockage of Eag1 open channel by drugs Díaz et al., 2009, Downie et al., 2008] or monocolonal antibodies Agarwal et al., 2010, Gómez-Varela et al., 2007) can inhibit the growth of cancer cell lines or tumors in mice. 


\subsubsection{Roles of hEag1 in neoplasia}

It is not only intriguing to understand the role of Eag1 from a basic research aspect, also of equal importance to understand the mechanism in tumors for diagnosis and therapeutic reasons Pardo and Stühmer, 2008a b, Wulff et al., 2009. As noted above, ectopic expression of ion channels in cancer cells is not uncommon. However, hEag1 is so far the only one the fulfills all four criteria: to be absent from its normal tissue counterpart, to be able to transform normal cells, to be able confer selective advantages and the inhibition of which can prevent cancer proliferation Pardo et al., 2005, Pardo, 2004.

Exactly what hEag1 coffers the tumor with remains unclear. hEag1 is involved in many signaling pathways. IGF-1 activation up-regulates hEag1 through increasing Akt/PI3K level Borowiec et al. 2007]. It is also well established that hEag1 is under progesterone control through mitosis-promoting factor Brüggemann et al., 1997, Camacho et al., 2000. In solid tumors, the interaction with oxygen homeostasis and angiogenesis seems to make the tumor more adaptive in a hypoxia environment by boosting a hypoxia-driven response and trimming the vascular systems around tumors Downie et al. 2008. The involvement of hEag1 in the etiology of leukemia, where angiogenesis is not present, is unknown.

\subsubsection{Discrepancy on the role of Eag1 conductance in tumorigenesis}

One particular, and perhaps the most intuitive, mechanism for the role of Eag1 in tumor is its permeability as a potassium channel. However, because of hEag1's distinguished character in tumorigenicity compared to other channels, it is unlikely that any normal property of an ion channel, $\mathrm{K}^{+}$permeability for instance, can explain its prominent relationship with cancer. This makes the 
hypothesis on the involvement of cell volume check point or membrane potential regulation in malignant transformation less appealing [Pardo, 2004].

In terms of its known interaction with oxygen homeostasis, vascularization or extracellular matrix organization Toral et al. 2007, there is no obvious link to $\mathrm{K}^{+}$flow. Besides, Drosophila Eag can induce oncogenic proliferation independently of ion influx [Hegle et al. 2006]. This issue becomes more debatable when it was found that non-conducting Eag1 from point mutation still promotes the tumor progression but to a lesser extent Downie et al., 2008. Yet another intriguing observation is that hEag2, the closest family member to hEag1, has no oncogenic properties. This result strongly indicates that the transforming capability hEag1 is not dependent on a portion of its sequence, at least not the ion-conducting pore, but on the protein and its conformation as a whole, probably carrying out some non-canonical functions as a channel.

\subsection{Nuclear envelope and inner nuclear membrane proteins}

\subsubsection{Structure of nuclear envelope}

During the interphase of eukaryotes, the nucleoplasm is separated from the cytoplasm by the nuclear envelope (NE). This is a membrane structure composed of two layers, the inner and the outer nuclear membranes (INM and ONM). Both are connected at the nuclear pore complex (NPC), which controls trafficking between the two compartments Mattaj, 2004. The space between outer and inner nuclear membrane (peri-nuclear space) is an extension of the lumen of the endoplasmic reticulum (ER). The surface of nuclear envelope is roughly $5 \%$ of ER, not taking into account the invaginations in the NE Georgatos, 2001. 
The nuclear lamina is an intermediate filament meshwork located beneath the inner nuclear membrane and it is composed mainly of polymerized lamin proteins Soullam and Worman, 1995 , Wu et al. 2002b. Lamina acts as the scaffold of the nuclear structure and provides the platform for numerous interactions. Although the outer nuclear membrane is an extension of the rough ER (rER), it has a distinct set of proteins, different from those found in the ER Schirmer and Gerace, 2005 (Fig 2).

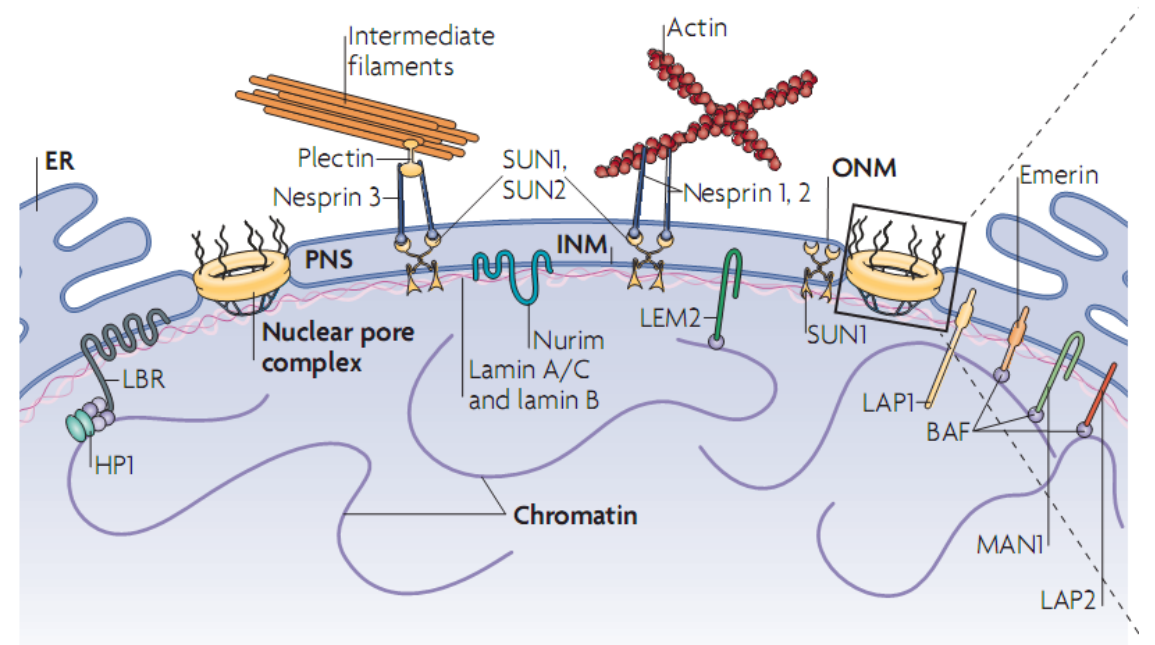

Figure 2: Structure of nuclear envelope and its associated proteins Güttinger et al. 2009]. See main text for details.

\subsubsection{Inner nuclear membrane proteins and their physiological roles}

The differences between the ER and the nuclear envelope in terms of protein composition are much more pronounced at the inner nuclear membrane; only a handful of transmembrane proteins can reach the inner nuclear membrane [Schirmer and Foisner, 2007]. The transmembrane proteins in the inner nuclear membrane come mainly from three groups: the LEM-domain (LUMA, Emerin 
and MAN1 domain) family, the SUN-domain (Sad1 and UNC-84 homology domain) family and the KASH-domain (Klarsicht, ANC-1 and SYNE1 homology) family [Tzur et al., 2006] (Fig 2).

LEM domain family in human includes LUMA, emerin, MAN1, lamina associated polypeptides (LAP) $1,2 \beta, 2 \gamma$ and LAP-emerin-MAN1 domain protein 2 (LEM2) Brachner et al., 2005]. They all contain a globular LEM domain at the $\mathrm{N}$ terminus and bind to lamin $\mathrm{A} / \mathrm{C}$ or lamin $\mathrm{B}$ and to BAF (barrier to autointegration factor) which is a chromatin associated protein. Some of them also bind to HA95, also a chromatin associated protein containing zinc finger for binding. Therefore, the functions of LEM proteins have always been tightly linked to chromatin organization and gene regulation at the inner nuclear membrane Gruenbaum et al., 2005, Heessen and Fornerod, 2007 (Fig 2).

In the simplest scenario, sequestering transcription factors, repressors or other regulators to the inner nuclear membrane may up or down-regulate the expression levels of a multitude of genes, as in the case for LAP2 $\beta$ [Dorner et al., 2006] and MAN1 [Lin et al., 2005]. At a higher level of complexity, inner nuclear membrane proteins can influence gene expression by direct interaction with chromatin. The chromatin in the vicinity of the nuclear envelope may contain genes that would be actively transcribed while in areas close to the NPC; those located away from the NPC (heterochromatin) would be silent Akhtar and Gasser, 2007]. The physical structure of heterochromatin does not influence only the transcription efficiency. In alternative splicing, nucleosome density correlates with exon-inclusion probability [Tilgner et al. 2009] and siRNA can affect the splicing product through heterochromatin Alló et al., 2009. Last but not least, during the open mitosis of higher eukaryotic cells, the nuclear envelope is at first completely disassembled and dissipated into the ER. After telophase, those nuclear envelope fragments have to be sequestered from the ER and reconstitute a new nuclear envelope. This segregation is mediated by interactions of inner nuclear membrane proteins with chromatin Anderson and Hetzer, 2007, Holaska et al., 2002, Mattaj, 2004. 
The SUN family composed of SUN1 and 2. These proteins have a SUN domain located at the very end of their $\mathrm{C}$ terminus facing peri-nuclear space [Tzur et al., 2006]. They function as bridges between cytoskeleton and nucleoskeleton by forming a LINC complex with the KASH proteins in the outer nuclear membrane Gruenbaum et al., 2005, Holmer and Worman, 2001. With SUN domain proteins linked to the lamina, KASH proteins further connect to cytoskeleton through other mediators Starr and Fischer, 2005] (Fig 2). This is essential for the correctly positioning the nuclei during interphase and the migration of nuclei in development. KASH domain proteins such as nesprin-1 are mainly found in the outer nuclear membrane. However, there is evidence for the presence of KASH proteins in the inner nuclear membrane and correspondingly, an inverted conformation of the LINC complex [Starr and Fischer, 2005].

There are some other inner nuclear membrane proteins that cannot be assigned to the aforementioned families. For example, ring-finger-binding protein (RFBP) belongs to lipid pump family but binds to a transcription factor RUSH in the inner nuclear membrane Mansharamani et al. 2001. Inositol 1,4,5-trisphosphate (InsP3) receptor is a ligand-gated calcium channel Humbert et al. 1996. Lamin B receptor (LBR) also binds to chromatin and lamin B Makatsori et al., 2004. In addition it may also be a sterol reductase [Georgatos, 2001]. There are very few functional studies on the nuclear rim protein (nurim) and its intimate binding to the inner nuclear membrane Hofemeister and O'Hare, 2005. Finally, one should always include the transmembrane proteins that are components of the NPC Anderson and Hetzer, 2008,

\subsubsection{Transport of transmembrane proteins into nucleus}

Small $(<40 \mathrm{kDa})$ soluble proteins can cross the NPC freely, while larger molecules are actively and selectively transported through the NPC in a Ran GTPase dependent manner Terry et al. 
2007]. The situation is more complex for transmembrane proteins. The model with the most experimental supports is the 'diffusion-retention' hypothesis Soullam and Worman, 1995. Inner nuclear membrane proteins on the ER presumably back-diffuse to the outer nuclear membrane and then employ the machinery for selective transport of large soluble proteins across the NPC Zuleger et al. 2008], at least in budding yeast King et al., 2006 and insect cells Braunagel et al., 2007. Once they cross the NPC, inner nuclear membrane proteins are normally trapped in the inner nuclear membrane, due to the aforementioned 'retention' taking place there.

Different regions of protein sequences have been found to be required for the inner nuclear membrane localization of transmembrane proteins. For example, the residues at the N-terminus of LAP2 $\beta$ Furukawa et al., 1995, 1998, MAN1 Wu et al., 2002b or LBR Soullam and Worman, 1993; in N Ostlund et al., 1999 and $\mathrm{C}$ Dabauvalle et al., 1999 termini of emerin; in transmembrane domain of nurim Rolls et al. 1999] and LUMA Bengtsson and Otto, 2008; in the N terminus and transmembrane domain of LEM2 Brachner et al., 2005]. Still, it is worth mentioning that there is so far no conserved NLS pattern for transmembrane proteins. And a canonical NLS for soluble protein is neither necessary nor sufficient to target transmembrane proteins into the inner nuclear membrane Soullam and Worman, 1995. Actually, the size of transmembrane segments is more a crucial determinant of inner nuclear membrane localization than the cytosolic domains Lusk et al. 2007 .

Another mechanism for inner nuclear membrane localization would be the recruitment of the nuclear-envelope-originated cytoplasmic vesicles or ER tubular networks that already contain the inner nuclear membrane proteins during the assembly of the nuclear envelope during mitosis Yang et al. 1997], as mentioned before. This mechanism, however, cannot be applied to all situations. Yeast posses transmembrane proteins in the inner nuclear membrane while the cells undergoes a closed mitosis, which does not involve nuclear envelope breakdown. 
There are two other less feasible ways for transporting membrane proteins into the nuclei: one involves sequential budding of vesicles from one side of the nuclear envelope and fusion with the other, which has only been described for viruses Mettenleiter, 2004; Transmembrane protein can also be transported to the nucleus in endosome Giri et al., 2005 or in a membrane-free form with the help of chaperons to shield the hydrophobic part [Wells and Marti, 2002]. Both normally result in the presence of the protein in the nucleoplasm.

\subsection{Ion channels in the nuclear envelope}

\subsubsection{Permeability of nuclear envelope to ions and electrophysiological studies of nuclear envelope}

NPC is a protein complex (around 60MDa) spanning nuclear envelope with a central canal surrounded by two layers of rings. This canal has been suggested to have hydrogel-like properties and to be permeable to ions Frey and Görlich, 2007. Since there are numerous NPCs at the nuclear envelope (10-50/ $\mu \mathrm{m}^{2}$ Mazzanti et al. 2001), it has been extensively debated whether the nuclear envelope can serve as a diffusion barrier to ion-flow between cyto- and nucleoplasm Bootman et al. 2000, Carafoli et al. 1997. If it were so, the ionic composition could be different between those two compartments, and there could be an electrical potential across the nuclear envelope.

From the very few reports on its ion composition Hoffman and Geibel, 2005, Kowarski et al. 1985, there seems to be an enrichment of $\mathrm{K}^{+}$and exclusion of $\mathrm{Cl}^{-}$in the nucleoplasm. In most

cases, the intranuclear potential is only slightly negative compared to the cytoplasm presumably due to the Gibbs-Donnan potential from DNA Mazzanti et al., 2001. Nevertheless, the intranuclear potential is dependent on the cytoplasmic $\mathrm{K}^{+}$concentration Draguhn et al., 1997, Mazzanti et al., 
1990], and it becomes more negative when cell progresses from late telophase to late anaphase Giulian and Diacumakos, 1977. This is probably due to the competitive binding between $\mathrm{K}^{+}$ and histone to the negatively-charged DNA back-bone at different conformations of chromatin in different cell cycle phases.

One obvious solution to this debate would come from measuring the conductance of the nuclear envelope electrophysiologically (Fig. 3), which is not as simple as once thought. On one hand, measurements on the impedance of whole Xenopus nuclei yielded results favoring a leaky nuclear envelope [Danker et al. [1999]. On the other hand, there are compelling evidence from patch-clamp studies suggesting that the NPC can completely close in a voltage-dependent manner and can prohibit any ion flow when occluded by cargos Bustamante, 2006, Mazzanti et al., 2001. From an experimental point of view, the fact that NPC can close in certain conditions also allows to measure currents from other smaller channels on either the outer or inner nuclear membrane. This is compatible with the existence of a difference in voltage between cyto- and nucleoplasm.

Regardless of the issue of ion exchange between cyto- and nucleoplasm, it should also be noted that channels at the outer nuclear membrane can participate in the regulation of ion exchange between the cytoplasm and peri-nuclear space, and those at the inner nuclear membrane could regulate the exchange between nucleoplasm and peri-nuclear space. Furthermore, it cannot be ruled out that those ion channels may have functions not associated to ion permeation.

\subsubsection{Channels in nuclear envelope}

Since the first patch-clamp study on the nuclear envelope in 1990 [Mazzanti et al., 1990], some ion channels have been characterized at the outer nuclear membrane Bustamante, 1994, Mazzanti et al. 


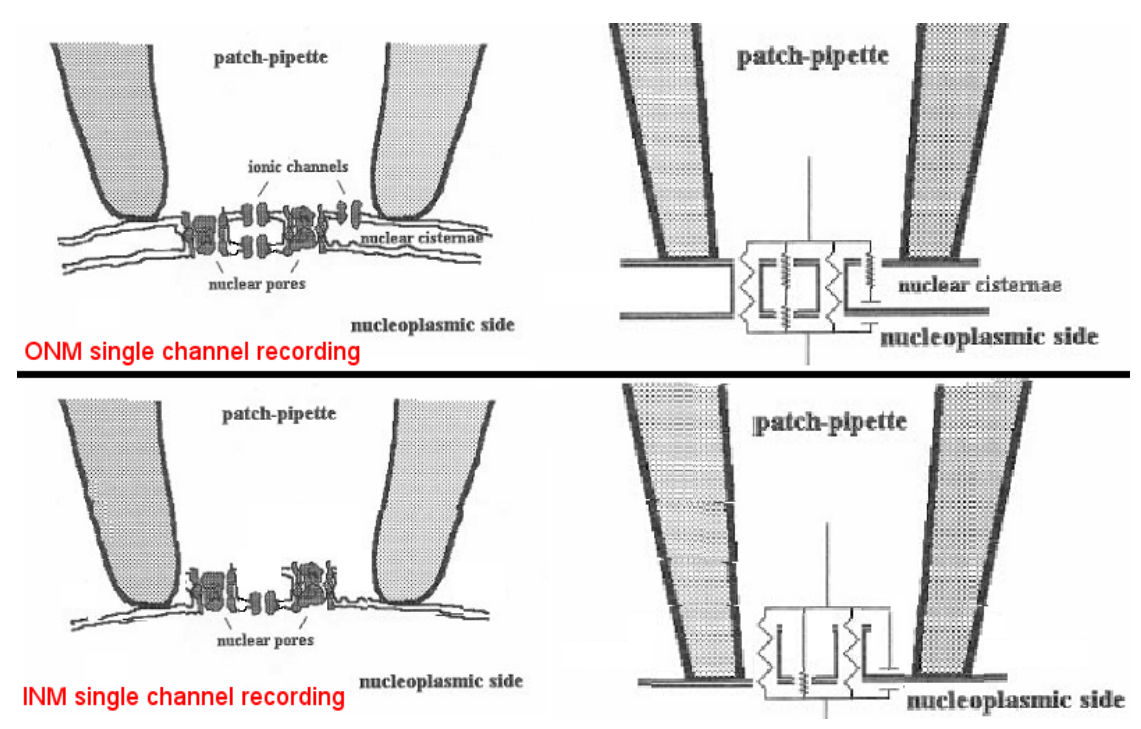

Figure 3: Model of 'nucleus-attached' single channel recording, adapted and modified from Mazzanti, 1998. The upper and lower panel show the diagram for recording on the outer or inner nuclear membrane, respectively. The left panel shows the scheme including NE, NPC, other ion channels and the pipette. The right panel demonstrates the corresponding electric circuits. The NPC and other nuclear channels are in parallel in this configuration, therefore the current through the larger conductor (in this case, the NPC) will dominate the total current recorded.

2001 in various systems, from the coconut endosperm Matzke et al., 1992 to human lymphocyte Franco-Obregón et al., 2000]. These include voltage-gated Tabares et al., 1991] or ligand-gated channels Mak and Foskett, 1994, Maruyama et al., 1995, and can be either highly Longin et al. 1997] or poorly [Draguhn et al., 1997] selective.

To the best of our knowledge, there has been only four reports on inner nuclear membrane channels so far. These are InsP3 receptor (biochemical approaches Humbert et al., 1996 and electrophysiological approaches Marchenko et al. 2005), a zinc and a calcium channel Longin et al., 1997], one chloride and one non-selective cation channel [Rousseau et al., 1996]. The role of InsP3 receptor would be to amplify cytoplasmic $\mathrm{Ca}^{2+}$ transients into the nucleoplasm Marchenko and Thomas, 2006]. For the rest, there is neither a molecular identity nor a physiological role 
proposed.

\subsection{Aims of this work}

The majority of Eag1 remains in intracellular pool, including the peri-nuclear region, in either heterologous systems Napp et al., 2005, neurons [Jeng et al., 2005, Martin et al., 2008, Saganich et al. 2001] or tumor cells de Queiroz et al., 2006, Farias et al., 2004, Hemmerlein et al., 2006]. Unpublished results in our lab also clearly showed that Lamin A/C colocalized with Eag1 by immunofluorescent studies in heterologous expressing system (Fig. 4 c, A. Sánchez, personal communication). Endogenous Eag1 has been detected at the inner nuclear membrane in cancer cell line MCF-7, and the hippocampus and cerebellum in rat by immunoelectron microscopy (IEM) (Fig. 4 a, b, M. Rubio, personal communication).

Hence, the aim of this study was to provide further evidence that Eag1 is localized at the inner nuclear membrane. Furthermore, it was also important to find methods able to discriminate between outer and inner nuclear membrane. And lastly, this study aimed at investigating if the Eag1 is still functioning as an ion channel in the inner nuclear membrane and what kind of topology it acquires there. 


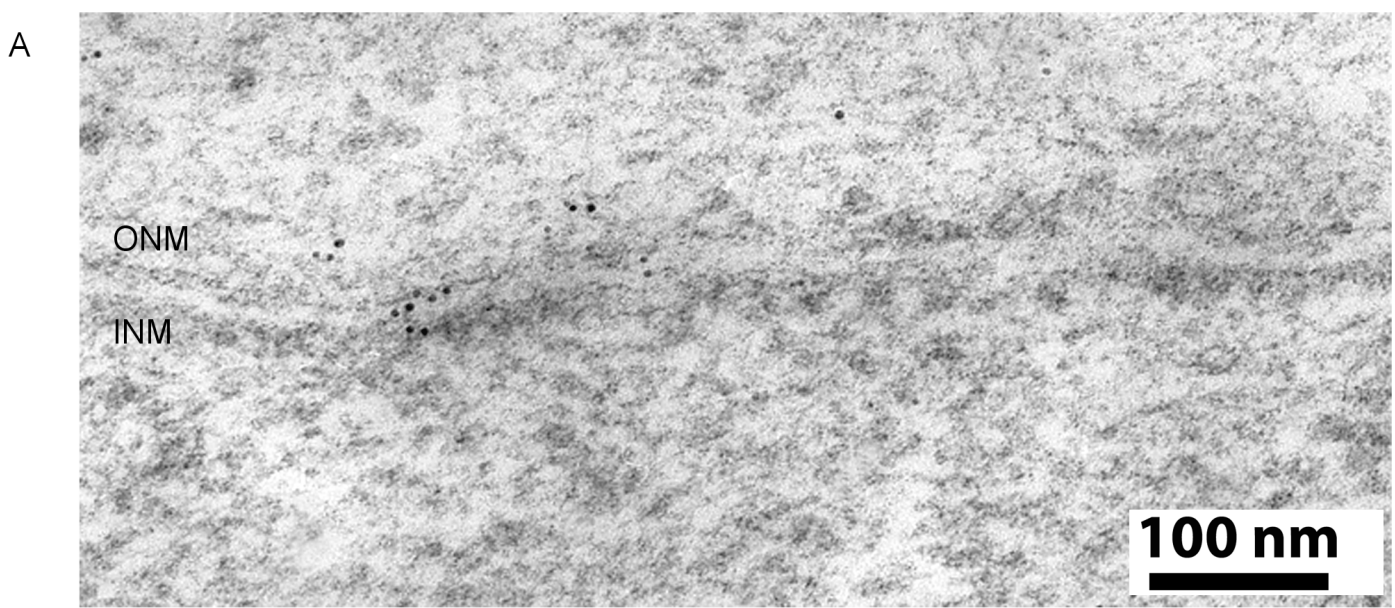

B

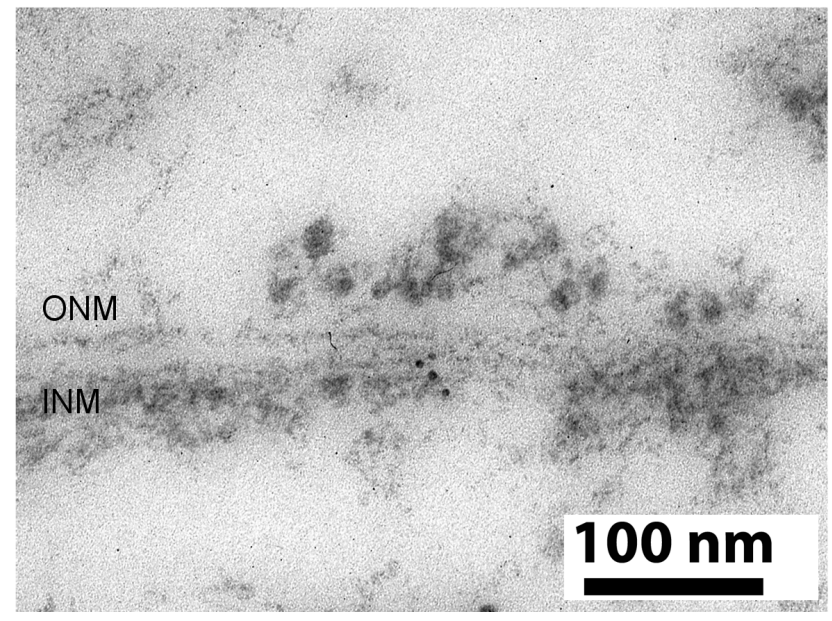

C

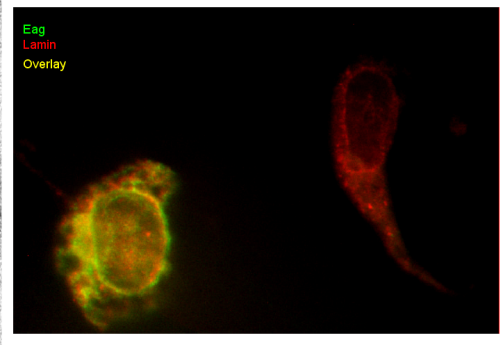

Figure 4: Eag1 is found at the INM by IEM in native expression systems and colocalized with Lamin A/C in CHO cells. a,b, IEM staining in MCF-7 cancer cell line (a) and rat hippocampus (b). Anti-Eag1 antibodies (mAb62) and anti-mouse antibodies conjugated with gold particles (5nm in diameter) were used for probing. Both show the presence of hEag1 at the INM in these native expression systems. c, Colocalization of hEag1 (green) and Lamin A/C (red) in CHO cells was detected by immunofluorescence staining. (A. Sánchez and M. Rubio, personal communications) 


\section{Materials and Methods}

\subsection{Chemicals and Solutions}

All chemicals unless otherwise stated were from either Sigma or Merck.

Table 1: List of solutions

\begin{tabular}{|c|c|c|}
\hline Solutions & Concentration & Component \\
\hline \multicolumn{3}{|l|}{ General } \\
\hline \multicolumn{3}{|l|}{ TBS } \\
\hline & $20 \mathrm{mM}$ & Tris \\
\hline & $0.15 \mathrm{M}$ & $\mathrm{NaCl}$ \\
\hline & pH 7.4 & \\
\hline \multicolumn{3}{|l|}{ LB medium } \\
\hline & $2.5 \%$ & Luria Broth Base (Invitrogen) \\
\hline \multicolumn{3}{|l|}{ PBS } \\
\hline & $137 \mathrm{mM}$ & $\mathrm{NaCl}$ \\
\hline & $43 \mathrm{mM}$ & $\mathrm{Na}_{2} \mathrm{HPO}_{4}$ \\
\hline & $27 \mathrm{mM}$ & $\mathrm{KCl}$ \\
\hline & $15 \mathrm{mM}$ & $\mathrm{KH}_{2} \mathrm{PO}_{4}$ \\
\hline & pH 7.3 & \\
\hline \multicolumn{3}{|l|}{ Imaging } \\
\hline \multicolumn{3}{|l|}{ HMK buffer } \\
\hline & $20 \mathrm{mM}$ & HEPES \\
\hline & $1 \mathrm{mM}$ & $\mathrm{MgCl}_{2}$ \\
\hline & $100 \mathrm{mM}$ & $\mathrm{KCl}$ \\
\hline & $\mathrm{pH} 7.5$ & \\
\hline
\end{tabular}

Live cell imaging extra-

cellular solution continued on next page 
continued from previous page

\begin{tabular}{lll}
\hline Solutions & Component & Concentration \\
\hline $10 \mathrm{mM}$ & $\mathrm{HEPES}$ \\
$1 \mathrm{mM}$ & $\mathrm{MgCl}_{2}$ \\
$2.5 \mathrm{mM}$ & $\mathrm{KCl}$ \\
$2 \mathrm{mM}$ & $\mathrm{CaCl}_{2}$ \\
$160 \mathrm{mM}$ & $\mathrm{NaCl}$ \\
$8 \mathrm{mM}$ & Glucose \\
$\mathrm{pH} 7.4$ &
\end{tabular}

\begin{tabular}{lll}
\hline Nuclear extraction & & \\
\hline Extraction buffer & & \\
& $10 \mathrm{mM}$ & HEPES \\
$30 \%$ & glycerin \\
$80 \mathrm{mM}$ & $\mathrm{KCl}$ \\
$16 \mathrm{mM}$ & $\mathrm{NaCl}$ \\
$1.5 \mathrm{mM}$ & $\mathrm{MgCl}_{2}$ \\
$1 \mathrm{mM}$ & DTT \\
1 tablet per 10ml & Complete protease inhibitor mix- \\
& ture (Roche Applied Science) \\
& $\mathrm{pH} 7.9$ &
\end{tabular}

Assay buffer in cytochrome c activity

$50 \mathrm{mM} \quad \mathrm{Na}_{2} \mathrm{HPO}_{4}$

$\mathrm{pH} 7.7$ by $\mathrm{KH}_{2} \mathrm{PO}_{4}$

Nuclear isolation

medium

$\begin{array}{ll}0.25 \mathrm{M} & \text { sucrose } \\ 25 \mathrm{mM} & \mathrm{KCl} \\ 5 \mathrm{mM} & \mathrm{MgCl}_{2} \\ 10 \mathrm{mM} & \text { Tris } \\ \text { pH } 7.4 \text { by } \mathrm{HCl} & \end{array}$

Hypoosmotic medium

$\begin{array}{ll}10 \mathrm{mM} & \text { Tris } \\ 10 \mathrm{mM} & \mathrm{Na}_{2} \mathrm{HPO}_{4}\end{array}$

continued on next page 
continued from previous page

\begin{tabular}{lll}
\hline Solutions & Component & Concentration \\
\hline & $\mathrm{pH} 8.0$ by HCl &
\end{tabular}

SDB

$\begin{array}{ll}2.3 \mathrm{M} & \text { sucrose } \\ 25 \mathrm{mM} & \mathrm{KCl} \\ 5 \mathrm{mM} & \text { Tris } \\ \text { pH } 7.4 \text { by } \mathrm{HCl} & \end{array}$

Modification buffer

$\begin{array}{ll}200 \mathrm{mM} & \text { HEPES } \\ 1 \mathrm{mM} & \mathrm{MgCl}_{2} \\ 250 \mathrm{mM} & \text { sucrose } \\ \text { pH } 8.5 \text { by } \mathrm{NaOH} & \end{array}$

LISM
$0.1 \mathrm{mM}$
$\mathrm{MgCl}_{2}$

SB8.5 buffer

$\begin{array}{ll}0.3 \mathrm{M} & \text { sucrose } \\ 0.1 \mathrm{mM} & \mathrm{MgCl}_{2} \\ 5 \mathrm{mM} & \text { 2-mercaptoethanol } \\ 10 \mathrm{mM} & \text { triethanolamine } \\ \text { pH8.5 by HCl } & \end{array}$

SB7.4 buffer

$\begin{array}{ll}0.3 \mathrm{M} & \text { sucrose } \\ 0.1 \mathrm{mM} & \mathrm{MgCl}_{2} \\ 5 \mathrm{mM} & \text { 2-mercaptoethanol } \\ 10 \mathrm{mM} & \text { triethanolamine } \\ \text { pH7.4 by } \mathrm{HCl} & \end{array}$

NMSM

\begin{tabular}{ll}
$20 \% \mathrm{v} / \mathrm{v}$ & glycerol \\
$1 \mathrm{mM}$ & EDTA \\
$10 \mathrm{mM}$ & Tris \\
$\mathrm{pH} 7.5$ by HCl & \\
\hline
\end{tabular}

continued on next page 
continued from previous page

\begin{tabular}{lll}
\hline Solutions & Component & Concentration \\
\hline & & \\
\hline Western Blot & & \\
\hline Denaturing lysis buffer & & \\
& $50 \mathrm{mM}$ & $\mathrm{NaHCO}_{3}$ \\
& $15 \mathrm{mM}$ & $\mathrm{Na}_{2} \mathrm{CO}_{3}$ \\
$2 \%$ & $\mathrm{SDS}$
\end{tabular}

NuPAGE LDS Sample

Buffer $(4 \times)$

Loading buffer

$\begin{array}{ll}106 \mathrm{mM} & \text { Tris HCl } \\ 141 \mathrm{mM} & \text { Tris base } \\ 2 \% & \text { LDS } \\ 10 \% & \text { Glycerol } \\ 0.51 \mathrm{mM} & \text { EDTA } \\ 0.22 \mathrm{mM} & \text { SERVA Blue G250 } \\ 0.175 \mathrm{mM} & \text { Phenol Red } \\ \text { pH } 8.5 & \end{array}$

$\begin{array}{ll}2.5 \mu \mathrm{l} & \text { NuPAGE LDS Sample Buffer }(4 \times) \\ 1 \mu \mathrm{l} & \text { NuPAGE Reducing Agent }(10 \times) \\ 6.5-\mathrm{x} \mu \mathrm{l} & \mathrm{ddH}_{2} \mathrm{O} \\ \mathrm{x} \mu \mathrm{l} & \text { sample }\end{array}$

Running buffer upper chamber

$\begin{array}{ll}10 \mathrm{ml} & \text { Tris-Acetate buffer } 20 \times \\ 190 \mathrm{ml} & \mathrm{ddH}_{2} \mathrm{O} \\ 500 \mu \mathrm{l} & \text { NuPAGE Antioxidant }\end{array}$

Running buffer lower chamber

$\begin{array}{ll}40 \mathrm{ml} & \text { Tris-Acetate buffer } 20 \times \\ 760 \mathrm{ml} & \mathrm{ddH}_{2} \mathrm{O}\end{array}$

Transfer buffer

$800 \mathrm{ml} \quad \mathrm{ddH}_{2} \mathrm{O}$

continued on next page 
continued from previous page

\begin{tabular}{lll}
\hline Solutions & Component & Concentration \\
\hline $200 \mathrm{ml}$ & Methanol \\
$10 \mathrm{mM}$ & $\mathrm{NaHCO}_{3}$ \\
$3 \mathrm{mM}$ & $\mathrm{Na}_{2} \mathrm{CO}_{3}$ \\
$0.01 \%$ & $\mathrm{SDS}$
\end{tabular}

TBST

$\begin{array}{ll}20 \mathrm{mM} & \text { Tris } \\ 0.15 \mathrm{M} & \mathrm{NaCl} \\ 0.05 \% & \text { Tween } 20\end{array}$

\begin{tabular}{lll}
\hline Electrophysiology & & \\
\hline Bath solution & & \\
& $150 \mathrm{mM}$ & $\mathrm{KCl}$ \\
$5 \mathrm{mM}$ & $\mathrm{MgCl}_{2}$ \\
$10 \mu \mathrm{M}$ & $\mathrm{LaCl}_{3}$ \\
$10 \mathrm{mM}$ & $\mathrm{HEPES}$ \\
& $\mathrm{pH} 7.4$ by $\mathrm{KOH}$ &
\end{tabular}

Pipette solution

$\begin{array}{ll}150 \mathrm{mM} & \mathrm{KCl} \\ 5 \mathrm{mM} & \mathrm{MgCl}_{2} \\ 10 \mu \mathrm{M} & \mathrm{LaCl}_{3} \\ 10 \mathrm{mM} & \mathrm{HEPES} \\ 200 \mu \mathrm{M} & \mathrm{CaCl}_{2} \\ \text { pH } 7.4 \text { by } \mathrm{KOH} & \end{array}$




\subsection{Antibodies}

Table 2: List of antibodies

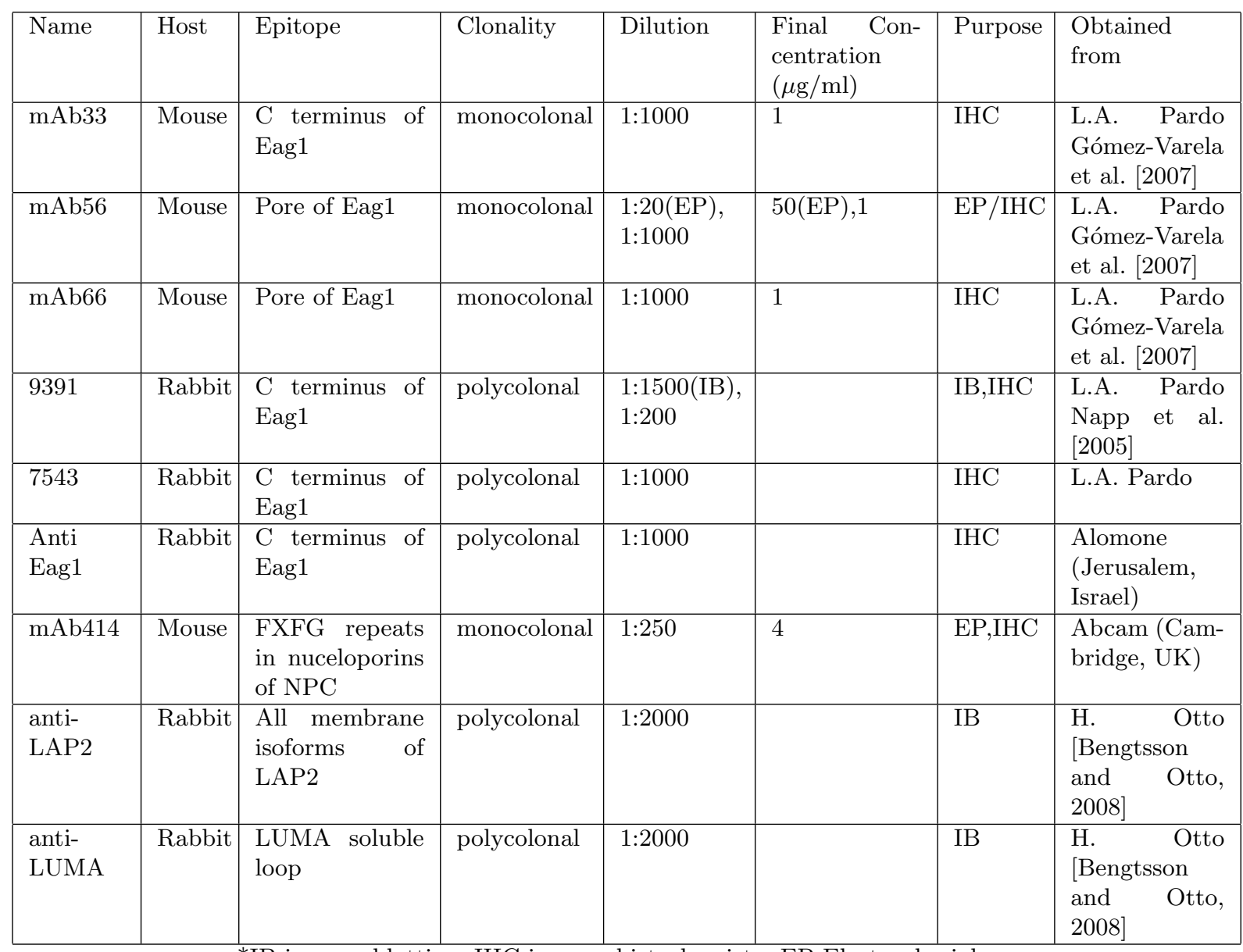

*IB-immnuoblotting, IHC-immunohistochemistry,EP-Electrophysiology 


\subsection{DNA constructs}

pCDNA3.1Eag1-Venus construct was generated A. Sánchez. Venus was inserted in frame to the end of the coding sequence of Eag1. The stop codon of Eag1 was replaced by three alanine residues as a linker. This tagged-Eag1 has been shown to preserve the electrophysiological characters of Eag1 in heterologous expression systems (doctoral thesis of J.T. Goncalves).

\subsection{Mutagenetic cloning}

pCDNA3.1-Eag1-mVenus construct was generated from pCDNA3.1Eag1-Venus by introducing a point monomeric mutation in Venus reported to minimize dimerization Nagai et al., 2002 using the QuikChange XL site-directed mutagenesis kit (Stratagene) according to the manufactures' instructions. The full coding region was latter on sequenced to assure that no additional mutation was introduced.

The principle of this method is to use two complementary primers, which contain the desired mutation(s) of the parental construct, to amplify the parental construct by PCR (Polymerase Chain Reaction). The methylated parental construct is latter on digested by Dpn I endonuclease while the amplified, un-methylated DNA containing the desired mutation(s) is transformed into competent cells for further expression.

\subsubsection{Primer and PCR}


Table 3: Primers for mutagenesis

\begin{tabular}{|l|l|l|}
\hline Protein & Mutations & Primer (5'-3') \\
\hline Venus & $\begin{array}{l}\text { monomeric } \\
\text { (L221K) }\end{array}$ & GCGATCACATGGTCCTGAAGGAGTTCGTGACCGCC \\
\hline Eag1 & $\begin{array}{l}\text { NLS (KRK to } \\
\text { ARA) }\end{array}$ & GAACGCATGGCACGAGCGAATGAGGC \\
\hline Eag1 & $\begin{array}{l}\text { NES (LRIL to } \\
\text { ARIA) }\end{array}$ & CTGAGATAGCCAGGATAGCAACTTCCAG \\
\hline
\end{tabular}

Table 4: PCR reaction solution

\begin{tabular}{|l|}
\hline $5 \mu \mathrm{l}$ of $10 \times$ reaction buffer \\
\hline $10 \mathrm{ng}$ of dsDNA template \\
\hline $125 \mathrm{ng}$ of oligonucleotide primer 1 \\
\hline $125 \mathrm{ng}$ of oligonucleotide primer 2 \\
\hline $1 \mu \mathrm{l}$ of dNTP mix \\
\hline $1 \mu \mathrm{l}$ of PfuUltra HF DNA polymerase $(2.5 \mathrm{U} / \mu \mathrm{l})$ \\
\hline $\mathrm{ddH} 2 \mathrm{O}$ to a final volume of $50 \mu \mathrm{l}$ \\
\hline
\end{tabular}

Table 5: PCR reaction for QuikChange mutagenesis

\begin{tabular}{|c|c|c|c|}
\hline Segment & Cycles & Temperature $\left({ }^{\circ} \mathrm{C}\right)$ & Time \\
\hline 1 & 1 & 95 & $1 \mathrm{~min}$ \\
\hline 2 & 18 & 95 & $50 \mathrm{~s}$ \\
\cline { 3 - 4 } & & 60 & $50 \mathrm{~s}$ \\
\cline { 3 - 4 } & & 68 & $10 \mathrm{~min}$ \\
\hline 3 & 1 & 68 & $7 \mathrm{~min}$ \\
\hline
\end{tabular}




\subsubsection{Enzymatic digestion and transformation}

Following temperature cycling, reaction tubes were placed on ice for $2 \mathrm{~min}$ to cool the reaction below $37^{\circ} \mathrm{C} .1 \mu \mathrm{l}$ of the Dpn I restriction enzyme $(10 \mathrm{U} / \mu \mathrm{l})$ was directly to each amplification reaction for digestion of DNA templates. Pipetting the solution up and down several times gently and thoroughly mixed each reaction mixture. Reaction mixtures were then spined down in a microcentrifuge for $1 \mathrm{~min}$ and each reaction was immediately incubated at $37^{\circ} \mathrm{C}$ for 1 hour for digestion of the parental DNA.

For transformation, the XL1-blue ultra-competent cells were gently thawed on ice. For each reaction to be transformed, $45 \mu \mathrm{l}$ of the super-competent cells were added to an eppendorf tube. Then $2 \mu \mathrm{l}$ of the $\beta$-mercaptoethanol provided with the kit were mixed to $45 \mu \mathrm{l}$ of cells. The contents of the tube were then swirled gently and incubated on ice for $10 \mathrm{~min} .2 \mu \mathrm{l}$ of the Dpn I-treated DNA were transferred from each reaction to separate aliquots of the super-competent cells. The transformation reactions were swirled gently and incubated on ice for $30 \mathrm{~min}$. Then they were heated for 45 seconds at $42^{\circ} \mathrm{C}$ and placed on ice for 2 min. $0.5 \mathrm{ml}$ of LB preheated to $42^{\circ} \mathrm{C}$ was incubated with the transformation reactions at $37^{\circ} \mathrm{C}$ for 1 hour with shaking around $250 \mathrm{rpm}$. The appropriate volume of each transformation reaction was plated on agar plates containing the 1 $\mathrm{mg} / \mathrm{ml}$ of ampicillin to grow overnight.

\subsubsection{Mini- and Midipreparation of DNA}

The colonies were incubated overnight in LB medium with $1 \mathrm{mg} / \mathrm{ml}$ of ampicillin. After miniprep by NucleoSpin Plasmid (Macherey-Nagel) and the sequence was confirmed by sequencing. Large quantity of DNA was prepared using PureLink HiPure Filter kit (Invitrogen). 


\section{Isolation of plasmids of small quantity}

1-5 $\mathrm{ml}$ of overnight saturated $E$. coli $\mathrm{LB}$ culture were centrifuged at $11,000 \times \mathrm{g}$ for $30 \mathrm{~s}$ and the pellets were resuspended in $250 \mu \mathrm{l}$ of buffer A1, mixed gently with $250 \mu \mathrm{l}$ of buffer A2 containing sodium dodecyl sulfa (SDS)/alkaline to lysis the cell at R.T. for around $5 \mathrm{~min}$. Then $300 \mu \mathrm{l}$ of buffer A3 was added to neutralize the lysates and precipitate proteins by potassium dodecyl sulfa. The lysates were centrifuged for $10 \mathrm{~min}$ at $11,000 \times \mathrm{g}$ and the supernatant were loaded to a column containing silica membrane where the plasmid bound. The flow-through was discarded after 1 min of centrifugation at $11,000 \times \mathrm{g}$ and the membranes were washed by $600 \mu \mathrm{l}$ of buffer A4 at 11,000×g, 1 min and dried at $11,000 \times \mathrm{g}, 2 \mathrm{~min}$. Finally the plasmid was eluded in low-ion, slightly alkaline solution by centrifugation for $1 \mathrm{~min}$ at $11,000 \times \mathrm{g}$.

\section{Isolation of plasmids of large quantity}

Bacterial were harvested by centrifuging the $15-25 \mathrm{ml}$ overnight LB-culture at 4,000× $\mathrm{g}$ for 10 min and resuspended in $4 \mathrm{ml} \mathrm{R3}$ with RNase A, mixed with $4 \mathrm{ml}$ of lysis buffer R7 and neutralized with $4 \mathrm{ml}$ precipitation buffer N3. The lysates were centrifuged at $12000 \times \mathrm{g}$ for $10 \mathrm{~min}$ at R.T to remove the precipitated proteins and debris. The supernatant were then loaded on columns (equilibrated with buffer EQ). The columns were washed twice by buffer W8 and the plasmid DNA was eluded by $5 \mathrm{ml}$ of buffer E4, precipitated by $3.5 \mathrm{ml}$ of isopropanol and pelleted by centrifugation at $15,000 \times \mathrm{g}$ for $30 \mathrm{~min}$ at $4^{\circ} \mathrm{C}$. The DNA was then resuspended in $3 \mathrm{ml}$ of $70 \%$ ethanol, centrifuged at $15,000 \times$ g for $5 \mathrm{~min}$ at $4^{\circ} \mathrm{C}$, air-dried in a sterile hood and resuspened in sterile $\mathrm{ddH}_{2} \mathrm{O}$. 


\subsection{Cell culture}

CHO cells were cultured in F12 Nutrient Mix (Gibco) containing $10 \%$ fetal calf serum at $37^{\circ} \mathrm{C}$ in a humidified atmosphere with 5\% $\mathrm{CO}_{2}$. HEK293 cells (DSMZ) stably expressing Eag1 (clone a, selected for high surface expression of Eag1, referred as HEK-Eag1 from below) were maintained in the same condition except using DMEM:F12+GlutaMax ${ }^{\mathrm{TM}}$ medium (Gibco) with Zeocin (Calya, $3 \mu \mathrm{g} / \mathrm{mL}$ ). Ts20 cells Kulka et al. 1988] were cultured in Eagle's minimal essential medium- $\alpha$ with nucleosides and deoxyribonucleosides (Gibco) plus $10 \%$ fetal calf serum at $30^{\circ} \mathrm{C}$ in a humidified atmosphere with $5 \% \mathrm{CO}_{2}$. The NES inhibitor leptomycin B (Sigma) was stocked at $5.5 \mathrm{ng} / \mu \mathrm{l}$ in $70 \%$ methanol at $-20^{\circ} \mathrm{C}$ and was used at 1:1000 dilution for 1 to $12 \mathrm{~h}$ to $\mathrm{CHO}$ cells.

\subsection{Transfection}

The cells were plated on glass coverslips and allowed to grow until they reached $70-90 \%$ confluency. Then they were transfected using Lipofectmine ${ }^{\mathrm{TM}} 2000$ (Invitrogen). OPTI-MEM I (Invitrogen) reduced serum medium without serum was mixed with DNA or Lipofectamine separately at R.T. for $5 \mathrm{~min}$. Then the two were mixed together and incubated at R.T. for $20 \mathrm{~min}$. The old medium from cells was removed before adding the transfection mixture. The cells were incubated at $37^{\circ} \mathrm{C}$ in incubator for $4 \mathrm{~h}$ before the transfection mixture was replaced by normal medium. An aliquot of Lipofectamine mixture for transfection of one coverslip in a 24-well plate contained $200 \mu \mathrm{l}$ of OPTI, $0.5 \mu \mathrm{g}$ of DNA and $1 \mu \mathrm{l}$ of Lipofectamine for CHO cells and $250 \mu \mathrm{l}$ of OPTI, $2 \mu \mathrm{g}$ of DNA and $4 \mu \mathrm{l}$ of Lipofectamine for Ts20 cells. Immunofluorescence staining and photobleaching experiment were carried out within 16-30 h after transfection. 


\subsection{Immunofluorescence Microscopy}

\subsubsection{Double staining of NPC and Eag1}

The method was adapted from [Maeshima et al., 2006] with modifications. The cells were washed with TBS and fixed with $2 \%$ Formalin solution (Sigma) for 15 min at R.T.. After 3 times washing with TBS, the remaining cross-linking reagent was quenched with $50 \mathrm{mM}$ glycine for $5 \mathrm{~min}$ in HMK

buffer. (From here on, the coverslips were washed five times by HMK between each incubation step.) The cells were then rinsed with HMK and permeabilized with HMK containing 0.5\% Triton X-100 (Sigma) for $5 \mathrm{~min}$. The unspecific epitopes were further blocked by $10 \%$ normal goat serum (NGS) (Gibco) in HMK for 30 min. The cells were then incubated with rabbit anti-Eag1 antibodies (Alomone) in HMK buffer supplemented with 1\% NGS for $1 \mathrm{~h}$ and incubated with anti-rabbit Alexa Fluor 488 (Invitrogen, 1:1000) for $1 \mathrm{~h}$. After a second blocking by 10\% NGS in HMK for 30 min, the cells were incubated with mouse anti-NPC for $1 \mathrm{~h}$ and incubated with anti-mouse Alexa Fluor 680 (1:1000). The coverslips were mounted using Prolong Gold Antifade reagent containing DAPI (Invitrogen) to counterstain DNA.

\subsubsection{Triton X-100 extraction}

Triton X-100 extraction experiments were performed as described in Hofemeister and O'Hare, 2005 with modifications. Briefly, CHO cells transfected with Eag1-mVenus were incubated on ice for 5 min with or without $3 \%$ Triton X-100 in extraction buffer to remove the lipid structures inside the cells before fixation. Then those cells were further fixed by $4 \%$ paraformaldehyde at R.T. for 15 min. The cells were then washed three times with TBS, incubated with $50 \mathrm{mM} \mathrm{NH}_{4} \mathrm{Cl}$ for 10 min 
to quench the remanent cross-linking reagents and mounted using Prolong Gold Antifade reagent containing DAPI (Invitrogen) to counterstain DNA.

\subsubsection{Digitonin permeabilization}

Digitonin permeabilization experiments were performed as described in Soullam and Worman 1995, with modifications. CHO cells transfected with Eag1-mVenus were fixed with $4 \%$ paraformaldehyde for $10 \mathrm{~min}$ at R.T.. The cells incubated for $10 \mathrm{~min}$ in $50 \mathrm{mM} \mathrm{NH} 4 \mathrm{Cl}$ diluted in PBS. After that, the cells were incubated for $5 \mathrm{~min}$ at $4^{\circ} \mathrm{C}$ in $40 \mu \mathrm{g} / \mathrm{ml}$ digitonin, which was diluted from 20 $\mathrm{mg} / \mathrm{ml}$ DMSO stock solution, or $0.5 \%$ Triton X-100 diluted in PBS. Then the unspecific binding sites were blocked in 10\% series bovine serum albumin (BSA) in PBS for $30 \mathrm{~min}$. The cells were incubated with the desired primary antibodies (either mAb66 or mAb33) for $1 \mathrm{~h}$ at a concentration of $0.5 \mu \mathrm{g} / \mathrm{ml}$ in TBS and mouse Alexa Fluor 546 antibody (Invitrogen) at 1:1000 dilution in TBS for 30 min and mounted with Prolong Gold Antifade reagent containing DAPI to counterstain DNA. The coverslips were washed three times by TBS between each incubation step.

\subsubsection{Microscopy}

Fluorescence signals were collected with a laser scanning confocal microscope (TCS-SP2; Leica) using oil immersion objective (HCX PL Apo, $63 \times / \mathrm{NA}=1.4$ ). The images were collected at $1024 \times 1024$ pixels, using 1 airy disk pinhole and a spatial sampling frequency above $100 \mathrm{~nm} /$ pixel.

ImageJ Abramoff et al., 2004] was employed for the post-acquisition image processing. The curved peri-nuclear region was straingtened using plugin "Straighten Curved Objects" Kocsis et al. 
Table 6: List of fluorophores and respective spectral settings

$\begin{array}{llll}\text { Fluorophore } & \begin{array}{l}\text { Excitation } \\ \text { Laser }\end{array} & \begin{array}{l}\text { Excitation Wave- } \\ \text { length }(\mathrm{nm})\end{array} & \begin{array}{l}\text { Collected } \\ \text { wavelength }(\mathrm{nm})\end{array} \\ \text { mVenus/Venus } & \mathrm{Ar} & 514 & 527-608 \\ \text { ALex488 } & \mathrm{Ar} & 488 & 510-612 \\ \text { Alex546 } & \mathrm{Ar} & 561 & 572-668 \\ \text { Alexa680 } & \mathrm{HeNe} & 633 & 700-800 \\ \text { DAPI } & \mathrm{BD} & 405 & 419-500\end{array}$

1991. JACoP plugin was used for colocalization analysis Bolte and Cordelières, 2006. Overlap coefficient according to Manders (R) was calculated at following:

$$
R=\frac{\sum_{i} S 1_{i} \cdot S 2_{i}}{\sqrt{\sum_{i}\left(S 1_{i}\right)^{2} \cdot \sum_{i}\left(S 2_{i}\right)^{2}}}
$$

with $S 1_{i}$ or $S 2_{i}$ representing the intensity of pixel i in channel 1 or 2 , respectively. $\mathrm{R}$ ranges from 0 to 1 with 0 indicating a complete exclusion and 1 indicating a complete colocalization.

\subsection{Nuclear Isolation and western blot}

\subsubsection{Triton X-100 extraction experiments}

Nuclear extraction was performed by NucBuster Protein Extraction Kit (Novagen, Darmstadt, Germany) according to manufacturers' instructions. Briefly, HEK-Eag1 were harvested by trypsinization and centrifuged at $500 \times \mathrm{g}$ at $4^{\circ} \mathrm{C}$ for $5 \mathrm{~min}$ in PBS. For every $50 \mu \mathrm{l}$ of cells, pellets were resuspended in $150 \mu \mathrm{l}$ NucBuster Reagent, vortexed, incubated on ice for 5 min, vortexed again for 
$15 \mathrm{~s}$ and centrifuged at $16,000 \times \mathrm{g}$ for $5 \mathrm{~min}$ at $4^{\circ} \mathrm{C}$. Subsequently, the supernatant corresponding to the cytoplasmic fraction were removed and stored. The pellets were resuspended in $0.5 \%$ Triton $\mathrm{X}$-100 in $12 \mu \mathrm{l}$ extraction buffer. After sedimented at $15,000 \times \mathrm{g}, 4^{\circ} \mathrm{C}$ for $3 \mathrm{~min}$, the supernatant containing the outer nuclear membrane fraction was saved for further analysis. Then the pellets were washed in extraction buffer at $15,000 \times \mathrm{g}, 4^{\circ} \mathrm{C}$ for $3 \mathrm{~min}$ and resuspended in $75 \mu \mathrm{l}$ NucBuster Extraction Reagent 2 supplemented with $1 \mu \mathrm{l}$ of $100 \times$ Protease Inhibitor Cocktail supplemented by the kit, $1 \mu \mathrm{l}$ of $100 \mathrm{mM}$ DTT. The suspension was then vortexed, incubated on ice for $5 \mathrm{~min}$, vortexed and centrifuged at $16,000 \times \mathrm{g}$ for $5 \mathrm{~min}$ at $4^{\circ} \mathrm{C}$. The final supernatant was the nuclear extract.

\subsubsection{Cytochrome c activity assay}

Cytochrome c assay was performed as described in Graham, 2001b. NADPH cytochrome c reductase is present in the ER and catalyzes the reduction of cytochrome c using NADPH as substrate, which results in an increase of absorbtion at 550nm $\left(\mathrm{A}_{550}\right)$.

$50 \mu \mathrm{l}$ of $25 \mathrm{mg} / \mathrm{ml}$ cytochrome c in assay buffer, $10 \mu \mathrm{l} 10 \mathrm{mM}$ EDTA, and $10 \mu \mathrm{l}$ of $1 \mathrm{mg} / \mathrm{ml}$ rotenone (to inhibit interference from mitochondrial oxidation) in ethanol were added to $1 \mathrm{ml}$ of assay buffer, following by mixing with samples. $A_{550}$ was recorded until the baseline was steady and then $0.1 \mathrm{ml}$ of $2 \mathrm{mg} / \mathrm{ml}$ fresh NADPH in assay buffer was added to the reaction. The increase in $\mathrm{A}_{550}$ was measured over a period of 1 to $2 \mathrm{~min}$. 


\subsubsection{Nuclear protein isolation}

The nuclear protein preparation method was based on low-ionic-strength method Graham, 2001a and [Schindler, 1984] with minor modifications. Plasma membranes were broken by homogenization in hypoosmotic solution and nuclei were isolated by ultracentrifugation in sucrose cushion based on the higher density of nuclei compared to other subcellular organelles. The outer nuclear membrane was further removed by citraconic anhydride (CA) and the nuclear envelope was broken down using low-ionic strength method (which outperforms high-ionic method in purity).

All the solutions contain $1 \mathrm{mM}$ PMSF to inhibit protease activity and all procedures were carried at $4^{\circ} \mathrm{C}$. For rat whole brain, male adult Wistar rat were sacrificed according to the institutional and governmental guidelines. The rats were first decapitated under $\mathrm{CO}_{2}$ anesthesia and whole brains were taken out and minced on ice in nuclear isolation medium (NIM). Then the mince was homogenized by Dounce homogenizer with a tightly fitted pestle for 25 times. For HEK-Eag1, the cells were dissociated with trypsin-EDTA, washed with PBS, resuspended in hypoosmotic medium 5 times the pellet volume and incubated on ice for $5 \mathrm{~min}$. Then the cells were homogenized by Dounce homogenizer with a tightly fitted pestle for 25 times and the osmolality was adjusted by adding same volume of $2 \times$ concentrated NIM.

The rat or HEK nuclei were washed twice by centrifugation at $800 \times \mathrm{g}$ for $10 \mathrm{~min}$ in NIM. The pellets were then resuspended in $8 \mathrm{ml} \mathrm{NIM}$, mixed thoroughly with $16 \mathrm{ml}$ sucrose density barrier (SDB) and laid on top of $8 \mathrm{ml} \mathrm{SDB}$. The tubes were centrifuged in SW28 rotor (Beckman) at $100,000 \times \mathrm{g}$ for $1 \mathrm{~h}$. After removing any material that had floated to the meniscus with a pasteur pipette and decanting all the liquid from above the pellet, the pellets were resuspended in modification buffer to have an $\mathrm{OD}_{260}$ value of 20 . The suspension were either subjected to (for inner nuclear membrane preparation) or not to (for whole nuclei preparation) CA (0.89 M stock solution 
in ethanol) to a final concentration of $8.8 \mathrm{mM}$ of $\mathrm{CA}$. The nuclei were then centrifuged at $15000 \times \mathrm{g}$ for $3 \mathrm{~min}$, resuspended in $0.4 \mathrm{ml}$ low-ionic-strength suspension medium (LISM) and broken by using 4 to 5 gentle strokes in the Dounce homogenizer. $1.6 \mathrm{ml} \mathrm{SB} 8.5$ buffer and DNase I were then added to a final concentration of $5 \mu \mathrm{g} / \mathrm{ml}$. The mixtures were incubated for $15 \mathrm{~min}$ with gentle stirring at $22^{\circ} \mathrm{C}$, mixed with an equal volume of ice-cold $\mathrm{ddH}_{2} \mathrm{O}$ and centrifuged in SW60ti rotor (Beckman) at $38,000 \times \mathrm{g}$ for $15 \mathrm{~min}$. The pellets were resuspended in $2 \mathrm{ml} \mathrm{SB7.4} \mathrm{buffer}$ with $1 \mu \mathrm{g} / \mathrm{ml}$ DNase I, incubated for 15 min with gentle stirring at R.T., mixed with an equal volume ice-cold $\mathrm{ddH}_{2} \mathrm{O}$ and centrifuged in SW60ti rotor at 38,000×g for $15 \mathrm{~min}$. Finally the sediments were resuspended in nuclear membrane storage medium (NMSM).

Whole cell lysate was extracted by lysating the cells or brain tissue in denaturing lysis buffer for $10 \mathrm{~min}$ at R.T., centrifuged at $11,000 \times \mathrm{g} 10 \mathrm{~m}$ min and homogenized with syringes of $0.5 \mathrm{~mm}$ diameter.

\subsubsection{Protein gel electrophoresis and western blot}

The protein concentration was then determined by Bradford based detergent-compatible colorimetric assay (Bio-Rad, Hercules, U.S). This assay is based on the shift of absorbance at 595nm of coomassie. After its binding to arginine and hydrophobic amino acids, coomassie changes from its unbound, green/red state into a bound, blue state.

Briefly, samples were diluted roughly to within $2-120 \mu \mathrm{g} / \mathrm{ml}$ and mixed with $4 \mu \mathrm{l}$ of BCA reagent A plus $200 \mu \mathrm{l}$ of $\mathrm{BCA}$ reagent $\mathrm{B}$. Then the probes were incubated at $37^{\circ} \mathrm{C}$ for $30 \mathrm{~min}$ and $\mathrm{A}_{595}$ was measured in a spectrophotometer. The concentrations were calculated by calibration with a standard curve from measuring a series of BSA solutions from 10 to $200 \mu \mathrm{g} / \mathrm{ml}$. 
10 to $100 \mu \mathrm{g}$ of proteins were incubated at $70{ }^{\circ} \mathrm{C}$ with NuPAGE loading buffer (Invitrogen) for $10 \mathrm{~min}$ and loaded to $3-8 \%$ gradient NuPAGE gel with a Tris-acetate system. The protein molecular weight standard ladder used was Precision Plus Protein Prestained Standards (BioRad). The separation the protein was achieved at $150 \mathrm{~V}, 45 \mathrm{~mA}$ for about $1.5 \mathrm{~h}$. Then the proteins were transferred to nitrocellulose membrane in transfer buffer at $10 \mathrm{mV}$ raising to $50 \mathrm{mV}$ with a step of $10 \mathrm{mV}$ increase every $10 \mathrm{~min}$. Then the membrane was rinsed in $\mathrm{ddH}_{2} \mathrm{O}$ and dried overnight.

The membrane was then rehydrated in $\mathrm{ddH}_{2} \mathrm{O}$ for 10 min and incubated in western blot enhancement with Quentix (Pierce) amount reagent A for $2 \mathrm{~min}$, washed 5 times with $\mathrm{ddH}_{2} \mathrm{O}$, incubated with reagent $\mathrm{B}$ for 10 min and rinsed 5 times with $\mathrm{ddH}_{2} \mathrm{O}$. Afterwards, non-specific bindings were blocked by TBST $+0.1 \%$ casein (Roche) for $1 \mathrm{~h}$, probed with first antibodies for $2 \mathrm{~h}$ followed by horseradish peroxidase-coupled secondary antibody $(1: 10,000)$ for $1 \mathrm{~h}$, with a washing step using 7 times extensive rinsing by $\mathrm{ddH}_{2} \mathrm{O}$ Wu et al. 2002a and 5 min incubation with TBST after each antibody incubation. Afterwards, blots were developed using Millipore Immobilon system which generates light by catalyzing the reaction of Luminol and $\mathrm{H}_{2} \mathrm{O}_{2}$ with horseradish peroxidase. The light was detected in a ChemDoc luminescence detection system (Bio-Rad). The same blots were then washed and stripped by western blot stripping reagent for $15 \mathrm{~min}$ (Pierce, Rockford, US) and redeveloped using same protocol with other antibodies.

\subsection{Electrophysiological recordings}

Nuclei from HEK-Eag1 were prepared essentially as those for western blot analysis as described previously except that all the solutions contain $10 \mathrm{mM}$ EGTA. After sedimented through $2.3 \mathrm{M}$ sucrose cushions, the nuclei were resuspended directly in NIM solution for outer nuclear membrane measurement. For inner nuclear membrane measurement, nuclei were further treated with CA in 
modification buffer and washed twice in NIM solution. The nuclei were all stored at $4^{\circ} \mathrm{C}$ in NIM and measured within $36 \mathrm{~h}$ after preparation.

Single channel recordings were performed in a solution with an osmolarity within 300-330 mmol/kg at R.T.. Suspended nuclei attached to the bottom of a plastic chamber within 5 min and were then perfused by gravity extensively with bath solution to remove trace amounts of EGTA. Currents were recorded in nucleus-attached configuration similar to the standard cell-attached techniques in either inside-out (for inner nuclear membrane) or outside-out (for outer nuclear membrane) mode using an EPC9 patch-clamp amplifier (HEKA Elektronik, Lambrecht, Germany). Pulse protocol generation and data acquisition were controlled with Pulse software (HEKA Elektronik). Data were filtered at $1 \mathrm{kHz}$ and acquired at $5 \mathrm{kHz}$. Patch pipettes were fabricated from WPI.PG10165-4 glass (World precision Instruments) with resistance values in the range of 7-12 M $\Omega$. It is also of equal importance that the shape of the pipette was monitored under microscope to ensure that its shank was slim for a better chance of achieving a stable seal. Sylgard liquid was applied to the tip of the pipette and solidified (polymerized) by exposing for $5 \mathrm{~s}$ to hot air under microscope. The nuclei were held at $0 \mathrm{mV}$ and voltage steps in increment of $20 \mathrm{mV}$ were applied over the range of -60 to $+60 \mathrm{mV}$ with $60 \mathrm{~s}$ durations. Off-line analysis of data was performed using TAC (Bruxton Corp. Seattle, US.). Astemizole (Sigma) was prepared in a $10 \mathrm{mM}$ stock solution in DMSO and used at 1:5000 dilution shielded from light. Solution exchanges were completed in 5 min. W-7 (Sigma) was used at $10 \mu \mathrm{M}$ concentration diluted from $100 \mathrm{mM}$ stock solution in DMSO. For antibody blockage, the tip of pipette was loaded with normal pipette solution then backfilled with $300 \mathrm{nM}$ mAb56.

Other chemicals used in the experiments: wheat germ agglutinin (Sigma) was used at 0.1 $\mathrm{mg} / \mathrm{ml}$ in the EGTA-containing bath solution and perfused extensively to remove trace sucrose (which binds to agglutinin) left during preparation. $\mathrm{Zn}^{2+}$ was used at $100 \mu \mathrm{M}$ in EGTA-free solutions. EGTA were used at $5 \mathrm{mM}$ and total $\mathrm{Ca}^{2+}$ concentration were $0.2 \mathrm{mM}$ and $0.7 \mathrm{mM}$ in 
the bath and pipette solution (diluted from $1 \mathrm{M} \mathrm{CaCl}_{2}$ stock solution), respectively, to achieve a stable seal in an EGTA-containing solution. Cl channel blocker SITS and niflumic acid were used at $500 \mu \mathrm{M}$ and $100 \mu \mathrm{M}$ (both were diluted 1:1000 from DMSO stock solutions), respectivelly.

\subsection{Photobleaching experiments}

The fluorescent proteins in the ROI were photo-bleached by brief, high intensity light and the fluorescence from the whole cell was monitored over time until the fluorescence in the ROI stopped recovering. The recovery of the fluorescence comes largely from the exchange of bleached fluorescent proteins inside ROI with the un-bleached ones outside and therefore serves to measure diffusion of proteins and their docking sites in live cells.

\subsubsection{Experiment condition}

CHO cells plated on $40 \mathrm{~mm}$ coverslips were transfected as describe above. Immediately before FRAP experiments, cells were incubated with Hoechst 33342 at $50 \mathrm{ng} / \mathrm{ml}$ for $5 \mathrm{~min}$ at R.T. to stain the nuclei and washed twice with TBS. FRAP was performed using a 40×, HCX PL Fluotar, $1.25 \times$ NA oil immersion objective on a Leica TCS SP II Confocal Microscope with identical parameters in all experiments. The living cells were kept in live cell imaging extracellular solution at $37^{\circ} \mathrm{C}$ in Focht Live-Cell Chamber System (Bioptechs Inc, Butler, US.) during the experiment. The temperature of the whole microscope system was also maintained at $37^{\circ} \mathrm{C}$. At a spatial sampling frequency around $40 \mathrm{~nm} /$ pixel, two $2 \mu \mathrm{m}$ strips either on the peri-nuclear region or through the cytoplasm were chosen as the ROI. The cells were scanned at $1400 \mathrm{~Hz}$ with Ar 514 laser at transmission of $7 \%$ every $0.47 \mathrm{sec}$ for 5 times before bleaching as the reference images at in 12-bit, 
$512 \times 512$ pixels format and then ROI were bleached 20 times at 100\% transmission. The first 10, 15 and the last 15 postbleached images were taken every $0.47,5$ and 20 seconds respectively, so that the kinetic of the initial recovery phase was sampled closely while the photobleaching in the slower phase at the plateau was minimized.

\subsubsection{Data analysis}

The backgrounds of all images were subtracted. All slow photobleaching of the postbleach images were corrected, such that the intensity of whole images should stay the same as the intensity out side of ROI in the reference images. Then the time-lapse images were corrected for lateral drift using StackReg [Thevenaz et al., 1998], which registers one image to its previous image by shifting and rotating the coordinates of the former image to achieve a maximum overlap.

The fluorescence intensities of the ROIs were normalized to a function of time as described in Snapp et al., 2003], using the difference between pre-bleached and first post-bleached image as a unit.

$$
F(t)^{\prime}=\frac{F(t)-F_{0}}{F_{\text {pre }}-F_{0}}
$$

$F(t)$ is the fluorescence intensity of the ROI at time t. $F_{0}$ is the ROI intensity of the first postbleach image, and $F_{\text {pre }}$ is the average ROI intensity of the first 5 reference images. $F(t)^{\prime}$ is the ROI fractional fluorescence intensity at time t.

The diffusion coefficients D were calculated as Ellenberg et al., 1997, which is the most widely 
used empirical formula in the field of inner nuclear membrane proteins.

$$
F(t)^{\prime}=F(\infty) \sqrt{1-\frac{\omega^{2}}{\omega^{2}+4 \pi \cdot D \cdot t}}
$$

$\mathrm{D}$ is the one dimensional diffusion constant; $\omega$ represents the width of the strip or the square, which was $2 \mu \mathrm{m}$ in this study. $t_{0}$ was taken as the midpoint of the last bleaching. $F(\infty)$ is the asymptote value of the fractional intensity when $t$ approaches infinity. All the fitting process was processed by Igor Pro 6.0.2 (WaveMetrics, Inc. Lake Oswego, OR).

Based on the fitting curves, the Mobile fractions $\left(M_{f}\right)$ were calculated as described in Snapp et al. 2003

$$
M_{f}=100 \times \frac{F_{p r e}-F_{0}}{F_{\infty}-F_{0}}
$$




\section{Results}

\subsection{Eag1 colocalizes with known inner nuclear membrane proteins}

Previous data suggested a localization of Eag1 to the nuclear envelope. To test this observation biochemically, subcellular fractionation of both rat brain and HEK-Eag1 cells were performed. After ultracentrifugation through sucrose cushions, nuclear pellets from the rat brains were treated with citraconic anhydride $(\mathrm{CA})$ that specifically removes the outer nuclear membrane Schindler et al. 1985.

Using PAGE the proteins from the whole cell lysates, nuclei and nuclei devoid of outer nuclear membrane were separated. The proteins were then probed for Eag1 and two established inner nuclear membrane proteins (LAP2 and LUMA) by sequentially blotting using specific antibodies.

Eag1, LAP2 and LUMA were all present predominantly in the nuclear fraction in comparison to the total brain homogenate, as shown by an increase of the band's intensity at a position compatible to the expected molecular mass of the respective protein. Removal of the outer nuclear membrane by CA resulted in a concurrent enrichment of all of the three proteins (Fig 5 b). This result suggests that Eag1 is present in the inner nuclear membrane under physiological conditions.

In HEK-Eag1 cells, a substantial amount of Eag1 was detected in the nuclear membrane fraction, which could be further enriched together with LAP2 and LUMA by CA in the inner nuclear membrane enriched fractions (Fig 5 a).

It should be noted that more Eag1 protein was found in the total cell extract compared to endogenous expression situation in the rat brain. This is a common phenomenon called 'back up' 
in overexpression systems that has been observed for many other inner nuclear membrane proteins, such as LBR Ellenberg et al., 1997, Soullam and Worman, 1993], MAN1 [Lin et al., 2000], Nurim Hofemeister and O'Hare, 2005, Rolls et al., 1999], LUMA Bengtsson and Otto, 2008 and emerin Ostlund et al., 1999]. It takes place when the overload of inner nuclear membrane proteins saturate the inner nuclear membrane retention sites, forcing the proteins to accumulate in the ER. This was also shown by immunofluorescence studies of Eag1 (Fig 6 lower left).

These data, from both heterologous and native systems, together indicate that Eag1 is localized in the inner nuclear membrane.

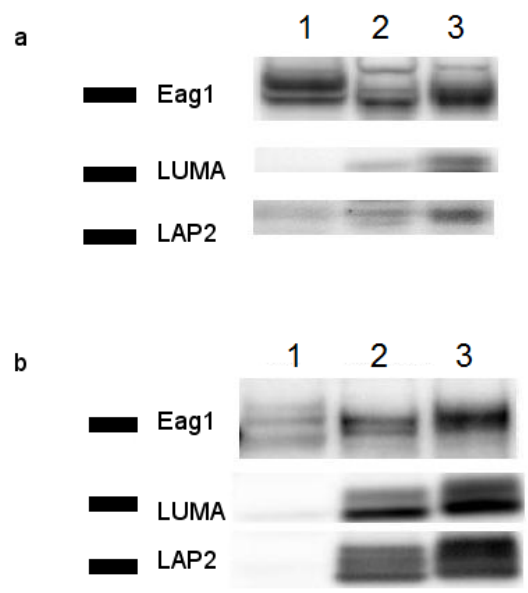

Figure 5: Eag1 protein is co-purified in the inner nuclear membrane fraction with other inner nuclear membrane proteins. Nuclear membrane fractions either from HEK-Eag1 (a) or rat brain homogenate (b) were sedimented by ultracentrifugation in sucrose gradient. Outer nuclear membrane was further removed by CA treatment. Protein from whole cell extract(lane 1), nuclear fraction (lane 2) and nuclei without outer nuclear membrane (lane 3) was separated by PAGE, transferred to nitrocellulose membrane and probed with anti-Eag1, anti-LUMA and anti-LAP2 antibodies in western blot analysis. Eag1 can be detected in both conditions in the inner nuclear membrane fractions. Positions of protein molecular weight markers indicated on left from top to bottom are 100, 37 and $37 \mathrm{kDa}$. 


\subsection{Neither side of the peri-nuclear Eag1 is accessible from the cytoplasm}

The outer nuclear membrane is continuous with the rER, where integral membrane proteins are synthesized. Those proteins could, in principle, diffuse to the outer nuclear membrane Soullam and Worman, 1993 and result in a peri-nuclear distribution pattern that is similar to, yet should not be mistaken as an inner nuclear membrane distribution.

An established way to distinguish between inner and outer nuclear membrane distribution is differential permeabilization studies of cells by digitonin Bengtsson and Otto, 2008, Lin et al. 2000, Ostlund et al., 1999, Wu et al., 2002b].

ER and nuclear envelope have a lower cholesterol content compared to the plasma membrane van Meer et al. 2008]. Since digitonin preferentially permeabilizes the cholesterol-rich membrane, ER and nuclear envelope remain largely intact upon digitonin treatment while the plasma membrane becomes porous. In those selectively-permeabilized cells, antibodies can only reach the cytoplasm and access the cytoplasmic side of ER/outer nuclear membrane proteins, but not the luminal domains of ER/outer nuclear membrane proteins or the inner nuclear membrane proteins shielded by nuclear envelope Adam et al. 1990.

In the case of Eag1, because the ER/peri-nuclear lumen is equivalent topologically to the extracellular space, the pore of ER/outer nuclear membrane Eag1 is expected to face the unreachable lumen, and the C terminus of Eag1 should otherwise face the exposed cytoplasm Deutsch, 2003. The inner nuclear membrane Eag1, regardless of its orientation, cannot be accessed as long as the outer nuclear membrane is intact. If Eag1 is indeed distributed at the inner nuclear membrane, in digitonin-permeabilized cells one would expect not to see a peri-nuclear rim by immunofluorescence. 
CHO cells were transfected transiently with Eag1-mVenus to monitor the distribution of Eag1 based on mVenus fluorescence. These cells were permeabilized either thoroughly with Triton X100 or selectively with digitonin. Then the cells were probed with antibodies against either the extracellular pore region (mAb66) or intracellular C terminus (mAb33).

In Triton-X-100-permeabilized cells, signals from the mVenus channel overlapped perfectly with the immunofluorescent staining (Fig 6 right panel), confirming the specificity and effectivity of these two antibodies. As shown, both the cytoplasmic and peri-nuclear pool of Eag1 can be equally stained by these two antibodies.

In those cells permeabilized by digitonin, due to the reasons explained above, most of intracellular Eag1 signal was abolished in mAb66 staining (Fig 6 lane 1 and 2 of left panel), suggesting the preservation of the integrity of ER/NE upon digitonin treatment. As mentioned, most of Eag1 resides in intracellular pool and hence has the extracellular poor region facing the ER/NE lumen unaccessible by antibodies in selective-permeabilized conditions.

Most importantly, mAb33 stained the intracellular Eag1 with the exception of that localized at the peri-nuclear rim (Fig 6 lane 3 and 4 of left panel). From the mVenus signal, there were two easily recognized pools in the picture, ER and peri-nuclear, of the intensities at similar level. However, this was no longer the case for the digitonin-permeabilized cells where the ER pool of Eag1 became the only dominating source of signal in the whole picture. This indicates that the peri-nuclear Eag1 is localized in a subcellular compartment different from ER/outer nuclear membrane, as the it could not be detected by cytoplasmic antibodies against either side of the channel, an observation strongly suggesting an inner nuclear membrane distribution. 


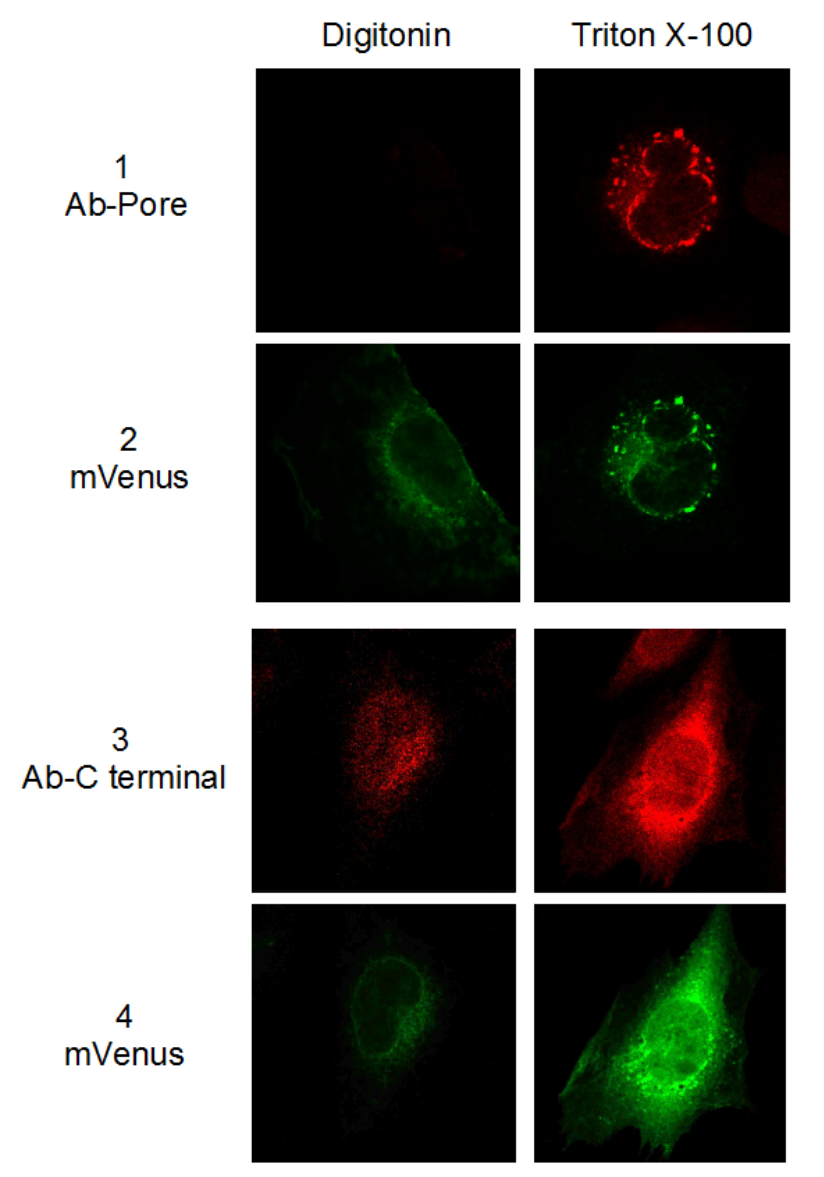

Figure 6: Peri-nuclear Eag1 is not accessible from cytoplasm. Transiently transfected CHO cells were permeabilized at $4^{\circ} \mathrm{C}$ by either digitonin (left panel) or Triton X-100 (right panel), fixed and labeled with anti-Eag1 antibody targeting either the pore (1) or the C-terminus (3). The corresponding fluorescence from mVenus is shown in 2 and 4 . The absence of peri-nuclear rim in digitonin-permeabilized cells indicates that the peri-nuclear pool of Eag1 is not accessible from the cytoplasm, thereby representing an inner nuclear membrane localization. 


\subsection{Peri-nuclear Eag1 distribution does not correlate with expression levels}

A serious concern is if that the peri-nuclear signal observed could just be an overexpression artifact. This of course would not apply to native tissues, where inner nuclear membrane localization had been shown by IEM (M. Rubin, personal communication) and subcellular fraction.

If there is an overload of Eag1 in the ER due to the overexpression, it could diffuse back to the outer nuclear membrane or even the inner nuclear membrane, resulting in the peri-nuclear distribution pattern. If this were the case, the density of peri-nuclear Eag1 would be either proportional to or less than that of the ER pool. On the other hand, if inner nuclear membrane-localization of Eag1 is a specifically regulated process, it will not show any such correlation and the density of peri-nuclear Eag1 will be higher than the ER pool.

To address this, the peri-nuclear fluorescence intensity was plotted against the cytoplasmic intensity from 89 randomly chosen Ts20 cells transiently expressing Eag1Venus. Three concentric rings were drawn around nuclear envelope based on the DNA staining. One was immediately inside the nuclear envelope, the second outside the nuclear envelope and the third outside the second one. The fluorescence intensity between the inner and middle rings was used as the peri-nuclear intensity and the one between the middle and outer was the cytoplasmic intensity (Fig 7 a).

It was revealed that the peri-nuclear fluorescence intensity of Eag1 did not dependent on cytoplasmic intensity. On the contrary, many cells have much higher peri-nuclear fluorescence than the immediate proximal cytoplasmic region, as they skewed to the peri-nuclear axis (Fig $7 \mathrm{~b})$. Those cells were classified blindly as cells with a peri-nuclear distribution of Eag1. Cells that were recognized as not having a peri-nuclear distribution were dispersed around the diagonal, indicating a random distribution. 
This result reinforces, together with EM and subcellular fraction findings, the concept that Eag1 is specifically enriched in the inner nuclear membrane by processes independent of the expression level in the ER.
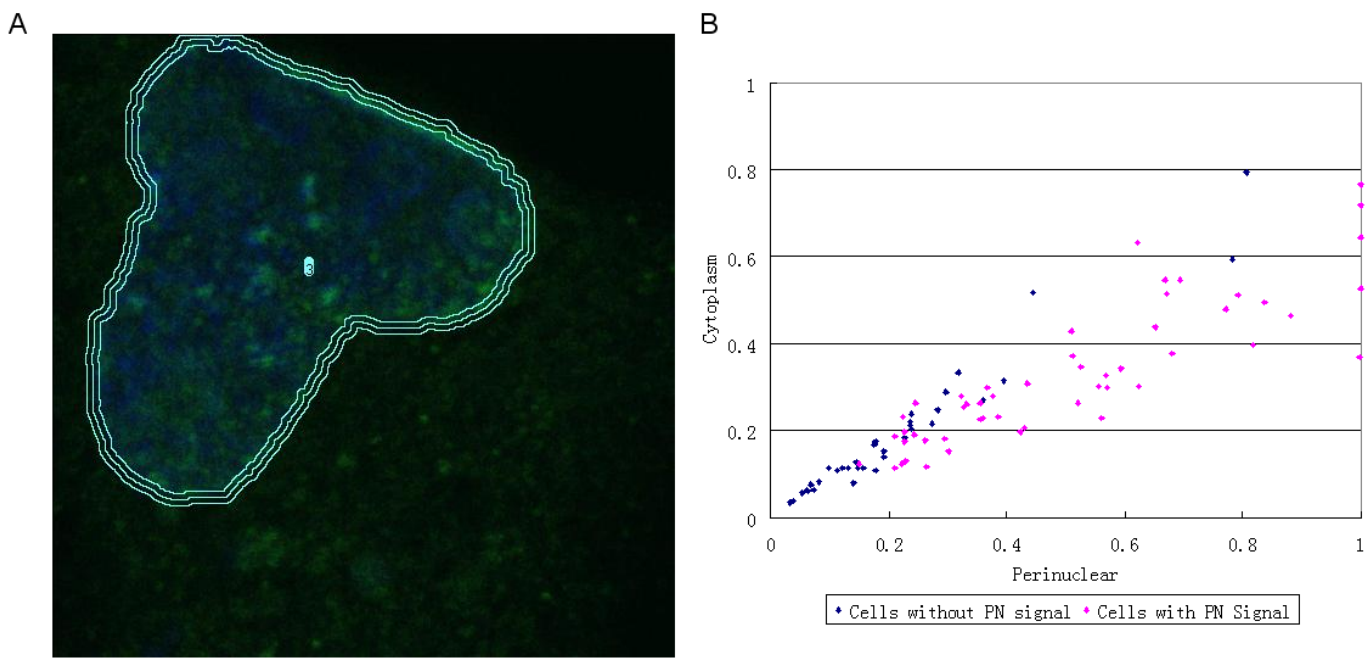

Figure 7: The peri-nuclear intensity of Eag1-Venus fluorescence shows no correlation with the cytoplasmic intensity. a, Scheme representing the peri-nuclear region (inner ring) and the cytoplasmic region (outer ring) chosen for plotting. b, Plot of peri-nuclear fluorescent intensity against cytoplasmic fluorescence intensity. Two populations have been grouped in an independent blind classification: blue (cells without peri-nuclear Eag1) and red (cells with peri-nuclear Eag1). The red population skews towards the peri-nuclear axis while the blue one displays good linearity, suggesting a specific mechanism underlying the peri-nuclear localization of Eag1. 


\subsection{Peri-nuclear Eag1 is resistant to Triton X-100 extraction}

Inner nuclear membrane proteins are characterized by resistance to non-ionic detergent extraction Ellis et al., 1998, Hofemeister and O'Hare, 2005, Rolls et al., 1999]. To confirm that peri-nuclear Eag1 also has the same characteristic, CHO cells transiently expressing Eag1-mVenus were incubated with extraction buffer containing $3 \%$ of Triton X-100 before fixation and the fluorescence was checked by confocal microscopy.

In control cells (without Triton X-100 treatment), there was a significant amount of proteins distributed all over the cells as a consequence of the 'back up' phenomenon explained before (Fig 8 a left). In those cells that had been extracted before fixation, the peri-nuclear pool of Eag1 persisted whereas the cytoplasm was clear of Eag1 (Fig 8 a right). Some punctate structures remained visible. This observation is compatible with that reported by Hofemeister and O'Hare, 2005 for

another inner nuclear membrane protein and probably represent stubborn aggregates resistance to extractions.

The resistance of peri-nuclear Eag1 to detergent extraction should also be observed at biochemical level and therefore subcellular fractionation with Triton-X 100 extraction experiments in the HEK-Eag1 cell line were performed. After detergent extraction of the nuclear fraction, a significant amount of Eag1 remained in the inner nuclear membrane fraction as marked by a reduction in activities of the ER/outer nuclear membrane marker: NADPH reductase (Fig 8 b). A considerable amount of Eag1 was also extracted, possibly representing the ER/outer nuclear membrane pool of Eag1 in this overexpression system.

Both results (imaging and biochemistry) suggest a tight retention of peri-nuclear Eag1, probably in association with detergent-resistant structures such as lamina or chromatin. 
a

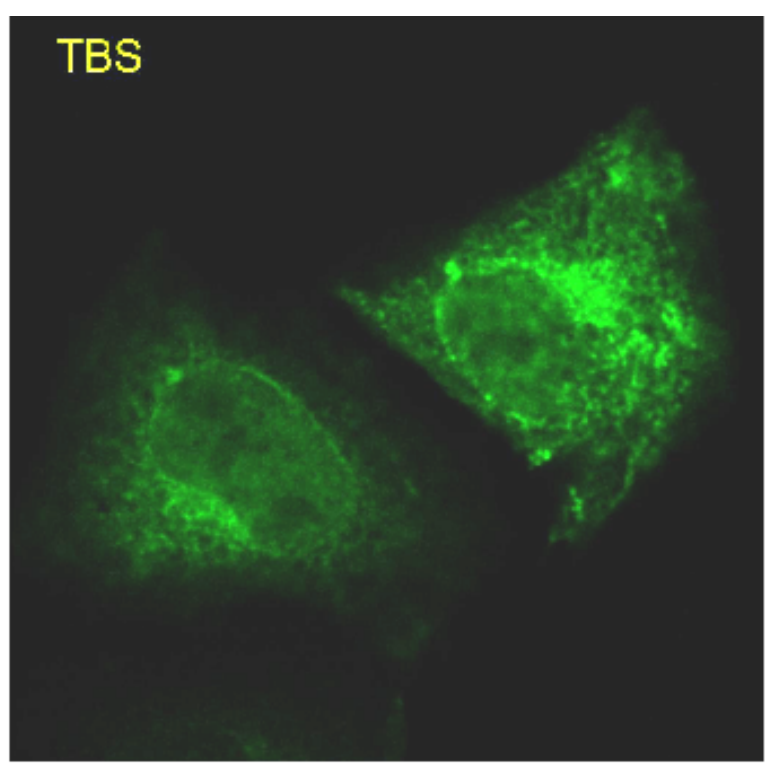

b

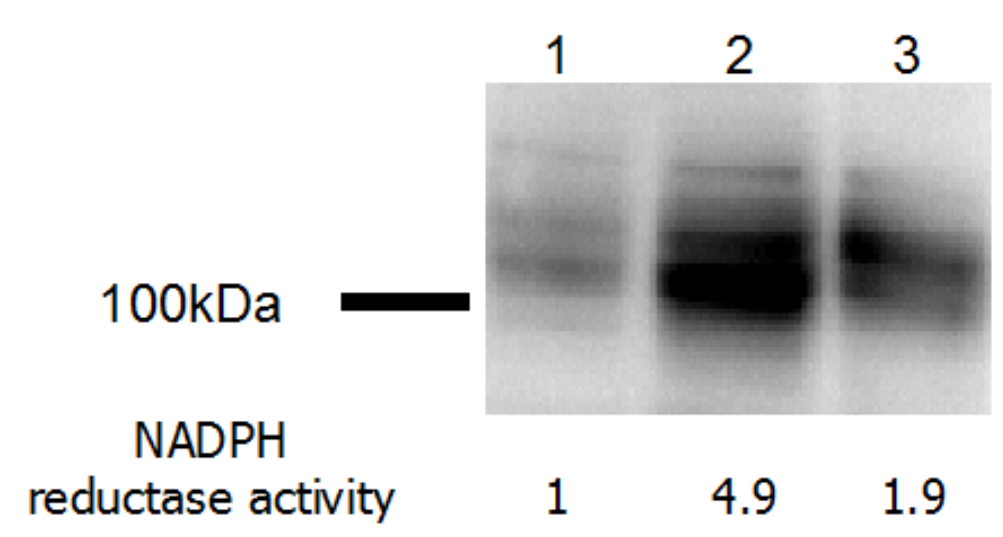

\section{$3 \%$ Triton $X-100$}

Figure 8: Peri-nuclear Eag1 is resistant to Triton X-100 extraction. a, CHO cells transfected with Eag1-mVenus were washed, incubated on ice without (left) or with (right) $3 \%$ Triton X-100 for 5 min, fixed with $4 \%$ paraformaldehyde and analyzed by laser scanning confocal microscopy. The cytoplasmic signal was largely removed by Triton X-100, while the peri-nuclear signal could still be detected. b, Western Blot analysis using anti-Eag1 antibody shows cytoplasmic protein (lane 1) and nuclear protein (lane 2) prepared by NucBuster (Novagen) from HEK-Eag1 cell line. One additional extraction by $0.5 \%$ Triton $\mathrm{X}-100$ was introduced to produce the Triton-resistant fraction (lane 3). Position of protein molecular weight marker is indicated on the left in $\mathrm{kDa}$. Enrichment in nuclear protein was indicated by NADPH reductase activity as seen in lane 2 compared to the cytoplasmic fraction. Removal of outer nuclear membrane protein in lane 3 was confirmed by a reduction of NADPH reductase activity while significant amounts of Eag1 protein still remained in this fraction. 


\subsection{Lateral diffusion is compromised in perinuclear Eag1}

Outer nuclear membrane/ER and inner nuclear membrane proteins have completely different environment. Inner nuclear membrane proteins are subjected to various interactions at the lamina and are more restrained in lateral diffusion compared to their ER counterparts Ellenberg et al., 1997, Ostlund et al., 1999, Wu et al., 2002b].

To compare the mobility of Eag1 in nuclear envelope and ER, 1-D FRAP experiments were carried out in CHO cells expressing Eag1-mVenus. Peri-nuclear regions where Eag1-mVenus signals were both thin and long and devoid of mass cytoplasmic signals around were chosen as ROI of nuclear envelope. Cytoplasmic regions where Eag1-mVenus signals were both bright and homogenous and devoid of aggregates were chosen as the ROI of ER. Two strips of $2 \mu \mathrm{m}$ width were then bleached at nuclear envelope and ER and the recoveries of fluorescent intensities were monitored for 5 min (Fig 9 a). The ER region regained almost all of the fluorescence within 3 min whereas the nuclear envelope region recovered only slowly and partially(Fig 9 b).

Quantitatively, nuclear envelope Eag1 not only had a smaller mobile fraction $\left(\mathrm{M}_{\mathrm{f}}\right)$ than ER Eag1 $(54.34 \pm 4.34 \%, \mathrm{n}=38$ compared to $89.96 \pm 4.87 \%, \mathrm{n}=33, \mathrm{p}<0.001)$ but also a smaller diffusion coefficient (D) $\left(4.37 \pm 0.81, \mathrm{n}=38\right.$ compared to $\left.10.30 \pm 2.09, \times 10^{-3} \mu \mathrm{m}^{2} / \mathrm{s}, \mathrm{n}=33, \mathrm{p}<0.001\right)$. These parameters are consistent with those reported for other inner nuclear membrane proteins Ellenberg et al., 1997, Ostlund et al., 1999, Wu et al., 2002b and meet the criteria of an inner nuclear membrane-targeted protein.

As an indicator of the photo-damage caused to the cell, a second FRAP experiment is normally induced in the same ROI as the first FRAP to compare of the D and $\mathrm{M}_{\mathrm{f}}$. The $\mathrm{D}$ should not change too much while the $\mathrm{M}_{\mathrm{f}}$ should be close to $100 \%$ since all the immobile proteins were bleached in 
the first FRAP experiment, otherwise it indicates a change in the environment, probably caused by photo-damage. A second bleaching in the same ROI was performed in some cells. D was not significantly different while $\mathrm{M}_{\mathrm{f}}$ was around $100 \%$ (data not shown). This indicated that no damage had been induced in the ROI or cells by laser during the time of the experiments.

Again, the significant amount of immobile Eag1 and the restricted diffusion of the remaining mobile protein point to a tight interaction of Eag1 with its inner nuclear membrane environment. 

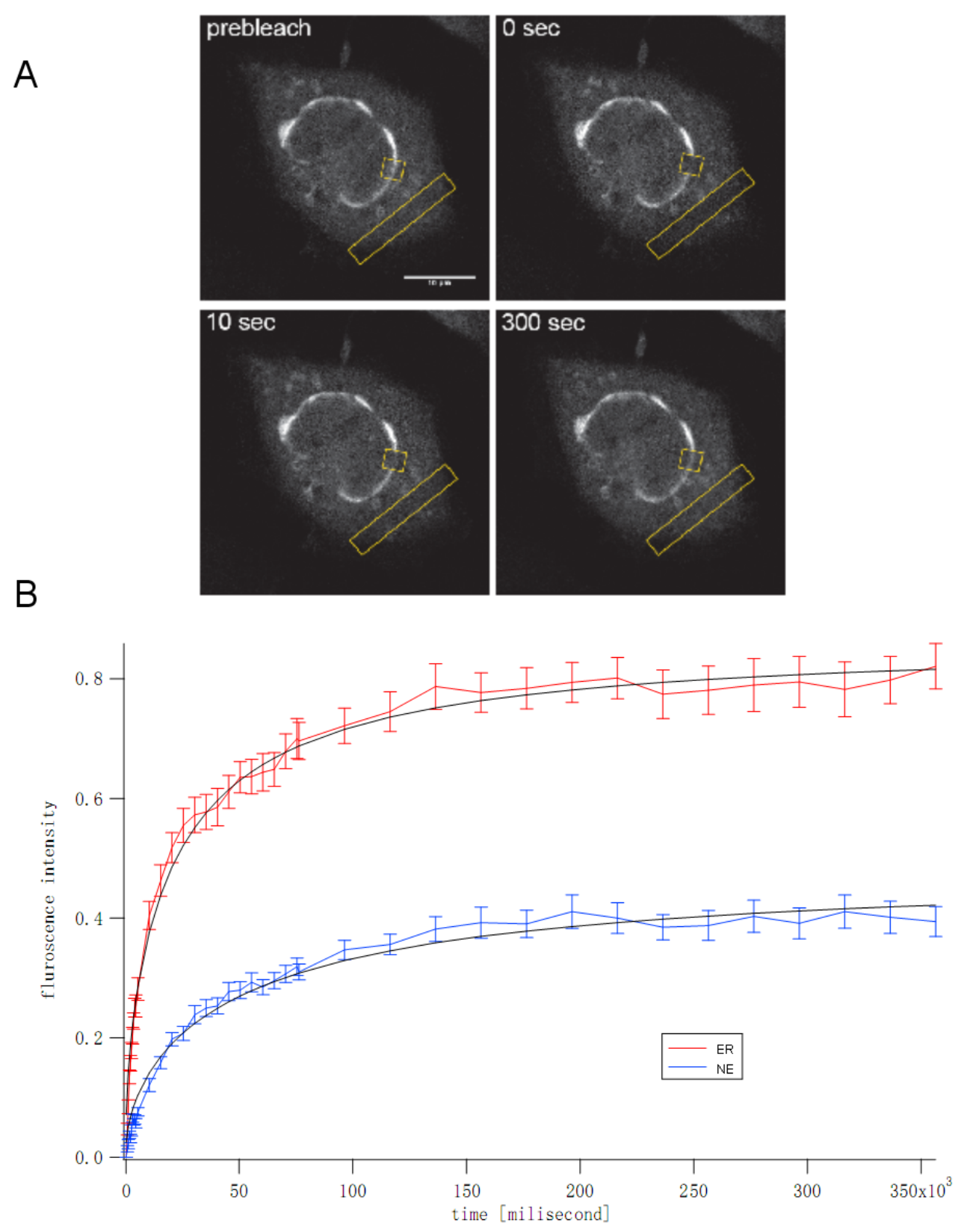

Figure 9: Quantitative FRAP analysis of lateral diffusion of Eag1 in CHO cells transiently expressing Eag1-mVenus. a, Upper panel shows the photobleaching in the peri-nuclear region and the ER membrane (bleached areas are indicated as boxes). The recovery is shown at 0,10 s and 300 s after bleaching. Bar, $10 \mu \mathrm{m}$. b, Lower panel shows the averaged and normalized fluorescent intensity during recovery from all cells. The first 10 data points were taken every 0.47 seconds, the next 15 every 5 seconds and the last 15 every 20 seconds. Fittings, as described in Material and Methods, are shown as black continuous curves. Diffusion62onstant (determined by the parameters resulted from fitting) in nuclear envelope (blue) and ER (red) membrane are $4.37 \pm 0.81(\mathrm{n}=38)$ and 10.30 $\pm 2.09(\mathrm{n}=33)\left(10^{-3} \mu \mathrm{m}^{2} / \mathrm{s}\right)$ respectively. Mobile fraction in the nuclear envelope and ER membrane are $54.34 \pm 4.34(\mathrm{n}=38)$ and $89.96 \pm 4.87(\mathrm{n}=33) \%$ respectively. Error bars indicate SEM. 


\subsection{Peri-nuclear Eag1 is not co-localized with NPC}

During these studies, it was often noticed that the inner nuclear membrane Eag1 was more of an intermittent than a continuous structure. Similar discrete nuclear envelope microdomains have already been reported for nurim [Rolls et al., 1999], emerin [Maeshima et al., 2006] and LBR Bailer et al. 1991. The spaces between these microdomains were devoid of NPC and therefore named 'NPC-free island' Maeshima et al. 2006. In addition, LBR in these regions has been shown to recruit heterochromatin Makatsori et al., 2004.

To gain further insight into this interesting pattern of distribution of Eag1, double staining of Eag1 and NPC were performed (Fig 10). A closer look revealed that Eag1 frequently resided at regions of low or no NPC staining, as indicated by Manders' colocalization coefficient (explained in Material and Methods) of $0.27 \pm 0.17(\mathrm{n}=15)$. Since the distribution of NPC on nuclear envelope is nearly ubiquitous, it is already quite difficult to observe an exclusion Eag1 from NPC. Besides, the segregation of inner nuclear membrane proteins from NPC only takes place in specific phases of cell cycle [Maeshima et al. 2006], which means even the segregation in complete in those cells, in other cells they will be found to overlap. Taking this two factors into account, the average level of segregation here indicates a practically exclusion of Eag1 from NPC in many cells.

Further more, peri-nuclear Eag1 was often found to be close to intense DAPI staining, which was likely to be heterochromatin. Similar results were observed using other antibodies against Eag1 $(7453,9391)$ in CHO cells transiently expressing Eag1, in CHO cells expressing Eag1-mVenus (data not shown) or by IEM in native expression systems (Fig. 4 a,b). Based on the separation of Eag1 and NPC, as well as the proximity of Eag1 to heterochromatin, a role for Eag1 in the recruitment of heterochromatin to the NPC-free island of the NE could be hereby proposed. 




Figure 10: Peri-nuclear Eag1 is localized to NPC-free islands. a, A picture of a CHO cell transiently expressing Eag1 and stained with anti-NPC antibodies (red) and anti-Eag1 (Alomone, green). In the peri-nuclear region marked by the boundary of DNA stained by DAPI (blue), exclusion of Eag1 from the region containing NPC can be seen. b, An enlargement of the peri-nuclear region showing the exclusion of Eag1 from NPC and proximity of Eag1 to heterochromatin. c, A straightened view of the whole peri-nuclear region. Note that Eag1 signals localize mostly between NPC signals 


\subsection{Single channel current compatible with Eag1 at the inner nuclear membrane}

The results on localization of Eag1 can not provide information to confirm if Eag1 is indeed functionally active at the nuclear envelope. Hence, single channel recording in the 'nucleus-attached' mode was performed. Nuclei were prepared by homogenization of HEK-Eag1 cells in hypoosmotic solutions and purified by density gradient centrifugation. Nuclei were patched directly for outer nuclear membrane measurement or treated with CA for inner nuclear membrane recordings (Fig 11 A).

\subsubsection{Large conductance NPC currents}

As mentioned in the introduction, the NPC needs to be in a non-conducting state so that it does not mask the smaller currents from other permeabilities. At first, recordings in a Ca-free solution using EGTA were performed since Eag1 current is readily inhibited by the binding of Ca-CaM Schönherr et al., 2000.

In this configuration, however, large openings of conductance up to $1 \mathrm{nS}$ were observed in nearly every nuclei during long lasting recording, especially when the patch was highly hyper- or depolarized or subjected to mechanical pressure (Fig 11 B).

This current was still present in $\mathrm{Cs}^{+}$-containing solutions $\left(\mathrm{Cs}^{+}\right.$blocks most of $\mathrm{K}^{+}$current but not Eag1 current) and was not affected by $\mathrm{Cl}$ channel blockers (data not shown).

The large conductance activity shows features compatible with NPC current. Two established NPC current blockers (mAb414 and wheat germ agglutinin [Bustamante et al., 1995]) reduced the 
current, and other two $\left(\mathrm{Zn}^{2+}\right.$ and $\mathrm{La}^{3+}$ Bustamante, 1993) suppressed it. The observation that NPC current remained after outer nuclear membrane removal suggests that integrity of the NPC can be preserved in the absence of most of the outer nuclear membrane. It can be explained by the fact that NPC and its associated membrane (nuclear-pore membrane) are quite independent and stable structures since they remain associated with lamina and inner nuclear membrane proteins even when both the outer and inner nuclear membranes have been extracted Cronshaw et al. 2002 .

As a result, the recording was performed in a solution containing $\mathrm{La}^{3+}$. To do this, EGTA need to be removed because the binding affinity of $\mathrm{La}^{3+}$ to EGTA is 5 times higher than that of $\mathrm{Ca}^{2+}$ Reeves and Condrescu 2003. Therefore, in the presence of EGTA, it takes a large amount of $\mathrm{La}^{3+}$ for the free $\left[\mathrm{La}^{3+}\right]$ to stay at a high $\mu \mathrm{M}$ range to inhibit NPC and there will be little free EGTA left to chelate $\mathrm{Ca}^{2+}$.

EGTA was still used throughout the purification process in an attempt to dissociate calmodulin from Eag1. Addition of W-7, a calmodulin antagonist, did not significantly increase the chance of finding an active Eag1 channel (data not shown), indicating that the calmodulin had been effectively removed during EGTA washing. For recording, EGTA was thoroughly washed out and $10 \mu \mathrm{M} \mathrm{La}{ }^{3+}$ was added to the solution. This concentration was used because it had no evident effect on plasma membrane Eag1, which is also inhibited by extracellular $\mathrm{La}^{3+}$ with an apparent $\mathrm{IC}_{50}$ of approximately $200 \mu \mathrm{M}$ (data not shown). 

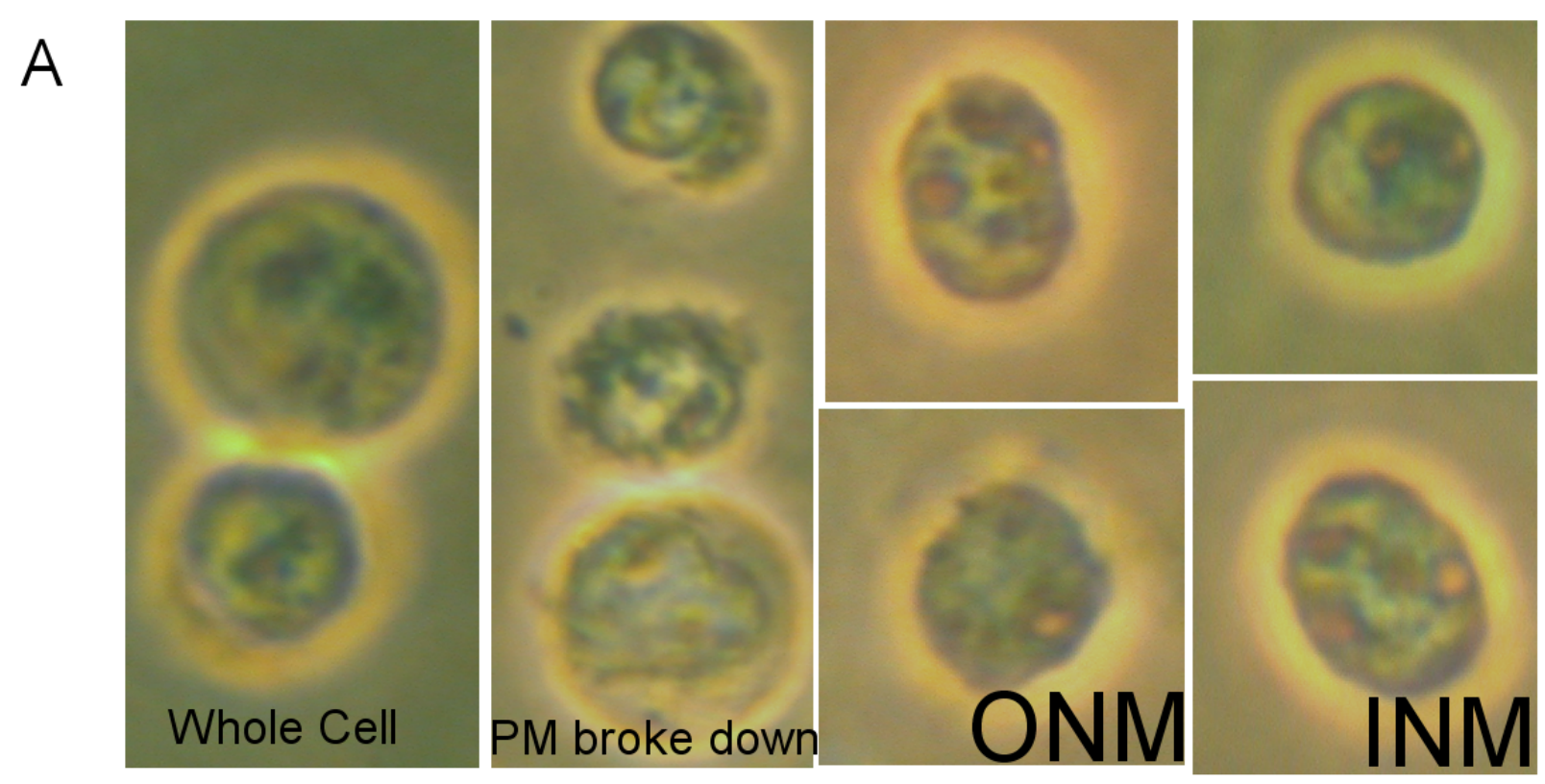

B

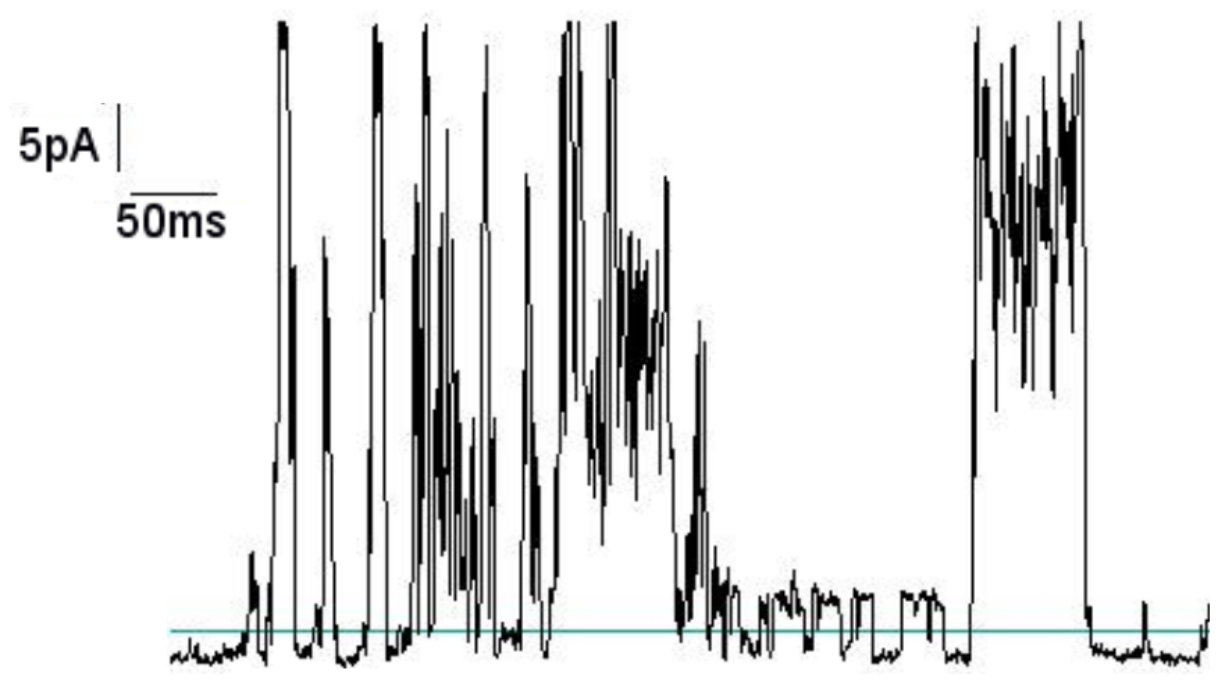

Figure 11: Nuclei for patch-clamp recordings and the large permeability from NPC. A, from left to right: HEK-Eag1 cell in isotonic solution, nuclei with debris attached and un-broken cell after homogenization, selected nuclei without debris attached for outer or inner nuclear membrane measurement. B, a sample trace at the outer nuclear membrane of HEK-Eag1 cell at $+100 \mathrm{mV}$. Note the presence of both large (NPC) and small conductance. 


\subsubsection{No Eag1-like Current observed in non-transfected cells}

Under these conditions, large conductance activity was more frequent in untreated, outer nuclear membrane preparations. 5 outer nuclear membrane recordings from HEK-Eag1 cells were without NPC current and had conductances around 4 to $14 \mathrm{pS}$.

Astemizole was used, which is a $\mathrm{H} 1$ histamine receptor inhibitor often used as blocker of Eag1 García-Ferreiro et al. 2004. It has not been reported to block other conductances than those of the EAG family, Eag1 among them, at a concentration of $2 \mu \mathrm{M}$. Only 2 out of 5 nuclei had reductions in $\mathrm{P}_{\mathrm{o}}$ by astemizole (both had conductances around $7 \mathrm{pS}$ ) while the rest were not affected. At this stage, it is not possible either to confirm or rule out the presence of Eag1 on the outer nuclear membrane in HEK-Eag1 cells by means of electrophysiological recordings.

To address the issue of specificity of the channel in a clean genetic background, the same recordings were performed on the outer and inner nuclear membrane of HEK cell line that has no endogenous Eag1 expression. 17\% of outer nuclear membrane recordings $(n=12)$ from HEK cells had conductances around 5 to $20 \mathrm{pS}$, none of which responded to astemizole. Only 1 out of 11 inner nuclear membrane recordings (NPC-current-free) from HEK cells had a conductance around $16 \mathrm{pS}$.

Altogether these observations together does not support the presence of Eag1 channel on the outer nuclear membrane of HEK-Eag1 cells or the outer/inner nuclear membrane of HEK cells. 


\subsubsection{Single channel currents compatible with Eag1 at the inner nuclear membrane of HEK-Eag1 cells - conductance and pharmacology}

At the inner nuclear membrane of HEK-Eag1 cells, 27 out of 64 CA-treated nuclei recorded still exhibited NPC current and thereby were excluded from further analysis. There was no electrical activity in 17 nuclei, while 20 nuclei showed comparatively small channel openings, compatible with Eag1 in terms of conductance $(7.8 \pm 0.5 \mathrm{pS}$ ) (Fig 12) and voltage dependence, with highest open probability at $-60 \mathrm{mV}$ and lowest at $+60 \mathrm{mV}$ in the pipette, which would represent membrane potential of opposite sign in an inside-out configuration, that is, if the extracellular side of the channel faces the pipette and the intracellular domains are located to the nucleoplasm.

To characterize the pharmacology of the channel, the nuclei were perfused with astemizole. This treatment reduced the $\mathrm{P}_{\mathrm{o}}$ at $+60 \mathrm{mV}$ (membrane potential) by $94 \pm 10 \%(\mathrm{n}=5)$, indicating a blockade of the channel by astemizole, without affecting the conductance.

Since the extracellular side of the channel appeared to be facing the pipette, mAb56 was used, which is a monoclonal antibody reported to bind to the extracellular loops of Eag1 and inhibit its current Gómez-Varela et al. 2007. To do this, layered loading of the pipette was performed by backfilling the antibody-containing solution $(45 \mu \mathrm{g} / \mathrm{ml})$ over antibody-free solution, with the aim of recording channel activity prior to the diffusion of the antibody to the pipette tip. The channel activity decreased in all patches tested $(n=6)$ within 10-20 minutes in the presence of mAb56 (Fig 13), a time course compatible with the described action of mAb56 on Eag1 whole-cell current on the plasma membrane.

Besides the activity attributed to Eag1, other conductances in the range of 20-40 pS were also detected, which were unaffected by astemizole or mAb56. 

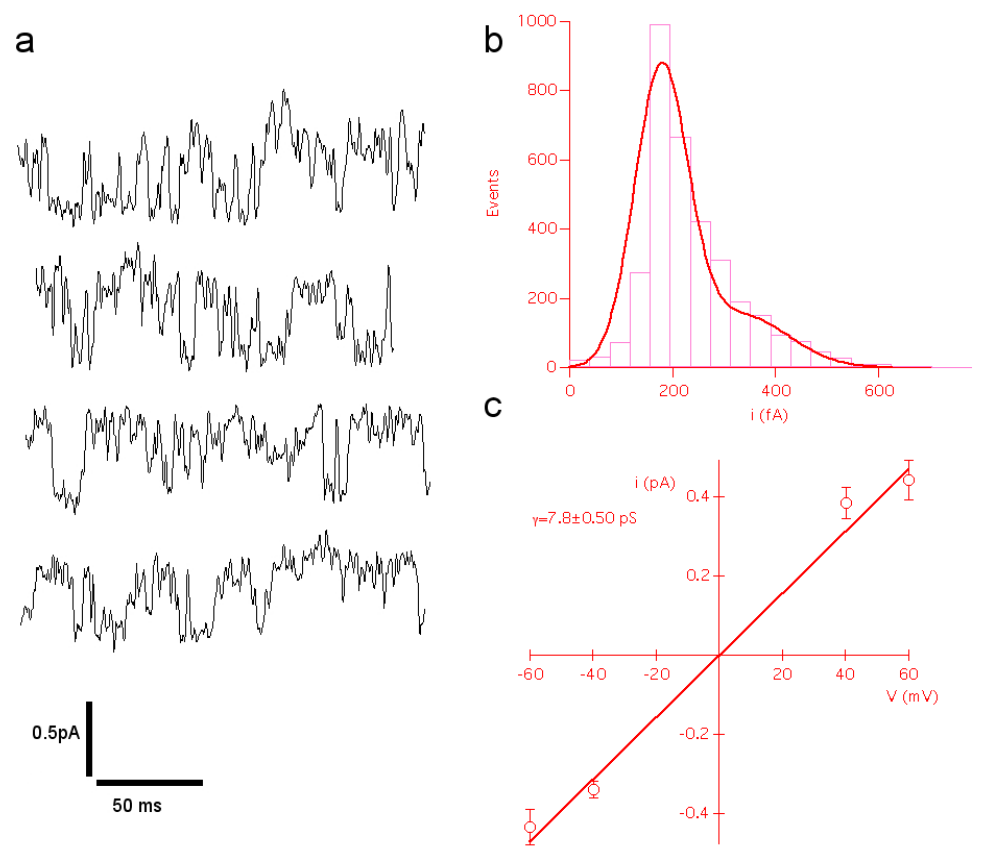

Figure 12: Single channel recording from the inner nuclear membrane of HEK-Eag1 cells. a, four sample traces from one continuous recording at the inner nuclear membrane at $+60 \mathrm{mV}$. b, Amplitude histogram of the opening events from (a) and the corresponding fitting. c, Plot of single channel current against voltage before astemizole perfusion. Error bars indicate SEM and the equation shows a linear fitting of the current $(\mathrm{pA})$ against voltage $(\mathrm{mV})$. It demonstrated that the current was compatible with Eag1 in terms of conductance.

Altogether, especially considering the selectivity of mAb56, this data strongly supports the molecular identity of the detected channel at the inner nuclear membrane as Eag1, as well as supports the expected orientation in the inner nuclear membrane, with the $\mathrm{C}$ terminus facing the nucleoplasm. 


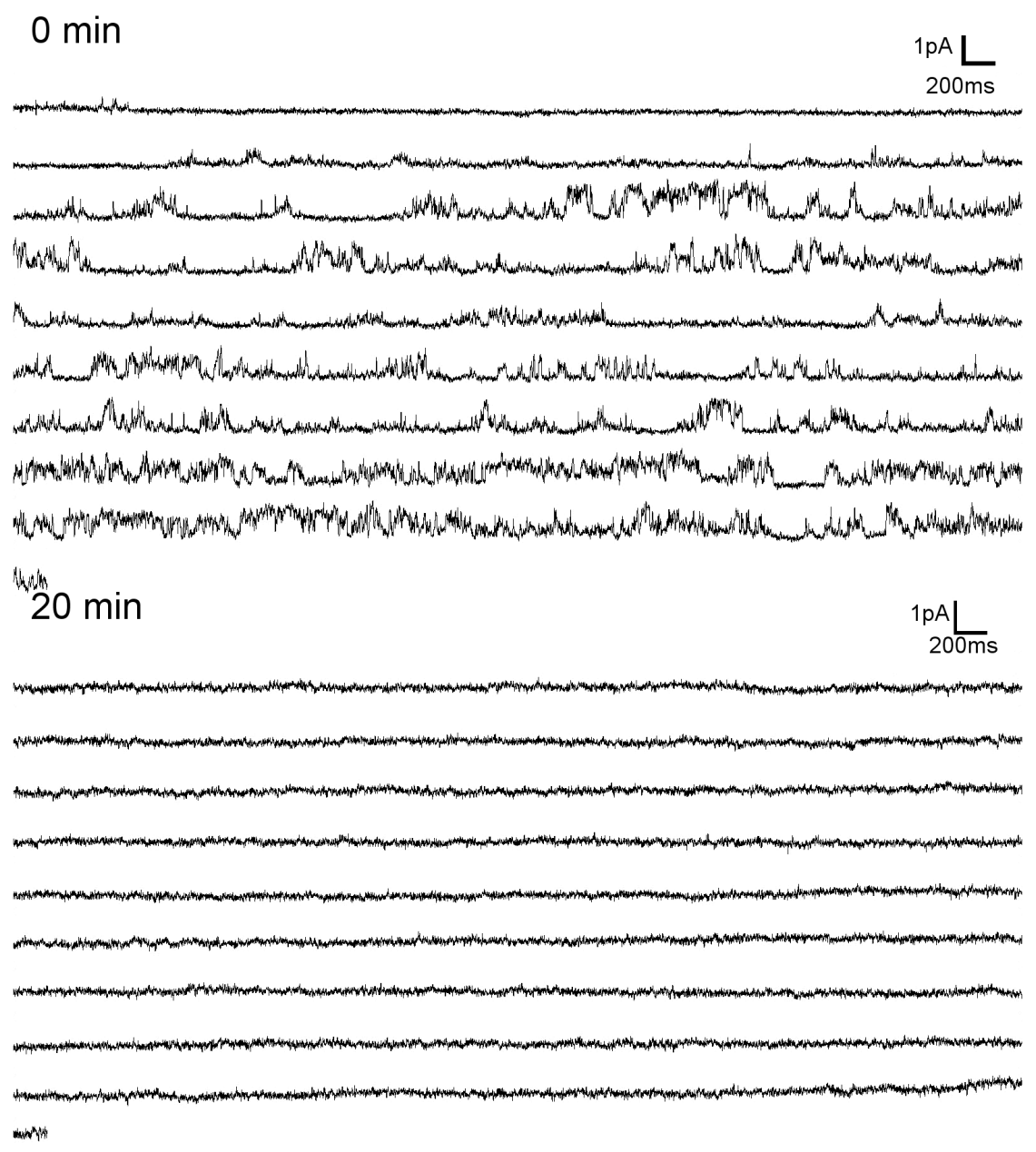

Figure 13: Single channel recording from the inner nuclear membrane of HEK-Eag1 cells with a pipette back-filled with mAb56. Upper panel was recorded at $+80 \mathrm{mV}$ and lower panel was recorded at the same voltage 20 mins later. The blockage of this current by a very specific Eag1-blocker highly suggests that the current indeed corresponds to Eag1. 


\section{Discussion}

It was reported here, for the first time, the presence of a functional voltage-gated ion channel with a defined molecular identity in the inner nuclear membrane.

This statement is based on both optical- and electronmicroscope data as well as biochemical evidence, both in native and heterologous systems. It not only fulfills all the criteria of a transmembrane protein localized to the inner nuclear membrane but it is also functional as an ion channel conducting potassium.

Evidences in favor of inner nuclear membrane localization include inaccessibility to antibodies of the channel after digitonin permeabilization, resistance to Triton X-100 extraction, limited lateral diffusion, co-segregation with established inner nuclear membrane markers, and electron microscopy.

Additionally, the electrophysiological experiments indicate an orientation of the protein with the extracellular loops of the channel facing the pipette, which favors localization at the inner nuclear membrane. The identity of the channel as Eag1 is supported not only by the fact that it is not found in nuclei of non-transfected cells, but also by its voltage dependence, single channel

conductance, and pharmacology, most importantly by the inhibition measured in the presence of mAb56, which is the most selective blocker available. 


\subsection{Inner nuclear membrane localization of Eag1 is not caused by overexpres- sion}

This distribution is not likely to be an overexpression artifact. Immunoelectron microscopy and subcellular fractionation have clearly shown that Eag1 is localized to the inner nuclear membrane in native systems. It is also unlikely that over-expressed Eag1 is forced to relocate to the inner nuclear membrane even in heterologous systems, since the expression levels in peri-nuclear regions are not correlated with cytoplasmic ones.

As the 'lateral-diffusion' model suggests, inner nuclear membrane proteins first have to arrive at the outer nuclear membrane before they diffuse and settle at the inner nuclear membrane. This model will predict that certain level of inner nuclear membrane proteins can also be found at the outer nuclear membrane, at least transiently or at low level. At this stage, it is not certain whether there is Eag1 in the outer nuclear membrane, especially in overexpression systems. For instance, Triton-X 100 extracted significant amount of Eag1. There are precedents of proteins expression both at the outer nuclear membrane and inner nuclear membrane. For example, emerin on the outer nuclear membrane is in direct contact with the cytoskeleton, thereby positioning the centrosome close to the nuclear envelope [Salpingidou et al., 2007]. Interesting, interactions of Eag1 with the cytoskeleton are well established Camacho et al., 2000].

\subsection{Diffusion coefficient (D) in FRAP analysis}

Part of the argument is based on the finding that the lateral diffusion of the peri-nuclear Eag1 is limited. However, there are two sources of error that could lead to an underestimation of D. 
First, the curvature of the membrane structure forces the transmembrane protein to diffuse in a curved route instead of a straight line between two points, which is slower than one dimensional diffusion. Since ER is a complex structure with many curvatures, simplification of this structure in modeling of FRAP experiment will inevitably lead to an underestimation of D in ER. The real difference between ER and peri-nuclear pool of Eag1 will be larger than what has been observed. It must however be pointed out that invagination of inner nuclear membrane can also take place in either cultured cells [Ellenberg et al., 1997] or human endometrium tissue Isaac et al., 2001.

The second factor is the limited pool of proteins surrounding the bleached region (ROI). FRAP models assume a Gaussian-shaped boundary [Axelrod et al. 1976] while the shape of the volume excited by the laser (PSF, point-spread-function) is irregular [Houtsmuller et al., 1999], more complicated with higher NA objectives (this is the reason why $40 \times$ instead of $63 \times$ objective was used here), which requires that the size of the ROI is much larger than that of PSF. FRAP models also assume an infinity pool of unbleached proteins Axelrod et al. 1976. In practice it means that the size of ROI should be smaller than $20 \%$ of that of the total region Wedekind et al. 1996. Both these requirements cannot be met at the same time for Eag1 in the peri-nuclear region due to its intermittent distribution pattern. It results in an underestimation of $\mathrm{D}$ in the peri-nuclear region.

It is unclear to what extent the two factors have affected the data, but in terms of the difference between ER and peri-nuclear pool, both factors could cancel out each other to a certain degree.

The post-bleach intensity was normalized to the intensity outside of the ROI in the reference image. This was done to compensate only for the unintended bleaching.

The low $\mathrm{D}$ and $\mathrm{M}_{\mathrm{f}}$ only indicate a lack of long-range mobility but do not rule out the possibility of an active local movement or interaction (i.e. Eag1 with heterochromatin at 'NPC-free islands'). 
Although both the inner nuclear membrane proteins and the heterochromatin are positionally stable structures, their bindings through HP1 Cheutin et al., 2003, Festenstein et al., 2003] or BAF1 [Shimi et al., 2004] are fast and dynamic processes and depend on condensation levels of chromosome, methylation levels of histone or phosphorylation states of inner nuclear membrane proteins Hirano et al. 2005.

\subsection{Reagents to separate inner nuclear membrane from outer nuclear membrane}

One of the major concerns was to distinguish clearly outer nuclear membrane from inner nuclear membrane proteins. The choice of effective and reliable reagent for removing outer nuclear membrane was therefore critical.

Although inner nuclear membrane proteins are generally characterized by resistance to rigorous extractions Dreger et al. 2001, Schirmer et al. 2003, the extraction of either proteins or lipids by Triton X-100 has no plateau Aaronson and Blobel, 1974, Schindler et al., 1985, which means that the inner nuclear membrane can also be extracted. For example, two well established inner nuclear membrane proteins, LUMA and emerin, were missing from a Triton-based proteomic assay designed to screen for inner nuclear membrane proteins Schirmer et al., 2003. Triton X-100 was employed to remove the outer nuclear membrane in the report of a zinc and calcium channel at the inner nuclear membrane [Longin et al., 1997]. Since it also extracted lipids from inner nuclear membrane, it has compromised the integrity of the inner nuclear membrane, resulting in a low success rate of giga-seal formation in that study.

Citric acid also extracts proteins from both inner and outer nuclear membranes Rosenberger et al. 1995. It was the reagent used to record $\mathrm{InsP}_{3}$ receptor current at the inner nuclear membrane 
in Marchenko et al. 2005.

To make the situation more complex, some ER or outer nuclear membrane protein can also survive high salt extraction Schirmer and Gerace, 2005]. For example, KASH domain proteins at the outer nuclear membrane are resistant to extraction due to their direct associations with SUN domain proteins at the inner nuclear membrane Gruenbaum et al. 2005.

Citraconic anhydride (CA) extraction of lipids saturates around 50\%, as confirmed by EM studies Schindler, 1984, Schindler et al., 1985. During the course of this thesis, CA-treated nuclei contained less outer nuclear membrane markers and had a corresponding enrichment in the inner nuclear membrane proteins. Hence, this study confirmes previous reports on the specificity of CA for removing outer nuclear membrane in biochemical assays.

CA-treated nuclei had the structural identity preserved, as examined by microscopy, and were amenable for patch-clamp recordings. This method provided a high chance of achieving giga-seals that are stable enough for perfusion and continuous recording. In addition to the evidences it provided for inner nuclear membrane-localization of Eag1, this study also shows that CA serves as a selective reagent for removal of the outer nuclear membrane for patch-clamp studies.

\subsection{Single channel activities recorded at the inner nuclear membrane is very likely from Eag1}

The properties of the current recorded at the inner nuclear membrane are compatible with those of Eag1. The current can be blocked by two specific blockers: astemizole, which has not been reported to block any channel outside the EAG family, and mAb56, which was engineered to discriminate 
between Eag1 and its closest homolog Eag2, and is therefore the most specific blocker for Eag1 so far. The conductance is in the same range as is reported for the plasma membrane Eag1. Besides, no similar current was measured in non-transfected cells.

At the membrane of CA-treated nuclei, it was observed that $\mathrm{P}_{\mathrm{o}}$ was higher when the pipette was hold at negative voltage. It suggests that Eag1 at the inner nuclear membrane has its extracellular pore facing the pipette, which is opposite to the orientation at the outer nuclear membrane.

It is important to measure the current at $0 \mathrm{mV}$ under unequal concentration of potassium to rule out some artifacts from the voltage applied. It has to be emphasized however that the stability of the seal at inner nuclear membrane was extremely sensitive to ion composition. Hence the pharmacological assays were employed instead to address the question of the specificity of the channel. The i-V curve of single channel recording measured at the inner nuclear membrane crossed the $\mathrm{x}$-axis around $0 \mathrm{mV}$. This indicted a lack of ionic or voltage difference across the inner nuclear membrane under this experimental condition, but not necessary in vivo. Since Ca-chelator had been used all through the nuclei preparation, the opening of NPC led to an equilibrium of the subtle difference in ion composition or potential across the inner nuclear membrane.

\subsection{NE electrophysiology}

It is disputed if the nuclear envelope serves as barrier to ions.

The presence of intranuclear voltage indicates that nuclear envelope may be an ion-barrier. This potential difference ranges from 0 to $-15 \mathrm{mV}$ in most of the cell types tested Mazzanti et al., 2001. And it is dependent on cytoplasmic $\left[\mathrm{K}^{+}\right]$but independent of membrane potential Giulian 
and Diacumakos, 1977, Mazzanti et al., 1990]. This potential difference relies on the selective permeability of nuclear envelope to ions, and a difference in ion compositions. The $\left[\mathrm{K}^{+}\right]$is $20 \%$ higher in the nucleoplasm than cytoplasm [Kowarski et al., 1985] and there is a nearly complete exclusion of $\mathrm{Cl}^{-}$from nucleoplasm Hoffman and Geibel, 2005]. Since there has not been any active transport systems for ions reported on the nuclear envelope (although a lipid pump has been found at the inner nuclear membrane), the main source for the separation of ions could be the negativelycharged backbones of DNA that are not completely shielded by histones.

Since NPC is the only channel spanning both layers of nuclear envelope and has a large pore if fully opened, it is intuitively believed to be responsible for the dominant permeability of nuclear envolope. However, under physiological conditions, it seems that most of NPCs are not permeable to small ions. That probably explains a lack of correlation between NPC density and the resistivity of nuclear envelope or the intranuclear voltage Mazzanti et al., 2001.

For NPC to be in an ion-impermeable state, the free $\left[\mathrm{Ca}^{2+}\right]$ should not be lower than the physiological level. $\mathrm{Ca}^{2+}$ is required for transport of small molecules through the NPC, during which ion flow is blocked by the seamless contact between NPC and the cargo. In the absence of free calcium, transport of molecules is strongly inhibited and NPCs are unplugged and become permeable to ions Bootman et al., 2000, Santella and Carafoli, 1997. The switch between conducting and non-conducting state of NPC by calcium is reversible as indicated by EM studies Jarnik and Aebi, 1991 and also observed in this study.

The outer nuclear membrane, on the other hand, seems to be quite leaky to small molecules. In many studies on the outer nuclear membrane channels employing 'nucleus-attached' configuration, changes in the ions or other small molecules in the bath solution affected the equilibrium potential and current of outer nuclear membrane channels Bustamante, 1992, Innocenti and Mazzanti, 1993. 
Tabares et al., 1991]. In addition, when one excised the outer nuclear membrane patch, there was no change in single channel conductances ([Franco-Obregón et al., 2000 and observations in this thesis). It was also observed that the outer nuclear membrane preparations had higher activities of large ion channels than that of the inner nuclear membrane in the same condition. This model is easy to imagine, considering the fact that the outer nuclear membrane is an extension of the ER, which is quite leaky to small molecules ([Gall et al., 2004, Simon et al., 1989]). The high permeability of outer nuclear membrane/ER could come from the translocons [Johnson and van Waes, 1999 , Lizák et al., 2008.

With the NPC plugged, the inner nuclear membrane should bear the barrier function between nucleo- and cytoplasm. Nuclear envelope can swell and shrink under osmotic pressure, which also indicates that it is a barrier of selective permeability Innocenti and Mazzanti, 1993, Maruyama et al., 1995. In this scenario, the nucleoskeleton would provide support to the inner nuclear membrane against osmotic changes, while the outer nuclear membrane would allow ions to cross and compensate for osmotic difference.

Several ion channels have been found on the outer nuclear membrane [Mazzanti et al., 1990]. Since the majority of recordings were performed in isolated nuclei in artificial solution, these results have been debated. However, observations from these experiments were similar to those performed on nuclei from Xenopus oocytes in situ (in their cytoplasmic environments Mazzanti et al., 1994]).

Channel activities reported from on the outer nuclear membrane were not from ER membranes. Coconut water is a syncytial endosperm where there is very few endomembrane and hence few ER connected to the outer nuclear membrane, as is shown by EM. In this sample, channel activities can still be frequently recorded on the nuclear envelope [Matzke et al., 1992. Besides, ER channel openers or blockers have no effect on nuclear channels activities recorded Bustamante, 2006]. The 
nuclear channel identities has also been verified by atomic force microscopy immediately after recording from the same patch [Danker et al., 1997, Franco-Obregón et al., 2000].

Eag1 on the outer nuclear membrane with their cytoplasmic side facing intracellular solution may be subjected to run-down as is observed frequently in inside-out patches from HEK cell line Stansfeld et al. 1996] or oocytes Ludwig et al., 1994. By this reasoning, even if Eag1 was present on the outer nuclear membrane, one might not be able to record its current.

At the inner nuclear membrane, there have been only 4 reports regarding ion channels. Three of them employed different reagents for removing outer nuclear membrane, whose draw-backs have been discussed above. The fourth report was based on measurements from reconstituted lipid bilayers from subcellular fractions after sonification of nuclear envelope Rousseau et al., 1996] which provides enough chances for contamination of the preparation with outer nuclear membrane.

\subsection{Possible role of Eag1 in the inner nuclear membrane as an ion channel}

At physiological ion condition, non-Watson-Crick bonds in guanine-rich sequence tend to form between intra- or intermolecular guanine residues (Hoogsteen base pair). The DNA or RNA then folds into a four-stranded structure called G-quadruplex Williamson et al., 1989. This structure has higher binding affinity to $\mathrm{K}^{+}$than to $\mathrm{Na}^{+}$Sen and Gilbert, 1990, Williamson, 1993]. And Eag1 can participate in this regulation by adjusting nucleoplasmic $\left[\mathrm{K}^{+}\right]$.

There are many regions on chromatin which are rich in guanine repeats, such as rDNA, immunoglobulin switch regions, promoters, genes, variable number terminal repeats, recombination sites, satellite and telomere DNA Qin and Hurley, 2008. The most studied case is the 3' end of 
telomere, which has a 12-16 bp guanine-rich single strand overhang Qin and Hurley, 2008, Sen and Gilbert, 1990. Once turned into a G-quadruplex, it is no longer recognized by telomere-binding proteins and may act as an initial point of alignment during meiotic pairing [Hardin et al., 1991].

A number of oncogenes promoter regions also have the potential to form G-quadruplex. For example, in c-MYC promoter region, this structure acts as a transcriptional repressor element. Single point mutations which disrupt the structure increased the expression level of myc in vivo, while a small molecule that stabilizes the structure, suppressed the transcriptional activation. More importantly, this effect is abolished in the same lymphoma cell line with only one difference - the G-guanine rich promoter has been disrupted by translocation [Siddiqui-Jain et al., 2002].

Compared to other $\mathrm{K}$ channels overexpressed in cancer, Eag1 has the advantage that it can directly affect nucleoplasmic $\left[\mathrm{K}^{+}\right]$and influence the formation of G-quadruplex in the malignancyrelevant regions. Eag1 would also play a role in the cell cycle-dependent change of intra-nucleus voltage by changing intranuclear $\left[\mathrm{K}^{+}\right]$Giulian and Diacumakos, 1977, Mazzanti et al., 2001.

\subsection{Transport of Eag1 into nucleus and the relevance to mitosis}

As previously mentioned, different regions of protein sequences have been found to be required for the inner nuclear membrane localization of transmembrane proteins. There is so far no conserved NLS pattern for transmembrane proteins. Many inner nuclear membrane proteins have no predicted NLS either [Lusk et al., 2007]. A canonical NLS for soluble protein does not guarantee a transmembrane protein to be transported into the inner nuclear membrane Soullam and Worman, 1995. Neither did the treatment with nuclear export inhibitor (leptomycin B) have any obvious effects on the localization of Eag1 (data not shown). More work needs to be done to unravel a 
probable NLS in Eag1.

There seems to be an upper limit of size around $75 \mathrm{kDa}$ for the cytoplasmic domain of inner nuclear membrane protein Ohba et al. 2004. This is close to the size of the cytoplasmic domain of a single subunit of Eag1, not to mention that potassium channels only function as a tetramers. If Eag1 is not transported to the inner nuclear membrane through NPC, it is also possible that Eag1containing membranes attach to chromatin during nuclear envelope reformation, which results in its inner nuclear membrane-localization. Inner nuclear membrane proteins are normally regulated closely in a cell-cycle dependent manner. The mitotic changes in their subcellular distributions and associations with chromatin or chromatin-associated proteins are normally dependent on the phosphorylation states Bailer et al., 1991, Ellis et al., 1998, Hirano et al., 2005, 2009. It would be interesting to further examine the mitotic regulation of Eag1's subcellular distribution and phosphorylation, since Eag1 has been shown to be regulated mitotically Brüggemann et al., 1997, Pardo et al., 1998 and the lack of mitosis in the neuronal systems may help to explain why Eag1 is not oncogenic there.

\subsection{Non-canonical role of Eag1 in the 'NPC-free islands'}

One interesting observation that may shed light on the role of Eag1 is its presence in the 'NPCfree islands'. This localization is common among inner nuclear membrane proteins and normally indicates interactions with heterochromatin, which is non-canonical for an ion channel.

The recruitment of heterochromatin by inner nuclear membrane proteins to nuclear envelope generally correlates with or even cause gene repression. It also modifies the histones and thereafter affects transcription by changing the higher-order structure of chromosome Akhtar and Gasser, 
2007, Somech et al., 2005. At the genomic level, inner nuclear membrane-mediated tethering of heterochromatin is crucial for genomic stability by inhibition of rDNA recombination Mekhail et al. 2008. In acute myeloid leukemias, Eag1 expression is associated with chromosome abnormalities or multiple aberrations [Agarwal et al. 2010]. It is worthy to investigate if the chromosome abnormalities in solid tumors is also correlated to Eag1 expression level.

The blockers that have been shown to slow down tumor growth are all open channel blockers (astemizole Ouadid-Ahidouch et al. 2001, imipramine de Queiroz et al., 2006, Gavrilova-Ruch et al. 2002 or mAb56 Gómez-Varela et al., 2007]). This does not necessary mean that it is the ion flow through the plasma membrane per se that is required for Eag1 to perform its role in cancer. It is possible that the blockers trap the channel in certain conformation state unfavorable for certain interactions with the inner nuclear membrane (i.e. with heterochromatin). Astemizole penetrates membrane easily and therefore can access inner nuclear membrane Eag1. Then how does the blockage of mAb56 on the plasma membrane have any effect on the inner nuclear membrane pool of Eag1? One explanation is through endocytosis pathway which either leads to fusion of surface-originated vesicles with $\mathrm{ER} / \mathrm{NE}$ or a direct transport of the endosome containing Eag1 into the nucleus, as explained above. 


\section{Summery}

hEag1 (human ether-à-go-go-1, Kv10.1) is a voltage-gated potassium channel expressed mostly in the brain in healthy subjects but also in many tumors under pathological conditions. Its ability to induce malignant transformation and to favour tumor progression can't be attributed entirely to its potassium permeation. hEag1 was shown to co-localize with lamin A/C. And electron microscopy studies in neurons and tumor cells indicated that it is localized at the inner nuclear membrane. The aim of the thesis was to confirm this localization.

The peri-nuclear hEag1 fulfils the established criteria for transmembrane proteins targeted to the inner nuclear membrane. The peri-nuclear hEag1 was not accessible to antibodies unless the nuclear envelope was permeabilized. Compared to the cytoplasm population, the peri-nuclear population was more resistant to Triton X-100 extraction and less mobile in lateral diffusion in FRAP analysis. It was also frequently found in the "NPC-free island", which normally associates with the heterochromatin. All these characters suggest a tight interaction with nuclear lamina, other

inner nuclear membrane proteins or chromatin. Furthermore, in density gradient centrifugation of extracts from both heterologous and native systems, hEag1 was enriched in fractions containing known inner nuclear membrane proteins.

It was also shown that hEag1 at the inner nuclear membrane is functional as an ion channel. Single channel currents detected at the inner nuclear membrane were compatible with that of hEag1 in terms of conductance and pharmacologic properties (inhibition by astemizole and a specific monoclonal antibody). This current was not detected in non-transfected cells. Moreover, the opening probability was higher when the pipette voltage was more negative, suggesting that hEag1 in the inner nuclear membrane has its $\mathrm{N}$ and $\mathrm{C}$ termini facing the nucleoplasm.

Our experiments strongly suggest that the channel is integrated in the inner nuclear membrane, with its $\mathrm{N}$ and C-termini exposed to the nucleoplasm, possibly in contact with the heterochromatin. 


\section{References}

R. P. Aaronson and G. Blobel. On the attachment of the nuclear pore complex. J Cell Biol, 62(3): 746-754, Sep 1974.

M. D. Abramoff, P. J. Magelhaes, and S. J. Ram. Image processing with imagej. Biophotonics International, 11(7):36-42, 2004.

S. A. Adam, R. S. Marr, and L. Gerace. Nuclear protein import in permeabilized mammalian cells requires soluble cytoplasmic factors. J Cell Biol, 111(3):807-816, Sep 1990.

Jasmin R Agarwal, Frank Griesinger, Walter Stuhmer, and Luis A Pardo. The potassium channel ether a go-go is a novel prognostic factor with functional relevance in acute myeloid leukemia. Mol Cancer, 9(1):18, Jan 2010. doi: 10.1186/1476-4598-9-18. URL http://dx.doi.org/10. 1186/1476-4598-9-18.

Asifa Akhtar and Susan M Gasser. The nuclear envelope and transcriptional control. Nat Rev Genet, 8(7):507-517, Jul 2007. doi: 10.1038/nrg2122. URL http://dx.doi.org/10.1038/nrg2122.

Mariano Alló, Valeria Buggiano, Juan P Fededa, Ezequiel Petrillo, Ignacio Schor, Manuel de la Mata, Eneritz Agirre, Mireya Plass, Eduardo Eyras, Sherif Abou Elela, Roscoe Klinck, Benoit Chabot, and Alberto R Kornblihtt. Control of alternative splicing through sirna-mediated transcriptional gene silencing. Nat Struct Mol Biol, 16(7):717-724, Jul 2009. doi: 10.1038/nsmb.1620. URL http://dx.doi.org/10.1038/nsmb.1620.

Daniel J Anderson and Martin W Hetzer. Nuclear envelope formation by chromatin-mediated reorganization of the endoplasmic reticulum. Nat Cell Biol, 9(10):1160-1166, Oct 2007. doi: 10.1038/ncb1636. URL http://dx.doi.org/10.1038/ncb1636.

Daniel J Anderson and Martin W Hetzer. The life cycle of the metazoan nuclear envelope. Curr Opin Cell Biol, 20(4):386-392, Aug 2008. doi: 10.1016/j.ceb.2008.03.016. URL http://dx.doi. org $/ 10.1016 / j \cdot c e b .2008 .03 .016$.

D. Axelrod, D. E. Koppel, J. Schlessinger, E. Elson, and W. W. Webb. Mobility measurement by analysis of fluorescence photobleaching recovery kinetics. Biophys J, 16(9):10551069, Sep 1976. doi: 10.1016/S0006-3495(76)85755-4. URL http://dx.doi.org/10.1016/ S0006-3495(76) 85755-4.

S. M. Bailer, H. M. Eppenberger, G. Griffiths, and E. A. Nigg. Characterization of a 54-kd protein of the inner nuclear membrane: evidence for cell cycle-dependent interaction with the nuclear lamina. J Cell Biol, 114(3):389-400, Aug 1991.

C. K. Bauer and J. R. Schwarz. Physiology of eag k+ channels. J Membr Biol, 182(1):1-15, Jul 2001. URL http://www. springerlink. com/content/ea5316pmdaxbul0v/. 
Luiza Bengtsson and Henning Otto. Luma interacts with emerin and influences its distribution at the inner nuclear membrane. J Cell Sci, 121(Pt 4):536-548, Feb 2008. doi: 10.1242/jcs.019281. URL http://dx.doi.org/10.1242/jcs.019281.

P. Bijlenga, T. Occhiodoro, J. H. Liu, C. R. Bader, L. Bernheim, and J. Fischer-Lougheed. An ether -à-go-go k+ current, ih-eag, contributes to the hyperpolarization of human fusion-competent myoblasts. J Physiol, 512 ( Pt 2):317-323, Oct 1998.

S. Bolte and F. P. Cordelières. A guided tour into subcellular colocalization analysis in light microscopy. J Microsc, 224(Pt 3):213-232, Dec 2006. doi: 10.1111/j.1365-2818.2006.01706.x. URL http://dx.doi.org/10.1111/j.1365-2818.2006.01706.x.

M. D. Bootman, D. Thomas, S. C. Tovey, M. J. Berridge, and P. Lipp. Nuclear calcium signalling. Cell Mol Life Sci, 57(3):371-378, Mar 2000.

Anne-Sophie Borowiec, Frédéric Hague, Noria Harir, Stéphanie Guénin, François Guerineau, Fabrice Gouilleux, Morad Roudbaraki, Kaiss Lassoued, and Halima Ouadid-Ahidouch. Igf-1 activates heag $\mathrm{k}(+)$ channels through an akt-dependent signaling pathway in breast cancer cells: role in cell proliferation. J Cell Physiol, 212(3):690-701, Sep 2007. doi: 10.1002/jcp.21065. URL http://dx.doi.org/10.1002/jcp.21065.

Andreas Brachner, Siegfried Reipert, Roland Foisner, and Josef Gotzmann. Lem2 is a novel man1related inner nuclear membrane protein associated with a-type lamins. J Cell Sci, 118(Pt 24): 5797-5810, Dec 2005. doi: 10.1242/jcs.02701. URL http://dx.doi.org/10.1242/jcs.02701.

Sharon C Braunagel, Shawn T Williamson, Qi Ding, Xiaogiang Wu, and Max D Summers. Early sorting of inner nuclear membrane proteins is conserved. Proc Natl Acad Sci U S A, 104(22):93079312, May 2007. doi: 10.1073/pnas.0703186104. URL http://dx.doi.org/10.1073/pnas. 0703186104 .

Tinatin I Brelidze, Anne E Carlson, and William N Zagotta. Absence of direct cyclic nucleotide modulation of meag1 and herg1 channels revealed with fluorescence and electrophysiological methods. J Biol Chem, 284(41):27989-27997, Oct 2009. doi: 10.1074/jbc.M109.016337. URL http://dx.doi.org/10.1074/jbc.M109.016337.

A. Brüggemann, L. A. Pardo, W. Stühmer, and O. Pongs. Ether-à-go-go encodes a voltage-gated channel permeable to $\mathrm{k}+$ and ca2+ and modulated by camp. Nature, 365(6445):445-448, Sep 1993. doi: 10.1038/365445a0. URL http://dx.doi.org/10.1038/365445a0

A. Brüggemann, W. Stühmer, and L. A. Pardo. Mitosis-promoting factor-mediated suppression of a cloned delayed rectifier potassium channel expressed in xenopus oocytes. Proc Natl Acad Sci U S A, 94(2):537-542, Jan 1997.

J. O. Bustamante. Nuclear ion channels in cardiac myocytes. Pflugers Arch, 421(5):473-485, Aug 1992. 
J. O. Bustamante. Restricted ion flow at the nuclear envelope of cardiac myocytes. Biophys J, 64 (6):1735-1749, Jun 1993. doi: 10.1016/S0006-3495(93)81545-5. URL http://dx.doi.org/10. 1016/S0006-3495(93)81545-5.

J. O. Bustamante. Nuclear electrophysiology. J Membr Biol, 138(2):105-112, Mar 1994.

J. O. Bustamante, J. A. Hanover, and A. Liepins. The ion channel behavior of the nuclear pore complex. J Membr Biol, 146(3):239-251, Aug 1995.

José Omar Bustamante. Current concepts in nuclear pore electrophysiology. Can J Physiol Pharmacol, 84(3-4):347-365, 2006. doi: 10.1139/y05-096. URL http://dx.doi.org/10.1139/y05-096.

J. Camacho, A. Sánchez, W. Stühmer, and L. A. Pardo. Cytoskeletal interactions determine the electrophysiological properties of human eag potassium channels. Pflugers Arch, 441(2-3):167174, Dec 2000.

E. Carafoli, P. Nicotera, and L. Santella. Calcium signalling in the cell nucleus. Cell Calcium, 22 (5):313-319, Nov 1997.

Robert J G Cardnell, Damian E Dalle Nogare, Barry Ganetzky, and Michael Stern. In vivo analysis of a gain-of-function mutation in the drosophila eag-encoded k+ channel. Genetics, 172(4): 2351-2358, Apr 2006. doi: 10.1534/genetics.105.048777. URL http://dx.doi.org/10.1534/ genetics.105.048777.

Thierry Cheutin, Adrian J McNairn, Thomas Jenuwein, David M Gilbert, Prim B Singh, and Tom Misteli. Maintenance of stable heterochromatin domains by dynamic hp1 binding. Science, 299 (5607):721-725, Jan 2003. doi: 10.1126/science.1078572. URL http://dx.doi.org/10.1126/ science.1078572.

K. S. COLE and J. W. MOORE. Potassium ion current in the squid giant axon: dynamic characteristic. Biophys J, 1:1-14, Sep 1960.

Janet M Cronshaw, Andrew N Krutchinsky, Wenzhu Zhang, Brian T Chait, and Michael J Matunis. Proteomic analysis of the mammalian nuclear pore complex. J Cell Biol, 158(5):915-927, Sep 2002. doi: 10.1083/jcb.200206106. URL http://dx.doi.org/10.1083/jcb.200206106.

M. C. Dabauvalle, E. Müller, A. Ewald, W. Kress, G. Krohne, and C. R. Müller. Distribution of emerin during the cell cycle. Eur J Cell Biol, 78(10):749-756, Oct 1999.

T. Danker, M. Mazzanti, R. Tonini, A. Rakowska, and H. Oberleithner. Using atomic force microscopy to investigate patch-clamped nuclear membrane. Cell Biol Int, 21(11):747-757, Nov 1997. doi: 10.1006/cbir.1997.0219. URL http://dx.doi.org/10.1006/cbir.1997.0219.

T. Danker, H. Schillers, J. Storck, V. Shahin, B. Krämer, M. Wilhelmi, and H. Oberleithner. Nuclear hourglass technique: an approach that detects electrically open nuclear pores in xenopus laevis oocyte. Proc Natl Acad Sci U S A, 96(23):13530-13535, Nov 1999. 
Lorenza Díaz, Irais Ceja-Ochoa, Iván Restrepo-Angulo, Fernando Larrea, Euclides Avila-Chávez, Rocío García-Becerra, Elizabeth Borja-Cacho, David Barrera, Elías Ahumada, Patricio Gariglio, Elizabeth Alvarez-Rios, Rodolfo Ocadiz-Delgado, Enrique Garcia-Villa, Elizabeth HernándezGallegos, Ignacio Camacho-Arroyo, Angélica Morales, David Ordaz-Rosado, Ethel GarcíaLatorre, Juan Escamilla, Luz Carmen Sánchez-Peña, Milena Saqui-Salces, Armando GamboaDominguez, Eunice Vera, Marisela Uribe-Ramírez, Janet Murbartián, Cindy Sharon Ortiz, Claudia Rivera-Guevara, Andrea De Vizcaya-Ruiz, and Javier Camacho. Estrogens and human papilloma virus oncogenes regulate human ether-à-go-go-1 potassium channel expression. Cancer Res, 69(8):3300-3307, Apr 2009. doi: 10.1158/0008-5472.CAN-08-2036. URL http://dx.doi.org/10.1158/0008-5472.CAN-08-2036.

Fernanda Mello de Queiroz, Guilherme Suarez-Kurtz, Walter Stühmer, and Luis A Pardo. Ether à go-go potassium channel expression in soft tissue sarcoma patients. Mol Cancer, 5:42, 2006. doi: 10.1186/1476-4598-5-42. URL http://dx.doi.org/10.1186/1476-4598-5-42.

Carol Deutsch. The birth of a channel. Neuron, 40(2):265 - 276, $2003 . \quad$ ISSN 0896-6273. doi: DOI:10.1016/S0896-6273(03)00506-3. URL http://www.sciencedirect.com/science/ article/B6WSS-49RHYCM-7/2/b4b03a488cd2f073c81ae55c3738e530.

Daniela Dorner, Sylvia Vlcek, Nicole Foeger, Andreas Gajewski, Christian Makolm, Josef Gotzmann, Christopher J Hutchison, and Roland Foisner. Lamina-associated polypeptide 2alpha regulates cell cycle progression and differentiation via the retinoblastoma-e2f pathway. J Cell Biol, 173(1):83-93, Apr 2006. doi: 10.1083/jcb.200511149. URL http://dx.doi.org/10.1083/ jcb.200511149.

Bryan R Downie, Araceli Sánchez, Hendrik Knötgen, Constanza Contreras-Jurado, Marco Gymnopoulos, Claudia Weber, Walter Stühmer, and Luis A Pardo. Eag1 expression interferes with hypoxia homeostasis and induces angiogenesis in tumors. J Biol Chem, 283(52):36234-36240, Dec 2008. doi: 10.1074/jbc.M801830200. URL http://dx.doi.org/10.1074/jbc.M801830200.

A. Draguhn, G. Börner, R. Beckmann, K. Buchner, U. Heinemann, and F. Hucho. Largeconductance cation channels in the envelope of nuclei from rat cerebral cortex. J Membr Biol, 158(2):159-166, Jul 1997.

M. Dreger, L. Bengtsson, T. Schöneberg, H. Otto, and F. Hucho. Nuclear envelope proteomics: novel integral membrane proteins of the inner nuclear membrane. Proc Natl Acad Sci U S A, 98 (21):11943-11948, Oct 2001. doi: 10.1073/pnas.211201898. URL http://dx.doi.org/10.1073/ pnas. 211201898.

R. Drysdale, J. Warmke, R. Kreber, and B. Ganetzky. Molecular characterization of eag: a gene affecting potassium channels in drosophila melanogaster. Genetics, 127(3):497-505, Mar 1991. 
A. E. Dubin, M. M. Liles, and G. L. Harris. The $\mathrm{k}+$ channel gene ether a go-go is required for the transduction of a subset of odorants in adult drosophila melanogaster. $J$ Neurosci, 18(15): 5603-5613, Aug 1998.

J. Ellenberg, E. D. Siggia, J. E. Moreira, C. L. Smith, J. F. Presley, H. J. Worman, and J. LippincottSchwartz. Nuclear membrane dynamics and reassembly in living cells: targeting of an inner nuclear membrane protein in interphase and mitosis. J Cell Biol, 138(6):1193-1206, Sep 1997.

J. A. Ellis, M. Craxton, J. R. Yates, and J. Kendrick-Jones. Aberrant intracellular targeting and cell cycle-dependent phosphorylation of emerin contribute to the emery-dreifuss muscular dystrophy phenotype. J Cell Sci, 111 ( Pt 6):781-792, Mar 1998.

J. E. Engel and C. F. Wu. Genetic dissection of functional contributions of specific potassium channel subunits in habituation of an escape circuit in drosophila. J Neurosci, 18(6):2254-2267, Mar 1998.

Luz María Barajas Farias, Deysi Bermúdez Ocaña, Lorenza Díaz, Fernando Larrea, Euclides AvilaChávez, Adriana Cadena, Luz María Hinojosa, Gerardo Lara, Luis Alberto Villanueva, Carlos Vargas, Elizabeth Hernández-Gallegos, Ignacio Camacho-Arroyo, Alfonso Dueñas-González, Enrique Pérez-Cárdenas, Luis A Pardo, Angélica Morales, Lucía Taja-Chayeb, Juan Escamilla, Carmen Sánchez-Peña, and Javier Camacho. Ether a go-go potassium channels as human cervical cancer markers. Cancer Res, 64(19):6996-7001, Oct 2004. doi: 10.1158/0008-5472.CAN-04-1204. URL http://dx.doi.org/10.1158/0008-5472.CAN-04-1204.

Richard Festenstein, Stamatis N Pagakis, Kyoko Hiragami, Debbie Lyon, Alain Verreault, Belaid Sekkali, and Dimitris Kioussis. Modulation of heterochromatin protein 1 dynamics in primary mammalian cells. Science, 299(5607):719-721, Jan 2003. doi: 10.1126/science.1078694. URL http://dx.doi.org/10.1126/science.1078694.

A. Franco-Obregón, H. W. Wang, and D. E. Clapham. Distinct ion channel classes are expressed on the outer nuclear envelope of t- and b-lymphocyte cell lines. Biophys J, 79(1): 202-214, Jul 2000. doi: 10.1016/S0006-3495(00)76284-9. URL http://dx.doi.org/10.1016/ S0006-3495(00)76284-9.

Steffen Frey and Dirk Görlich. A saturated fg-repeat hydrogel can reproduce the permeability properties of nuclear pore complexes. Cell, 130(3):512-523, Aug 2007. doi: 10.1016/j.cell.2007. 06.024. URL http://dx.doi.org/10.1016/j.cell.2007.06.024.

S. Frings, N. Brüll, C. Dzeja, A. Angele, V. Hagen, U. B. Kaupp, and A. Baumann. Characterization of ether-à-go-go channels present in photoreceptors reveals similarity to ikx, a k+ current in rod inner segments. J Gen Physiol, 111(4):583-599, Apr 1998.

K. Furukawa, N. Panté, U. Aebi, and L. Gerace. Cloning of a cdna for lamina-associated polypeptide 2 (lap2) and identification of regions that specify targeting to the nuclear envelope. EMBO J, 14 (8):1626-1636, Apr 1995. 
K. Furukawa, C. E. Fritze, and L. Gerace. The major nuclear envelope targeting domain of lap2 coincides with its lamin binding region but is distinct from its chromatin interaction domain. $J$ Biol Chem, 273(7):4213-4219, Feb 1998.

Sylvie Le Gall, Andrea Neuhof, and Tom Rapoport. The endoplasmic reticulum membrane is permeable to small molecules. Mol Biol Cell, 15(2):447-455, Feb 2004. doi: 10.1091/mbc. E03-05-0325. URL http://dx.doi.org/10.1091/mbc.E03-05-0325.

B. Ganetzky and C. F. Wu. Neurogenetic analysis of potassium currents in drosophila: synergistic effects on neuromuscular transmission in double mutants. J Neurogenet, 1(1):17-28, Sep 1983.

B. Ganetzky, G. A. Robertson, G. F. Wilson, M. C. Trudeau, and S. A. Titus. The eag family of k+ channels in drosophila and mammals. Ann N Y Acad Sci, 868:356-369, Apr 1999.

Rafael E García-Ferreiro, Daniel Kerschensteiner, Felix Major, Francisco Monje, Walter Stühmer, and Luis A Pardo. Mechanism of block of heag $1 \mathrm{k}+$ channels by imipramine and astemizole. $J$ Gen Physiol, 124(4):301-317, Oct 2004. doi: 10.1085/jgp.200409041. URL http://dx.doi.org/ 10.1085/jgp.200409041.

O. Gavrilova-Ruch, K. Schönherr, G. Gessner, R. Schönherr, T. Klapperstück, W. Wohlrab, and S. H. Heinemann. Effects of imipramine on ion channels and proliferation of igr1 melanoma cells. J Membr Biol, 188(2):137-149, Jul 2002. doi: 10.1007/s00232-001-0181-3. URL http: //dx.doi.org/10.1007/s00232-001-0181-3.

S. D. Georgatos. The inner nuclear membrane: simple, or very complex? EMBO J, 20(12):29892994, Jun 2001. doi: 10.1093/emboj/20.12.2989. URL http://dx.doi.org/10.1093/emboj/ 20.12.2989.

Dipak K Giri, Mohamed Ali-Seyed, Long-Yuan Li, Dung-Fang Lee, Pin Ling, Geoffrey Bartholomeusz, Shao-Chun Wang, and Mien-Chie Hung. Endosomal transport of erbb-2: mechanism for nuclear entry of the cell surface receptor. Mol Cell Biol, 25(24):11005-11018, Dec 2005. doi: 10.1128/MCB.25.24.11005-11018.2005. URL http://dx.doi.org/10.1128/MCB.25. 24.11005-11018.2005

D. Giulian and E. G. Diacumakos. The electrophysiological mapping of compartments within a mammalian cell. J Cell Biol, 72(1):86-103, Jan 1977.

David Gómez-Varela, Esther Zwick-Wallasch, Hendrik Knötgen, Araceli Sánchez, Thore Hettmann, Dmitri Ossipov, Rüdiger Weseloh, Constanza Contreras-Jurado, Mike Rothe, Walter Stühmer, and Luis A Pardo. Monoclonal antibody blockade of the human eag1 potassium channel function exerts antitumor activity. Cancer Res, 67(15):7343-7349, Aug 2007. doi: 10.1158/0008-5472. CAN-07-0107. URL http://dx.doi.org/10.1158/0008-5472.CAN-07-0107. 
David Gómez-Varela, Tobias Kohl, Manuela Schmidt, María E Rubio, Hiroshi Kawabe, Ralf B Nehring, Stephan Schäfer, Walter Stühmer, and Luis A Pardo. Characterization of eag1 channel lateral mobility in rat hippocampal cultures by single-particle-tracking with quantum dots. PLoS One, 5(1):e8858, 2010. doi: 10.1371/journal.pone.0008858. URL http://dx.doi.org/10.1371/ journal.pone.0008858.

J. M. Graham. Isolation of nuclei and nuclear membranes from animal tissues. Curr Protoc Cell Biol, Chapter 3:Unit 3.10, Nov 2001a. doi: 10.1002/0471143030.cb0310s12. URL http: //dx.doi.org/10.1002/0471143030.cb0310s12.

J. M. Graham. Isolation of peroxisomes from tissues and cells by differential and density gradient centrifugation. Curr Protoc Cell Biol, Chapter 3:Unit 3.5, May 2001b. doi: 10.1002/0471143030. cb0305s06. URL http://dx.doi.org/10.1002/0471143030.cb0305s06.

L. C. Griffith, J. Wang, Y. Zhong, C. F. Wu, and R. J. Greenspan. Calcium/calmodulin-dependent protein kinase ii and potassium channel subunit eag similarly affect plasticity in drosophila. Proc Natl Acad Sci U S A, 91(21):10044-10048, Oct 1994.

Yosef Gruenbaum, Ayelet Margalit, Robert D Goldman, Dale K Shumaker, and Katherine L Wilson. The nuclear lamina comes of age. Nat Rev Mol Cell Biol, 6(1):21-31, Jan 2005. doi: 10.1038/ nrm1550. URL http://dx.doi.org/10.1038/nrm1550.

Stephan Güttinger, Eva Laurell, and Ulrike Kutay. Orchestrating nuclear envelope disassembly and reassembly during mitosis. Nat Rev Mol Cell Biol, 10(3):178-191, Mar 2009. doi: 10.1038/ nrm2641. URL http://dx.doi.org/10.1038/nrm2641.

C. C. Hardin, E. Henderson, T. Watson, and J. K. Prosser. Monovalent cation induced structural transitions in telomeric dnas: G-dna folding intermediates. Biochemistry, 30(18):4460-4472, May 1991.

Stijn Heessen and Maarten Fornerod. The inner nuclear envelope as a transcription factor resting place. EMBO Rep, 8(10):914-919, Oct 2007. doi: 10.1038/sj.embor.7401075. URL http://dx. doi.org/10.1038/sj.embor.7401075.

Andrew P Hegle, Daniel D Marble, and Gisela F Wilson. A voltage-driven switch for ionindependent signaling by ether-à-go-go k+ channels. Proc Natl Acad Sci U S A, 103(8):28862891, Feb 2006. doi: 10.1073/pnas.0505909103. URL http://dx.doi.org/10.1073/pnas. 0505909103 .

Bernhard Hemmerlein, Rüdiger M Weseloh, Fernanda Mello de Queiroz, Hendrik Knötgen, Araceli Sánchez, María E Rubio, Sabine Martin, Tessa Schliephacke, Marc Jenke, Heinz-JoachimRadzun, Walter Stühmer, and Luis A Pardo. Overexpression of eag1 potassium channels in clinical tumours. Mol Cancer, 5:41, 2006. doi: 10.1186/1476-4598-5-41. URL http: //dx.doi.org/10.1186/1476-4598-5-41. 
Yasuhiro Hirano, Masashi Segawa, Fumiko S Ouchi, Yoshio Yamakawa, Kazuhiro Furukawa, Kunio Takeyasu, and Tsuneyoshi Horigome. Dissociation of emerin from barrier-to-autointegration factor is regulated through mitotic phosphorylation of emerin in a xenopus egg cell-free system. J Biol Chem, 280(48):39925-39933, Dec 2005. doi: 10.1074/jbc.M503214200. URL http://dx. doi.org/10.1074/jbc.M503214200

Yasuhiro Hirano, Yuka Iwase, Kohei Ishii, Masahiro Kumeta, Tsuneyoshi Horigome, and Kunio Takeyasu. Cell cycle-dependent phosphorylation of man1. Biochemistry, 48(7):1636-1643, Feb 2009. doi: 10.1021/bi802060v. URL http://dx.doi.org/10.1021/bi802060v.

Helmut Hofemeister and Peter O'Hare. Analysis of the localization and topology of nurim, a polytopic protein tightly associated with the inner nuclear membrane. J Biol Chem, 280(4): 2512-2521, Jan 2005. doi: 10.1074/jbc.M410504200. URL http://dx.doi.org/10.1074/jbc . M410504200.

Joseph F Hoffman and John P Geibel. Fluorescent imaging of cl- in amphiuma red blood cells: how the nuclear exclusion of cl- affects the plasma membrane potential. Proc Natl Acad Sci U $S$ A, 102(3):921-926, Jan 2005. doi: 10.1073/pnas.0408597102. URL http://dx.doi.org/10. 1073/pnas.0408597102.

James M Holaska, Katherine L Wilson, and Malini Mansharamani. The nuclear envelope, lamins and nuclear assembly. Curr Opin Cell Biol, 14(3):357-364, Jun 2002.

L. Holmer and H. J. Worman. Inner nuclear membrane proteins: functions and targeting. Cell Mol Life Sci, 58(12-13):1741-1747, Nov 2001.

A. B. Houtsmuller, S. Rademakers, A. L. Nigg, D. Hoogstraten, J. H. Hoeijmakers, and W. Vermeulen. Action of dna repair endonuclease ercc1/xpf in living cells. Science, 284(5416):958-961, May 1999.

J. P. Humbert, N. Matter, J. C. Artault, P. Köppler, and A. N. Malviya. Inositol 1,4,5-trisphosphate receptor is located to the inner nuclear membrane vindicating regulation of nuclear calcium signaling by inositol 1,4,5-trisphosphate. discrete distribution of inositol phosphate receptors to inner and outer nuclear membranes. J Biol Chem, 271(1):478-485, Jan 1996.

B. Innocenti and M. Mazzanti. Identification of a nucleo-cytoplasmic ionic pathway by osmotic shock in isolated mouse liver nuclei. J Membr Biol, 131(2):137-142, Jan 1993.

C. Isaac, J. W. Pollard, and U. T. Meier. Intranuclear endoplasmic reticulum induced by nopp140 mimics the nucleolar channel system of human endometrium. J Cell Sci, 114(Pt 23):4253-4264, Dec 2001.

M. Jarnik and U. Aebi. Toward a more complete 3-d structure of the nuclear pore complex. $J$ Struct Biol, 107(3):291-308, Dec 1991. 
Chung-Jiuan Jeng, Chi-Chen Chang, and Chih-Yung Tang. Differential localization of rat eag1 and eag2 k+ channels in hippocampal neurons. Neuroreport, 16(3):229-233, Feb 2005.

Marc Jenke, Araceli Sánchez, Francisco Monje, Walter Stühmer, Rüdiger M Weseloh, and Luis A Pardo. C-terminal domains implicated in the functional surface expression of potassium channels. EMBO J, 22(3):395-403, Feb 2003. doi: 10.1093/emboj/cdg035. URL http://dx.doi.org/10. 1093/emboj/cdg035.

A. E. Johnson and M. A. van Waes. The translocon: a dynamic gateway at the er membrane. Annu Rev Cell Dev Biol, 15:799-842, 1999. doi: 10.1146/annurev.cellbio.15.1.799. URL http: //dx.doi.org/10.1146/annurev.cellbio.15.1.799.

Guey-Mei Jow and Chung-Jiuan Jeng. Differential localization of rat eag1 and eag2 potassium channels in the retina. Neurosci Lett, 431(1):12-16, Jan 2008. doi: 10.1016/j.neulet.2007.11.017. URL http://dx.doi.org/10.1016/j.neulet.2007.11.017.

W. D. Kaplan and W. E. Trout. The behavior of four neurological mutants of drosophila. Genetics, 61(2):399-409, Feb 1969.

Megan C King, C. Patrick Lusk, and Günter Blobel. Karyopherin-mediated import of integral inner nuclear membrane proteins. Nature, 442(7106):1003-1007, Aug 2006. doi: 10.1038/nature05075. URL http://dx.doi .org/10.1038/nature05075.

E. Kocsis, B. L. Trus, C. J. Steer, M. E. Bisher, and A. C. Steven. Image averaging of flexible fibrous macromolecules: the clathrin triskelion has an elastic proximal segment. J Struct Biol, 107(1):6-14, Aug 1991.

D. Kowarski, H. Shuman, A. P. Somlyo, and A. V. Somlyo. Calcium release by noradrenaline from central sarcoplasmic reticulum in rabbit main pulmonary artery smooth muscle. $J$ Physiol, 366: 153-175, Sep 1985.

R. G. Kulka, B. Raboy, R. Schuster, H. A. Parag, G. Diamond, A. Ciechanover, and M. Marcus. A chinese hamster cell cycle mutant arrested at g2 phase has a temperature-sensitive ubiquitinactivating enzyme, e1. J Biol Chem, 263(30):15726-15731, Oct 1988.

Karl Kunzelmann. Ion channels and cancer. J Membr Biol, 205(3):159-173, Jun 2005. doi: 10.1007/s00232-005-0781-4. URL http://dx.doi.org/10.1007/s00232-005-0781-4.

Tanja la Cour, Lars Kiemer, Anne Mølgaard, Ramneek Gupta, Karen Skriver, and Søren Brunak. Analysis and prediction of leucine-rich nuclear export signals. Protein Eng Des Sel, 17(6):527-536, Jun 2004. doi: 10.1093/protein/gzh062. URL http://dx.doi.org/10.1093/protein/gzh062.

Brigitte LeBoeuf, Todd R Gruninger, and L. Rene Garcia. Food deprivation attenuates seizures through camkii and eag k+ channels. PLoS Genet, 3(9):1622-1632, Sep 2007. doi: 10.1371/ journal.pgen.0030156. URL http://dx.doi.org/10.1371/journal.pgen.0030156. 
F. Lin, D. L. Blake, I. Callebaut, I. S. Skerjanc, L. Holmer, M. W. McBurney, M. Paulin-Levasseur, and H. J. Worman. Man1, an inner nuclear membrane protein that shares the lem domain with lamina-associated polypeptide 2 and emerin. J Biol Chem, 275(7):4840-4847, Feb 2000.

Feng Lin, Juliet M Morrison, Wei Wu, and Howard J Worman. Man1, an integral protein of the inner nuclear membrane, binds smad2 and smad3 and antagonizes transforming growth factorbeta signaling. Hum Mol Genet, 14(3):437-445, Feb 2005. doi: 10.1093/hmg/ddi040. URL http://dx.doi.org/10.1093/hmg/ddi040.

Beáta Lizák, Miklós Csala, Angelo Benedetti, and Gábor Bánhegyi. The translocon and the nonspecific transport of small molecules in the endoplasmic reticulum (review). Mol Membr Biol, 25(2):95-101, Feb 2008. doi: 10.1080/09687680701670481. URL http://dx.doi.org/10.1080/ 09687680701670481

A. S. Longin, P. Mezin, A. Favier, and J. Verdetti. Presence of zinc and calcium permeant channels in the inner membrane of the nuclear envelope. Biochem Biophys Res Commun, 235(1):236-241, Jun 1997. doi: 10.1006/bbrc.1997.6752. URL http://dx.doi.org/10.1006/bbrc.1997.6752.

J. Ludwig, H. Terlau, F. Wunder, A. Brüggemann, L. A. Pardo, A. Marquardt, W. Stühmer, and O. Pongs. Functional expression of a rat homologue of the voltage gated either á go-go potassium channel reveals differences in selectivity and activation kinetics between the drosophila channel and its mammalian counterpart. EMBO J, 13(19):4451-4458, Oct 1994.

C. Patrick Lusk, Günter Blobel, and Megan C King. Highway to the inner nuclear membrane: rules for the road. Nat Rev Mol Cell Biol, 8(5):414-420, May 2007. doi: 10.1038/nrm2165. URL http://dx.doi.org/10.1038/nrm2165.

Kazuhiro Maeshima, Kazuhide Yahata, Yoko Sasaki, Reiko Nakatomi, Taro Tachibana, Tsutomu Hashikawa, Fumio Imamoto, and Naoko Imamoto. Cell-cycle-dependent dynamics of nuclear pores: pore-free islands and lamins. J Cell Sci, 119(Pt 21):4442-4451, Nov 2006. doi: 10.1242/ jcs.03207. URL http://dx.doi.org/10.1242/jcs.03207.

D. O. Mak and J. K. Foskett. Single-channel inositol 1,4,5-trisphosphate receptor currents revealed by patch clamp of isolated xenopus oocyte nuclei. J Biol Chem, 269(47):29375-29378, Nov 1994.

Dimitra Makatsori, Niki Kourmouli, Hara Polioudaki, Leonard D Shultz, Kelvin McLean, Panayiotis A Theodoropoulos, Prim B Singh, and Spyros D Georgatos. The inner nuclear membrane protein lamin b receptor forms distinct microdomains and links epigenetically marked chromatin to the nuclear envelope. J Biol Chem, 279(24):25567-25573, Jun 2004. doi: 10.1074/jbc.M313606200. URL http://dx.doi.org/10.1074/jbc.M313606200.

M. Mansharamani, A. Hewetson, and B. S. Chilton. Cloning and characterization of an atypical type iv p-type atpase that binds to the ring motif of rush transcription factors. J Biol Chem, 276 (5):3641-3649, Feb 2001. doi: 10.1074/jbc.M004231200. URL http://dx.doi.org/10.1074/ jbc.M004231200. 
Sergey M Marchenko and Roger C Thomas. Nuclear ca2+ signalling in cerebellar purkinje neurons. Cerebellum, 5(1):36-42, 2006. doi: 10.1080/14734220600554438. URL http://dx.doi.org/10. $1080 / 14734220600554438$.

Sergey M Marchenko, Victor V Yarotskyy, Tatiana N Kovalenko, Platon G Kostyuk, and Roger C Thomas. Spontaneously active and insp3-activated ion channels in cell nuclei from rat cerebellar purkinje and granule neurones. J Physiol, 565(Pt 3):897-910, Jun 2005. doi: 10.1113/jphysiol. 2004.081299. URL http://dx.doi.org/10.1113/jphysiol.2004.081299.

S. Martin, C. Lino de Oliveira, F. Mello de Queiroz, L. A. Pardo, W. Stühmer, and E. Del Bel. Eag1 potassium channel immunohistochemistry in the cns of adult rat and selected regions of human brain. Neuroscience, 155(3):833-844, Aug 2008. doi: 10.1016/j.neuroscience.2008.05.019. URL http://dx.doi.org/10.1016/j.neuroscience.2008.05.019.

Y. Maruyama, H. Shimada, and J. Taniguchi. $\mathrm{Ca}(2+)$-activated $\mathrm{k}(+)$-channels in the nuclear envelope isolated from single pancreatic acinar cells. Pflugers Arch, 430(1):148-150, May 1995.

Iain W Mattaj. Sorting out the nuclear envelope from the endoplasmic reticulum. Nat Rev Mol Cell Biol, 5(1):65-69, Jan 2004. doi: 10.1038/nrm1263. URL http://dx.doi.org/10.1038/nrm1263.

A. J. Matzke, C. Behensky, T. Weiger, and M. A. Matzke. A large conductance ion channel in the nuclear envelope of a higher plant cell. FEBS Lett, 302(1):81-85, May 1992.

M. Mazzanti, L. J. DeFelice, J. Cohn, and H. Malter. Ion channels in the nuclear envelope. Nature, 343(6260):764-767, Feb 1990. doi: 10.1038/343764a0. URL http://dx.doi.org/10. $1038 / 343764 \mathrm{a} 0$.

M. Mazzanti, B. Innocenti, and M. Rigatelli. Atp-dependent ionic permeability on nuclear envelope in in situ nuclei of xenopus oocytes. FASEB J, 8(2):231-236, Feb 1994.

M. Mazzanti, J. O. Bustamante, and H. Oberleithner. Electrical dimension of the nuclear envelope. Physiol Rev, 81(1):1-19, Jan 2001.

Michele Mazzanti. Ion permeability of the nuclear envelope. News Physiol Sci, 13:44-50, Feb 1998.

Karim Mekhail, Jan Seebacher, Steven P Gygi, and Danesh Moazed. Role for perinuclear chromosome tethering in maintenance of genome stability. Nature, 456(7222):667-670, Dec 2008. doi: 10.1038/nature07460. URL http://dx.doi.org/10.1038/nature07460.

Thomas C Mettenleiter. Budding events in herpesvirus morphogenesis. Virus Res, 106(2):167-180, Dec 2004. doi: 10.1016/j.virusres.2004.08.013. URL http://dx.doi.org/10.1016/j .virusres . 2004.08.013.

R. Meyer and S. H. Heinemann. Characterization of an eag-like potassium channel in human neuroblastoma cells. J Physiol, 508 ( Pt 1):49-56, Apr 1998. 
R. Meyer, R. Schönherr, O. Gavrilova-Ruch, W. Wohlrab, and S. H. Heinemann. Identification of ether à go-go and calcium-activated potassium channels in human melanoma cells. J Membr Biol, 171(2):107-115, Sep 1999.

Takeharu Nagai, Keiji Ibata, Eun Sun Park, Mie Kubota, Katsuhiko Mikoshiba, and Atsushi Miyawaki. A variant of yellow fluorescent protein with fast and efficient maturation for cellbiological applications. Nat Biotechnol, 20(1):87-90, Jan 2002. doi: 10.1038/nbt0102-87. URL http://dx.doi.org/10.1038/nbt0102-87.

Joanna Napp, Francisco Monje, Walter Stühmer, and Luis A Pardo. Glycosylation of eag1 (kv10.1) potassium channels: intracellular trafficking and functional consequences. J Biol Chem, 280(33): 29506-29512, Aug 2005. doi: 10.1074/jbc.M504228200. URL http://dx.doi.org/10.1074/ jbc.M504228200.

Tomoyuki Ohba, Eric C Schirmer, Takeharu Nishimoto, and Larry Gerace. Energy- and temperature-dependent transport of integral proteins to the inner nuclear membrane via the nuclear pore. J Cell Biol, 167(6):1051-1062, Dec 2004. doi: 10.1083/jcb.200409149. URL http://dx.doi.org/10.1083/jcb.200409149.

C. Ostlund, J. Ellenberg, E. Hallberg, J. Lippincott-Schwartz, and H. J. Worman. Intracellular trafficking of emerin, the emery-dreifuss muscular dystrophy protein. J Cell Sci, 112 ( Pt 11): 1709-1719, Jun 1999.

H. Ouadid-Ahidouch, X. Le Bourhis, M. Roudbaraki, R. A. Toillon, P. Delcourt, and N. Prevarskaya. Changes in the $\mathrm{k}+$ current-density of mcf-7 cells during progression through the cell cycle: possible involvement of a h-ether.a-gogo k+ channel. Receptors Channels, 7(5):345-356, 2001.

L. A. Pardo, A. Brüggemann, J. Camacho, and W. Stühmer. Cell cycle-related changes in the conducting properties of r-eag k+ channels. J Cell Biol, 143(3):767-775, Nov 1998.

L. A. Pardo, D. del Camino, A. Sánchez, F. Alves, A. Brüggemann, S. Beckh, and W. Stühmer. Oncogenic potential of eag $\mathrm{k}(+)$ channels. EMBO J, 18(20):5540-5547, Oct 1999. doi: 10.1093/ emboj/18.20.5540. URL http://dx.doi.org/10.1093/emboj/18.20.5540.

L. A. Pardo, C. Contreras-Jurado, M. Zientkowska, F. Alves, and W. Stühmer. Role of voltagegated potassium channels in cancer. J Membr Biol, 205(3):115-124, Jun 2005. doi: 10.1007/ s00232-005-0776-1. URL http://dx.doi.org/10.1007/s00232-005-0776-1.

Luis A Pardo. Voltage-gated potassium channels in cell proliferation. Physiology (Bethesda), 19:285-292, Oct 2004. doi: 10.1152/physiol.00011.2004. URL http://dx.doi.org/10.1152/ physiol.00011.2004. 
Luis A Pardo and Walter Stühmer. Eag1 as a cancer target. Expert Opin Ther Targets, 12(7):837843, Jul 2008a. doi: 10.1517/14728222.12.7.837. URL http://dx.doi.org/10.1517/14728222. 12.7 .837 .

Luis A Pardo and Walter Stühmer. Eag1: an emerging oncological target. Cancer Res, 68(6): 1611-1613, Mar 2008b. doi: 10.1158/0008-5472.CAN-07-5710. URL http://dx.doi.org/10. 1158/0008-5472.CAN-07-5710.

Yong Qin and Laurence H Hurley. Structures, folding patterns, and functions of intramolecular dna g-quadruplexes found in eukaryotic promoter regions. Biochimie, 90(8):1149-1171, Aug 2008. doi: 10.1016/j.biochi.2008.02.020. URL http://dx.doi.org/10.1016/j.biochi.2008.02.020

John P Reeves and Madalina Condrescu. Lanthanum is transported by the sodium/calcium exchanger and regulates its activity. Am J Physiol Cell Physiol, 285(4):C763-C770, Oct 2003. doi: 10.1152/ajpcell.00168.2003. URL http://dx.doi.org/10.1152/ajpcell.00168.2003.

G. A. Robertson, J. M. Warmke, and B. Ganetzky. Potassium currents expressed from drosophila and mouse eag cdnas in xenopus oocytes. Neuropharmacology, 35(7):841-850, 1996.

M. M. Rolls, P. A. Stein, S. S. Taylor, E. Ha, F. McKeon, and T. A. Rapoport. A visual screen of a gfp-fusion library identifies a new type of nuclear envelope membrane protein. J Cell Biol, 146 (1):29-44, Jul 1999.

U. Rosenberger, M. Shakibaei, C. Weise, P. Franke, and K. Buchner. Citric acid extracts a specific set of proteins from isolated cell nuclei. J Cell Biochem, 59(2):177-185, Oct 1995. doi: 10.1002/ jcb.240590207. URL http://dx.doi.org/10.1002/jcb.240590207.

E. Rousseau, C. Michaud, D. Lefebvre, S. Proteau, and A. Decrouy. Reconstitution of ionic channels from inner and outer membranes of mammalian cardiac nuclei. Biophys J, 70(2): 703-714, Feb 1996. doi: 10.1016/S0006-3495(96)79610-8. URL http://dx.doi.org/10.1016/ S0006-3495(96)79610-8.

M. J. Saganich, E. Machado, and B. Rudy. Differential expression of genes encoding subthresholdoperating voltage-gated k+ channels in brain. J Neurosci, 21(13):4609-4624, Jul 2001.

Georgia Salpingidou, Andrei Smertenko, Irena Hausmanowa-Petrucewicz, Patrick J Hussey, and Chris J Hutchison. A novel role for the nuclear membrane protein emerin in association of the centrosome to the outer nuclear membrane. J Cell Biol, 178(6):897-904, Sep 2007. doi: 10.1083/jcb.200702026. URL http://dx.doi.org/10.1083/jcb.200702026.

L. Santella and E. Carafoli. Calcium signaling in the cell nucleus. FASEB J, 11(13):1091-1109, Nov 1997.

M. Schindler. Alterations in nuclear anatomy by chemical modification of proteins in isolated rat liver nuclei. Exp Cell Res, 150(1):84-96, Jan 1984. 
M. Schindler, J. F. Holland, and M. Hogan. Lateral diffusion in nuclear membranes. J Cell Biol, 100(5):1408-1414, May 1985.

Eric C Schirmer and Roland Foisner. Proteins that associate with lamins: many faces, many functions. Exp Cell Res, 313(10):2167-2179, Jun 2007. doi: 10.1016/j.yexcr.2007.03.012. URL http://dx.doi.org/10.1016/j.yexcr.2007.03.012.

Eric C Schirmer and Larry Gerace. The nuclear membrane proteome: extending the envelope. Trends Biochem Sci, 30(10):551-558, Oct 2005. doi: 10.1016/j.tibs.2005.08.003. URL http: //dx.doi.org/10.1016/j.tibs.2005.08.003.

Eric C Schirmer, Laurence Florens, Tinglu Guan, John R Yates, and Larry Gerace. Nuclear membrane proteins with potential disease links found by subtractive proteomics. Science, 301 (5638):1380-1382, Sep 2003. doi: 10.1126/science.1088176. URL http://dx.doi.org/10.1126/ science.1088176.

R. Schönherr, K. Löber, and S. H. Heinemann. Inhibition of human ether à go-go potassium channels by ca $(2+) /$ calmodulin. EMBO J, 19(13):3263-3271, Jul 2000. doi: 10.1093/emboj/19.13.3263. URL http://dx.doi.org/10.1093/emboj/19.13.3263.

D. Sen and W. Gilbert. A sodium-potassium switch in the formation of four-stranded g4-dna. Nature, 344(6265):410-414, Mar 1990. doi: 10.1038/344410a0. URL http://dx.doi.org/10. 1038/344410a0.

Takeshi Shimi, Takako Koujin, Miriam Segura-Totten, Katherine L Wilson, Tokuko Haraguchi, and Yasushi Hiraoka. Dynamic interaction between baf and emerin revealed by frap, flip, and fret analyses in living hela cells. J Struct Biol, 147(1):31-41, Jul 2004. doi: 10.1016/j.jsb.2003.11.013. URL http://dx.doi.org/10.1016/j·jsb.2003.11.013.

Adam Siddiqui-Jain, Cory L Grand, David J Bearss, and Laurence H Hurley. Direct evidence for a g-quadruplex in a promoter region and its targeting with a small molecule to repress c-myc transcription. Proc Natl Acad Sci U S A, 99(18):11593-11598, Sep 2002. doi: 10.1073/pnas. 182256799. URL http://dx.doi.org/10.1073/pnas.182256799.

S. M. Simon, G. Blobel, and J. Zimmerberg. Large aqueous channels in membrane vesicles derived from the rough endoplasmic reticulum of canine pancreas or the plasma membrane of escherichia coli. Proc Natl Acad Sci U S A, 86(16):6176-6180, Aug 1989.

Erik L Snapp, Nihal Altan, and Jennifer Lippincott-Schwartz. Measuring protein mobility by photobleaching gfp chimeras in living cells. Curr Protoc Cell Biol, Chapter 21:Unit 21.1, Aug 2003. doi: 10.1002/0471143030.cb2101s19. URL http://dx.doi.org/10.1002/0471143030 . cb2101s19. 
Raz Somech, Sigal Shaklai, Orit Geller, Ninette Amariglio, Amos J Simon, Gideon Rechavi, and Einav Nili Gal-Yam. The nuclear-envelope protein and transcriptional repressor lap2beta interacts with hdac3 at the nuclear periphery, and induces histone h4 deacetylation. J Cell Sci, 118 (Pt 17):4017-4025, Sep 2005. doi: 10.1242/jcs.02521. URL http://dx.doi.org/10.1242/jcs. 02521

B. Soullam and H. J. Worman. The amino-terminal domain of the lamin b receptor is a nuclear envelope targeting signal. J Cell Biol, 120(5):1093-1100, Mar 1993.

B. Soullam and H. J. Worman. Signals and structural features involved in integral membrane protein targeting to the inner nuclear membrane. J Cell Biol, 130(1):15-27, Jul 1995.

C. E. Stansfeld, J. Röper, J. Ludwig, R. M. Weseloh, S. J. Marsh, D. A. Brown, and O. Pongs. Elevation of intracellular calcium by muscarinic receptor activation induces a block of voltageactivated rat ether-à-go-go channels in a stably transfected cell line. Proc Natl Acad Sci US A, 93(18):9910-9914, Sep 1996.

Daniel A Starr and Janice A Fischer. Kash 'n karry: the kash domain family of cargo-specific cytoskeletal adaptor proteins. Bioessays, 27(11):1136-1146, Nov 2005. doi: 10.1002/bies.20312. URL http://dx.doi.org/10.1002/bies.20312.

L. Tabares, M. Mazzanti, and D. E. Clapham. Chloride channels in the nuclear membrane. $J$ Membr Biol, 123(1):49-54, Jul 1991.

H. Terlau, J. Ludwig, R. Steffan, O. Pongs, W. Stühmer, and S. H. Heinemann. Extracellular mg2+ regulates activation of rat eag potassium channel. Pflugers Arch, 432(2):301-312, Jun 1996.

Laura J Terry, Eric B Shows, and Susan R Wente. Crossing the nuclear envelope: hierarchical regulation of nucleocytoplasmic transport. Science, 318(5855):1412-1416, Nov 2007. doi: 10. 1126/science.1142204. URL http://dx.doi.org/10.1126/science.1142204.

P. Thevenaz, U. E. Ruttimann, and M. Unser. A pyramid approach to subpixel registration based on intensity. IEEE Trans Image Process, 7(1):27-41, 1998. doi: 10.1109/83.650848. URL http://dx.doi.org/10.1109/83.650848.

Hagen Tilgner, Christoforos Nikolaou, Sonja Althammer, Michael Sammeth, Miguel Beato, Juan Valcárcel, and Roderic Guigó. Nucleosome positioning as a determinant of exon recognition. Nat Struct Mol Biol, 16(9):996-1001, Sep 2009. doi: 10.1038/nsmb.1658. URL http://dx.doi.org/ $10.1038 / \mathrm{nsmb} .1658$

Claudia Toral, M. Eugenia Mendoza-Garrido, Erika Azorín, Elizabeth Hernández-Gallegos, Juan Carlos Gomora, Dulce María Delgadillo, Carmen Solano-Agama, and Javier Camacho. Effect of extracellular matrix on adhesion, viability, actin cytoskeleton and $\mathrm{k}+$ currents of cells expressing human ether à go-go channels. Life Sci, 81(3):255-265, Jun 2007. doi: 10.1016/j.lfs.2007.05.014. URL http://dx.doi.org/10.1016/j.lfs.2007.05.014. 
Yonatan B Tzur, Katherine L Wilson, and Yosef Gruenbaum. Sun-domain proteins: 'velcro' that links the nucleoskeleton to the cytoskeleton. Nat Rev Mol Cell Biol, 7(10):782-788, Oct 2006. doi: 10.1038/nrm2003. URL http://dx.doi.org/10.1038/nrm2003.

Gerrit van Meer, Dennis R Voelker, and Gerald W Feigenson. Membrane lipids: where they are and how they behave. Nat Rev Mol Cell Biol, 9(2):112-124, Feb 2008. doi: 10.1038/nrm2330. URL http://dx.doi.org/10.1038/nrm2330.

Zhiguo Wang. Roles of $\mathrm{k}+$ channels in regulating tumour cell proliferation and apoptosis. Pflugers Arch, 448(3):274-286, Jun 2004. doi: 10.1007/s00424-004-1258-5. URL http://dx.doi.org/ $10.1007 / \mathrm{s} 00424-004-1258-5$.

J. Warmke, R. Drysdale, and B. Ganetzky. A distinct potassium channel polypeptide encoded by the drosophila eag locus. Science, 252(5012):1560-1562, Jun 1991.

Claudia Weber, Fernanda Mello de Queiroz, Bryan R Downie, Arnt Suckow, Walter Stühmer, and Luis A Pardo. Silencing the activity and proliferative properties of the human eagi potassium channel by rna interference. J Biol Chem, 281(19):13030-13037, May 2006. doi: 10.1074/jbc. M600883200. URL http://dx.doi.org/10.1074/jbc.M600883200.

P. Wedekind, U. Kubitscheck, O. Heinrich, and R. Peters. Line-scanning microphotolysis for diffraction-limited measurements of lateral diffusion. Biophys J, 71(3):1621-1632, Sep 1996. doi: 10.1016/S0006-3495(96)79366-9. URL http://dx.doi.org/10.1016/S0006-3495(96)79366-9.

D. Weinshenker, A. Wei, L. Salkoff, and J. H. Thomas. Block of an ether-a-go-go-like k(+) channel by imipramine rescues egl-2 excitation defects in caenorhabditis elegans. J Neurosci, 19(22): 9831-9840, Nov 1999.

Alan Wells and Ulrich Marti. Signalling shortcuts: cell-surface receptors in the nucleus? Nat Rev Mol Cell Biol, 3(9):697-702, Sep 2002. doi: 10.1038/nrm905. URL http://dx.doi.org/10. $1038 / \mathrm{nrm} 905$.

J. R. Williamson. G-quartets in biology: reprise. Proc Natl Acad Sci U S A, 90(8):3124, Apr 1993.

J. R. Williamson, M. K. Raghuraman, and T. R. Cech. Monovalent cation-induced structure of telomeric dna: the g-quartet model. Cell, 59(5):871-880, Dec 1989.

W. F. Wonderlin and J. S. Strobl. Potassium channels, proliferation and g1 progression. J Membr Biol, 154(2):91-107, Nov 1996.

Min Wu, Peter G Stockley, and William J Martin. An improved western blotting technique effectively reduces background. Electrophoresis, 23(15):2373-2376, Aug 2002a. doi: 3.0.CO;2-W. URL http://dx.doi.org/3.0.CO;2-W.

Wei Wu, Feng Lin, and Howard J Worman. Intracellular trafficking of man1, an integral protein of the nuclear envelope inner membrane. J Cell Sci, 115(Pt 7):1361-1371, Apr 2002b. 
Heike Wulff, Neil A Castle, and Luis A Pardo. Voltage-gated potassium channels as therapeutic targets. Nat Rev Drug Discov, 8(12):982-1001, Dec 2009. doi: 10.1038/nrd2983. URL http: //dx.doi.org/10.1038/nrd2983

L. Yang, T. Guan, and L. Gerace. Integral membrane proteins of the nuclear envelope are dispersed throughout the endoplasmic reticulum during mitosis. J Cell Biol, 137(6):1199-1210, Jun 1997.

Y. Zhong and C. F. Wu. Alteration of four identified $\mathrm{k}+$ currents in drosophila muscle by mutations in eag. Science, 252(5012):1562-1564, Jun 1991.

Ulrike Ziechner, Roland Schönherr, Anne-Kathrin Born, Oxana Gavrilova-Ruch, Ralf W Glaser, Miroslav Malesevic, Gerhard Küllertz, and Stefan H Heinemann. Inhibition of human ether à go-go potassium channels by ca2+/calmodulin binding to the cytosolic n- and c-termini. FEBS $J, 273(5): 1074-1086$, Mar 2006. doi: 10.1111/j.1742-4658.2006.05134.x. URL http://dx.doi. org/10.1111/j.1742-4658.2006.05134.x.

Nikolaj Zuleger, Nadia Korfali, and Eric C Schirmer. Inner nuclear membrane protein transport is mediated by multiple mechanisms. Biochem Soc Trans, 36(Pt 6):1373-1377, Dec 2008. doi: 10.1042/BST0361373. URL http://dx.doi.org/10.1042/BST0361373. 


\section{Appendix}

\subsection{Abbreviations}

Table 7: Abbreviations

BAF barrier to autointegration factor

bp $\quad$ Base pairs

BSA Bovine serum albumin

${ }^{\circ} \mathrm{C} \quad$ Degrees Celsius (centigrades)

CA citraconic anhydride

CaM calmodulin

CHO Chinese hamster ovary

CNS central nervous system

DAPI 4,6-diamidino-2-phenylindole

$\mathrm{ddH}_{2} \mathrm{O}$ double distilled (or miliQ) water

DTT dithiothreitol

DMSO dimethyl sulfoxide

EDTA Ethylened acid iaminetetraacetic

EGTA ethylene glycol tetraacetic acid

EM electron microscopy

h hour(s)

HEK human embryonic kidney

continued on next page 
continued from previous page

HEPES 4-(2-hydroxyethyl)-1-piperazineethanesulfonic acid

IB Immunoblotting

IEM immunoelectron microscopy

INM inner nuclear membrane

InsP3 Inositol 1,4,5-trisphosphate

KASH Klarsicht, ANC-1 and SYNE1 homology

kDa Kilodalton

K.O. knock-out (null mutant)

LB Luria-Bertani broth

LBR lamin B receptor

LEM Luma, Emerin and MAN1

LISM Low-ionic-strength suspension medium

M molar per litter

$\mathrm{mM}$ millimolar

$\mathrm{mA}$ milliAmpere

min minute(s)

ml milliliter

mYFP monomeric yellow fluorescent protein

mVenus monomeric Venus

$\mu \mathrm{g} \quad$ microgram

$\mu \mathrm{l} \quad$ microliter

ng nanogram

continued on next page 
continued from previous page

$\mu \mathrm{m} \quad$ micrometer

nm nanometer

NA numerical aperture

$\mathrm{NE} \quad$ nuclear envelope

NES nuclear export signa

NLS nuclear localization signal

NMJ neuromuscular junction

NMSM Nuclear membrane storage medium

NPC nuclear pore complex

nurim nuclear rim protein

OD optical density

ONM outer nuclear membrane

PAGE Polyacrylamid gel electrophorese

PBS phosphate-buffered saline

PCR Polymerase chain reaction

RFBP ring-finger-binding protein

PMSF phenylmethylsulphonyl fluoride

PSF point-spread-function

ROI region of interest

RT room temperature

rER rough endoplasmic reticulum

sec second(s)

continued on next page 
continued from previous page

SDB Sucrose density barrier

SDS Sodium dodecyl sulfa

SEM standard error mean

SUN Sad1 and UNC-84 homology

TBS Tris-buffered saline

V Volt

WB western blotting 


\subsection{Publications}

Ye Chen, Araceli Sánchez, Marí E Rubio, Walter Stühmer, Luis A Pardo. (2010). Functional Kv10.1 channels localize at the internal nuclear membrane. (manuscript in preparation) 


\subsection{Curriculum Vitae}

\section{Personal details:}

Name:

Nationality:

Date and place of birth:

\section{Education:}

September 2006- March 2010:

October 2005- :

September 2000- July 2004:

\section{Scholarships:}

September 2006- August 2009:

September 2005- August 2006:

2003:
Ye Chen

P.R. China

4th.Oct.1982 in Ningde, P.R. China
$\mathrm{PhD}$ candidate in the Department of Molecular Biology of Neuronal Signals, Max-PlanckInstitute of Experimental Medicine, Göttingen, Germany

International Max Planck Research School for Neuroscience, Göttingen, Germany

B.Sc. in Biology Tsinghua University, Beijing, P.R. China
Neuroscience Early Stage Research Training (NEUREST), Marie Curie Actions Fellowship International Max Planck Research School Stipend

3rd class scholarship of Tsinghua University (Sponsored by City University of Hong Kong) 